\title{
Carlos DZiK
}

\section{Resposta imune contra HERV-K em pacientes}

\section{com câncer de próstata localizado e metastático}

\author{
Tese apresentada à Faculdade de Medicina da \\ Universidade de São Paulo para obtenção do \\ título de Doutor em Ciências \\ Programa de Alergia e Imunopatologia \\ Orientador: Prof. Dr. Esper Georges Kallás
}

*Versão corrigida. Resolução CoPGr6018/11, de 13 de outubro de 2011. A versão original está disponível na Biblioteca FMUSP.

\section{São Paulo}


Dados Internacionais de Catalogação na Publicação (CIP)

Preparada pela Biblioteca da

Faculdade de Medicina da Universidade de São Paulo

Creprodução autorizada pelo autor

\section{Dzik, Carlos}

Resposta imune contra HERV-K em pacientes com câncer de próstata localizado e metastático / Carlos Dzik -- São Paulo, 2017.

Tese(doutorado)--Faculdade de Medicina da Universidade de São Paulo. Programa de Alergia e Imunopatologia.

Orientador: Esper Georges Kallás.

Descritores: 1.Neoplasias da próstata 2.Imunidade 3.Biblioteca genômica 4.Biologia computacional 5.ELISPOT 6.Retroviridae 7.Linfócitos T 8.Imunidade ativa 9.Interferon gama

USP/FM/DBD-303/17 


\section{DEDICATÓRIA}

Dedico esta tese a quem é responsável por eu estar aqui neste momento, nesta vida... sem os quais nada existiria...

Aos meus pais...

Dedico esta tese a quem outrora, sem perceber, quase como num acaso, me forneceu um certo amálgama de identificação... quase imperceptível e sem palavras ou intenções claras... de que tanto precisei para um dia querer me tornar médico.

A meu pai...

Dedico esta tese aos tantos pacientes, que espero ter ajudado algum dia, graças aos meus (e deles) anjos da guarda e mestres pelo caminho... e para quem espero ter me comportado com honestidade e um mínimo de conflito de interesses, como aprendemos ao sair da escola de medicina... onde juramos de acordo com o paradigma... de servir aos pacientes.

Pena que na atualidade muitas vezes vemos este paradigma tão importante ter os seus vetores invertidos... 


\section{AGRADECIMENTOS}

Agradeço em primeiríssimo lugar à minha esposa - Berta - com sua preocupação constante e visceral nestes últimos quase 30 anos e em particular nestes últimos 4 anos, com o seu sofrimento cúmplice... e apoio cego, generoso e amoroso...

Quem a conhece sabe do que estou falando...

...e aos meus filhos Rony, André e Milena... pela paciência comigo ... e aceitação de minhas tantas imperfeições como pai.

Agradeço ao meu amigo e orientador, o Prof. Dr. Esper G. Kallás, a quem chamo Esper, que provavelmente depositou muito mais confiança em mim do que devia...

...basicamente por me dar a oportunidade de voltar para o banco da escola... depois de um diálogo rápido e objetivo às portas da estação do metrô Clínicas, numa tarde ensolarada do verão do ano de 2013. ... espero que ele se lembre disso !!!... e não se arrependa !!

Agradeço e MUITO à Dra Priscilla Ramos Costa, minha co-orientadora, que foi responsável maior pela realização dos protocolos de Citometria de Fluxo e pelas orientações tão preciosas nas análises dos dados. Sem ela eu estaria em sérios apuros !!!

Agradeço à Helena Tomyiana pela orientação na realização dos ensaios de Elispot. Espero que ela não tenha ficado chateada comigo por todas as minhas indagações e questionamentos cheios de ignorância durante parte daquele processo.

Agradeço a disponibilidade, interesse, atenção e competência do Dr. Pedro Galante, um tremendo especialista em bioinformática genômica do Centro de Oncologia Molecular do Hospital Sírio-Libanês, a quem fui apresentado há pouco tempo, e que de certa forma me deslumbrou com estes meandros da genômica humana, a Biologia de nosso século, campo este não mais possível para leigos como eu. 


\section{Normatização adotada}

Esta tese está de acordo com as seguintes normas, em vigor no momento desta publicação:

Referências: adaptado de International Committee of Medical Journal Editors (Vancouver).

Universidade de São Paulo. Faculdade de Medicina. Divisão de Biblioteca e Documentação. Guia de apresentação $d$ dissertações, teses e monografias. Elaborado por Anneliese Carneiro da Cunha, Maria Julia de A. L.Freddi, Maria F. Crestana, Marinalva de Souza Aragão, Suely Campos Cardoso, Valéria Vilhena. $3^{\text {a }}$ ed. São Paulo: Divisão de Biblioteca e Documentação;2011.

Abreviaturas e títulos dos periódicos de acordo com List of Journals Indexed in Index Medicus. 


\section{SUMÁRIO}

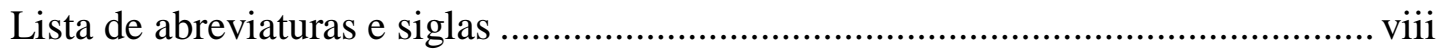

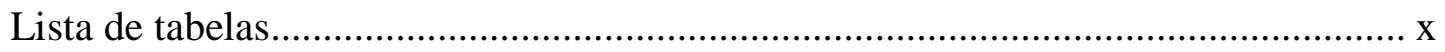

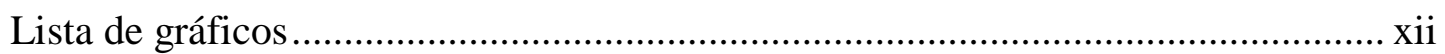

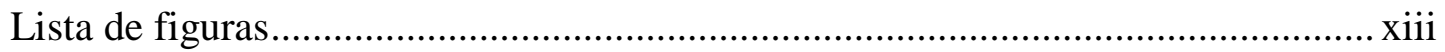

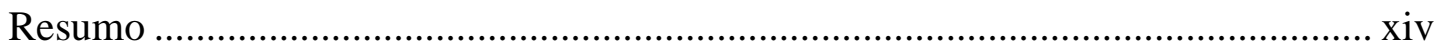

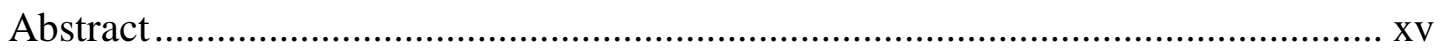

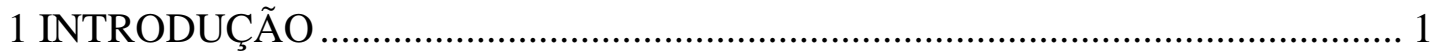

1.1-Epidemiologia do câncer de próstata ............................................................ 2

1.2-Tratamento do câncer de próstata localizado...................................................... 3

1.3-Tratamento do câncer de próstata metastático .................................................. 3

1.4-_Câncer de próstata e imunidade ................................................................... 4

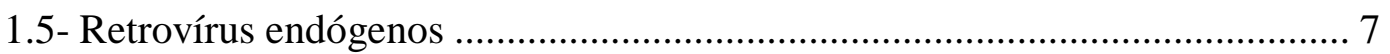

1.6 Retro-elementos endógenos humanos (HERE) no câncer .............................. 8

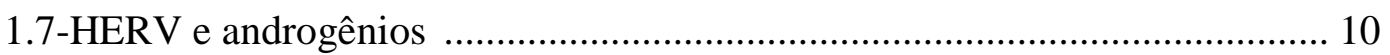

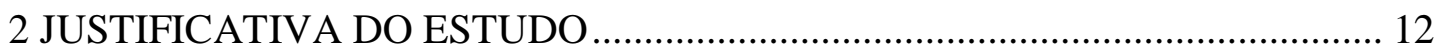

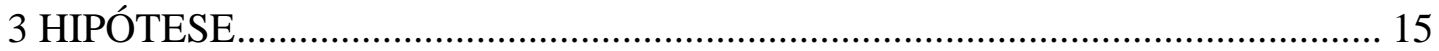

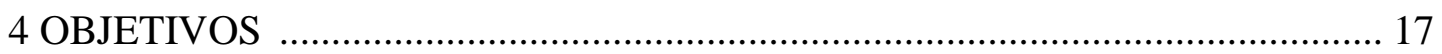

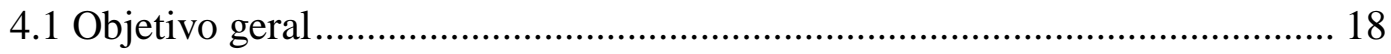

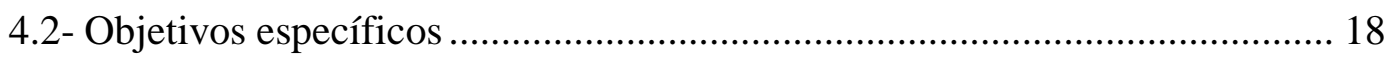

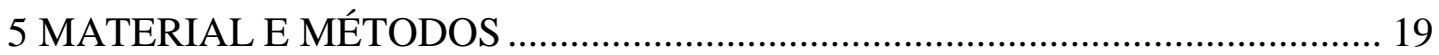

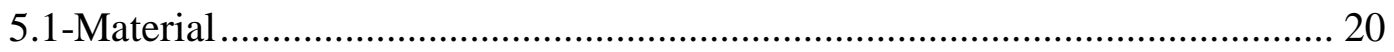

5.1.1-Casuística e considerações éticas ....................................................... 20

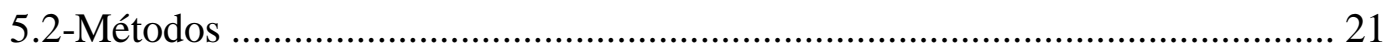

5.2.1 Análise genômica - dados públicos (TCGA) ........................................ 21

5.2.2 Separação de CMSP (Células Mononucleares de Sangue Periférico) .... 22

5.2.3 Avaliação de Resposta Imune Celular por ELISPOT ............................ 23

5.2.4 Citometria de Fluxo-Imunofenotipagem-Perfil de Ativação e Senescência celular .............................................................................. 25

5.2.4.1 Marcação de Superfície Celular ................................................. 26

5.2.4.2 Estratégias de Análise dos Dados de Citometria de Fluxo ......... 27 
5.2.4.3 Análise Estatística ................................................................. 29

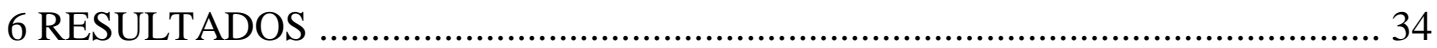

6.1 Análise demográfica e clínica das coortes pesquisadas ............................... 35

6.2 Resultados de Análise genômica da expressão gênica de HERV-K............... 36

6.3 Resultado de ELISPOT-Interferon gama contra peptídeos de HERV-K........ 37

6.4 Resultado de avaliação de ativação e senescência linfocitária por

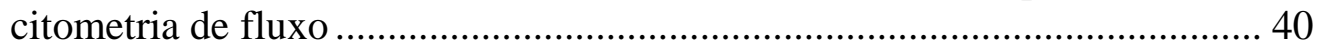

6.4.1 Perfil de Diferenciação dos Linfócitos T CD4+ ...................................... 41

6.4.1.1 Perfil de Ativação de Linfócitos T CD4+ ................................... 43

6.4.1.2 Perfil de Senescência/Exaustão de Linfócitos T CD4+ .............. 46

6.4.2 Perfil de Diferenciação dos Linfócitos T CD8+ ..................................... 53

6.4.2.1 Perfil de Ativação dos Linfócitos T CD8+ ................................ 55

6.4.2.2 Perfil de Senescência/Exaustão de Linfócitos T CD8+ .............. 59

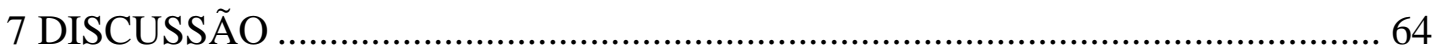

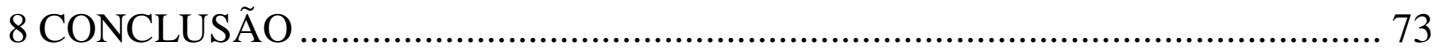

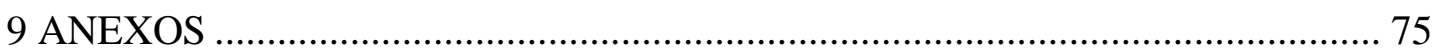

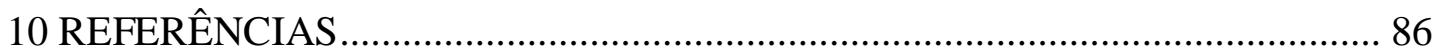

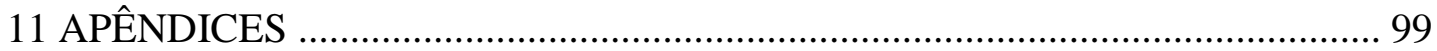




\section{LISTAS}

ABREVIATURAS E SIGLAS

AR

ARE

CD

cDNA

CMSP

CTA

CTSP-1

ELISPOT

ENCODE

HER2-neu

HERV

HERV-K

FoxP3

GENCODE

GRE

LINE

LTR

MDSC

MMTV

NY-BR-1

ORF

PAP

PSA

PSMA

RNAseq
Androgen Receptor

Androgen Response Elements

Cluster of Differentiation

Complementary DNA

Células Mononucleares de Sangue Periférico

Cancer Testis Antigen

Um tipo específico de CTA, associado a tumores

Enzyme-Linked Immuno Spot

Encyclopedia of DNA Elements

Human Epidermal Receptor

Human Endogenous RetroVirus

Human Endogenous RetroVirus da família

Forckheadbox P3(Fator de transcrição da família Fox)

Genome of the ENCODE

Glucocorticoid Response Elements

Long Interspersed Nuclear Elements

Long Terminal Repeat (Sequencias repetidas de nucleotídeos localizados nas pontas dos retrovírus endógenos.

Myeloid Derived Suppressor Cells

Mouse mammary Tumor Virus

Antigeno da classe dos Cancer Testis Antigen

Open Reading Frame

Prostatic Acid Phosphatase

Prostate Specific Antigen

Prostatic Specific Membrane Antigen

RNA sequencing 
Score de Gleason

SEREX

TCGA

TCR

TDA

TZFP

UCSC
Score de risco na patologia. Varia de 6 a 10, sendo 10 o mais grave.

SErological Recombinant cDNA EXpression cloning

The Cancer Genome Atlas

T Cell Receptor

Terapia de Deprivação Androgênica

Testicular Zinc Finger Protein

University California-Santa Cruz 


\section{TABELAS}

Tabela 1 - Informações descrevendo a função e a finalidade de cada molécula caracterizada através dos painéis de citometria de fluxo .... 32

Tabela 2 - Informações dos anticorpos e reagentes utilizados no painel de citometria de fluxo...

Tabela 3 - Características Demográficas dos pacientes e Grupo Controle

Tabela 4 - Distribuição dos diferentes imunofenótipos entre as coortes

Tabela 5 - Comparação das medianas das porcentagens de linfócitos T CD4 selecionados para marcadores de senescência e exaustão, isoladamente.

Tabela 6 - Imunofenótipo selecionado isoladamente para CD38 na população global de CD4

Tabela 7 - Comparação das medianas das porcentagens de linfócitos T CD4 selecionados para marcadores de senescência e exaustão, isoladamente.

Tabela 8 - Diferenças entre as sub-populações linfocitárias de CD4, quando selecionado isoladamente para CD28

Tabela 9 - Diferenças entre as sub-populações linfocitárias de CD4, quando selecionado isoladamente para CD57

Tabela 10 - Diferenças entre as sub-populações linfocitárias de CD4, quando selecionado isoladamente para CD28.

Tabela 11 - Diferenças entre as sub-populações linfocitárias de CD4, quando selecionado isoladamente para PD1

Tabela 12 - Distribuição dos diferentes imunofenótipos entre as coortes, na população global de CD8

Tabela 13 - Perfil de CD8 total, quando selecionado isoladamente por marcadores de ativação celular, na comparação entre as coortes....... 56

Tabela 14 - Medianas da porcentagem dos linfócitos T CD8 marcados por CD38, distribuídos pelas sub-populações ontogenéticas.

Tabela 15 - Comparação das medianas das porcentagens de linfócitos T CD8 selecionados para marcadores de senescência e exaustão, isoladamente. 
Tabela 16 - Dados da comparação entre a mediana das porcentagens dos linfócitos T CD8, selecionados para marcação de CD95 .................... 61

Tabela 17 - Comparação entre as coortes quando selecionadas apenas para PD-L1 nas populações de linfócitos T CD4, CD8 e nas APCs 63 


\section{GRÁFICOS}

Gráfico 1 - Mediana da porcentagem de células com os marcadores isoladamente analisados na população total de linfócitos $\mathrm{T}$ CD4+

Gráfico 2 - Imunofenótipo selecionado isoladamente para CD38 na população global de CD4 ….......................................................... 44

Gráfico 3 - Perfil de CD4 total, quando selecionado isoladamente por marcadores de senescência e exaustão, na comparação entre as coortes

Gráfico 4 - Diferenças entre as sub-populações linfocitárias de CD4, quando selecionado isoladamente para CD28

Gráfico 5 - Diferenças entre as sub-populações linfocitárias de CD4, quando selecionado isoladamente para CD57

Gráfico 6 - Diferenças entre as sub-populações linfocitárias de CD4, quando selecionado isoladamente para CD95

Gráfico 7 - Diferenças entre as sub-populações linfocitárias de CD4, quando selecionado isoladamente para PD1

Gráfico 8 - Perfil de CD8 total, quando selecionado isoladamente por marcadores de ativação celular, na comparação entre as coortes ...55

Gráfico 9 - Perfil de CD8 total, quando selecionado isoladamente por marcadores de ativação celular, na comparação entre as coortes ...56

Gráfico 10 - Diferenças entre as sub-populações linfocitárias de CD8, quando selecionado isoladamente para CD38

Gráfico 11 - Perfil de CD8 total, quando selecionado isoladamente por marcadores de senescência e exaustão, na comparação entre as coortes

Gráfico 12 - Comparação entre a mediana das porcentagens dos linfócitos $\mathrm{T}$ CD8, selecionados para marcação de CD95.

Gráfico 13 - Comparação entre as coortes quando selecionadas apenas para PD-L1 nas populações de linfócitos T CD4, CD8 e nas APCs 


\section{FIGURAS}

Figura 1 - Desenho esquemático de um gene de um retrovírus endógeno............. 8

Figura 2 - Esquema mostrando pareamento de leituras de RNA-seq expressas diretamente com o DNA. .............................................. 22

Figura 3 - Estratégia de análise de células TCD4+ e CD8+...............................2 28

Figura 4 - Eixo $Y=$ No de spots. Eixo $X=$ pacientes. Neste gráfico encontramos contagens de 50 spots em 2 pacientes, apenas. Um com doença localizada para gag (\#15) e outro do grupo controle para env (\#S3G6006).

Figura 5 - Eixo $Y=N o$ de spots. Eixo $X=$ pacientes. Neste gráfico encontramos contagens acima do limiar de positividade -80 spotscontra env em um paciente com doença localizada.

Figura 6 - Distribuição dos diferentes imunofenótipos entre as coortes

Figura 7 - Distribuição dos diferentes imunofenótipos entre as coortes, na população global de CD8 


\section{RESUMO}

Dzik C. Resposta imune contra HERV-K em pacientes com câncer de próstata localizado e metastático [Tese]. São Paulo: Faculdade de Medicina, Universidade de São Paulo; 2017.

Objetivo: Retrovirus Endógeno Humano (HERV) compreende ao redor de $8 \%$ do genoma humano. Apesar do fato de que em sua maioria são genes não-funcionais devido a processos de mutação ou perda de material genético no processo de retrotransposição, existem evidências do aumento da expressão de HERVs em tecido de câncer de próstata. Nós estudamos e comparamos a imunogenicidade de peptídeos da família HERV em 2 coortes de pacientes com câncer de próstata. Posteriormente examinamos o estado de ativação e senescência linfocitária nestas coortes. Desenho Experimental: Células Mononucleares de Sangue Periférico (CMSP) de 65 pacientes com câncer localizado da próstata em situação de hormônio-sensibilidade e de 24 pacientes com câncer de próstata metastático e em situação de resistência à castração, comparados a um grupo controle de 12 indivíduos normais foram avaliados em relação ao seu estado de resposta imune pela técnica de ELISPOT contra um conjunto de peptídeos derivados dos exons gag e env do gene da família HERV-K HML-2. Como parte de nosso estudo, foi realizado de forma preliminar uma análise genômica in silico de 500 pacientes com câncer de próstata sequenciados e disponíveis para análise pública do banco de dados TCGA, com o objetivo de reforçar o racional de nossa interrogação científica. Além disso, como estudo de correlação, fizemos uma análise por citometria de fluxo da ativação celular de linfócitos $\mathrm{T}$ de nossas coortes para determinarmos a imunofenotipagem $\mathrm{e}$ ontogenia linfocitária em nossos indivíduos investigados, no momento de nossa pesquisa de sua resposta imune. Resultados: Nossa análise da resposta imune contra peptídeos de HERV-K HML-2 por ELISPOT-Interferon Gama não mostrou nenhum resultado significativo. Nenhum paciente apresentou dados significativos de resposta de acordo com nossos critérios, apesar de nossos dados preliminares de expressão gênica terem mostrado expressão gênica em torno de $17 \%$ em pacientes com doença localizada. Nossos dados de ativação linfocitária mostraram maior ativação e senescência nos pacientes com doença disseminada e resistente à castração. Conclusões: Este parece ser o primeiro estudo a interrogar a presença de resposta celular imune contra peptídeos de HERV-K em pacientes com câncer de próstata. Nosso achados não mostraram resposta imune relevante em doença localizada ou disseminada e em diferentes estados de ativação linfocitária ou status de integridade hormonal. Apesar destes resultados, pesquisa posterior poderia utilizar diferente metodologia, como por exemplo a utilização de citometria de fluxo bem como a busca de diferentes citoquinas envolvidas, tais como as relacionadas a resposta $\mathrm{Th} 2$, ao invés de Th1.

Descritores: neoplasias da próstata; imunidade; biblioteca genômica; biologia computacional; ELISPOT; retroviridae; linfócitos T; imunidade ativa; interferon gama 


\section{ABSTRACT}

Dzik C. Imune response against HERV-K in patients with localized and metastatic prostate cancer [dissertation]. São Paulo: "Faculdade de Medicina, Universidade de São Paulo"; 2017.

Purpose: Human Endogenous Retrovirus (HERV) comprises $8 \%$ of human genome. Despite the fact that most of it is non-functional due to mutations or loss of genetic material in the process of retrotransposition, there are some evidence of increased expression of HERV in prostate cancer tissue. We studied the cellular immunogenicity of peptides from HERV-K family in 2 cohorts of prostate cancer patients. Experimental Design: PBMCs from 65 patients with hormone-intact localized prostate cancer and 24 patients with castrate-metastatic disease, matched with 12 normal controls were evaluated for cellular immune response by ELLISPOT against a pool of gag and env peptides from HERV-K family of HML-2 type. As an independent supportive study we did in silico genomic analysis of 500 prostate cancer patients from TCGA database to give another evidence of the prevalence of HERV-K gene expression in prostate cancer genome, reinforcing the rational of our questions. Results: Our analysis of cellular immune response against HERV-K HML-2 peptides by Interferon-gama ELISPOT did not show any meaningful results. No patient showed any minimal criteria of response, despite the fact that in our preliminary genomic analysis we obtained HERV expression in about $17 \%$ of a cohort of 500 patients with localized prostate cancer. In regards to the flow cytometry data of the lymphocytes we showed stronger activation and senescence status in the cohort of patients with castration sensitive and resistant disseminated disease, compared to the localized disease cohort. Conclusions: To the authors's knowledge this is the first study to look for cellular immune response against peptides derived from coding HERV-K transcripts in prostate cancer patients. Our findings did not show relevant immune response in neither localized nor metastatic castrate prostate cancer patients. Despite those results, further research could continue using different methodology, like flow cytometry as well as looking for different cytokines involved, such as those related to a Th2 response, instead of Th1.

Descriptors: prostatic neoplasms; immunity; genomic library; computational biology; enzyme-linked immunospot assay; retroviridae; T-lymphocytes; immunity, active; interferon-gamma. 
1 INTRODUÇÃO

$=$ 


\section{INTRODUÇÃO}

\subsection{Epidemiologia do câncer de próstata}

O câncer de próstata é a neoplasia maligna mais prevalente na população masculina em todo o mundo. Os fatores de risco mais importantes para o desenvolvimento da doença são: idade, história familiar e cor da pele. A raça negra apresenta um risco maior de ocorrência deste câncer com prognóstico pior, seja em função de biologia tumoral mais grave ou relacionado a aspectos sócio-econômicos e culturais como será mencionado mais adiante ${ }^{(1)}$. Em relação à idade, a maioria dos homens é diagnosticada após os 65 anos de idade, com probabilidade muito pequena de ocorrer descoberta clínica da doença em indivíduos com menos de 50 anos. A literatura descreve um aumento vertiginoso nas taxas de diagnóstico a partir dos anos 80, provavelmente graças à melhoria do atendimento à saúde básica, incrementada pelo advento da dosagem do antígeno prostático específico (PSA) ${ }^{(2-7)}$.

A história familiar também é importante, pois o risco de diagnóstico em homens com pai ou irmão previamente diagnosticados com câncer de próstata aumenta em 2 a 3 vezes. Este risco é quase 11 vezes maior, se o pai ou irmão tiverem sido diagnosticados antes dos 40 anos de idade, caracterizando uma predisposição genético-hereditária importante. Estima-se que tenham ocorrido cerca de 1 milhão de casos novos no ano de 2012 e aproximadamente $70 \%$ destes casos novos ocorreram em países desenvolvidos. Existe uma variação internacional na incidência e nas taxas de mortalidade do câncer de próstata a depender das políticas de rastreamento, tratamento, estilo de vida e fatores sócio-econômicos e genéticos. De forma geral a 
incidência do câncer de próstata tende a ser maior nas regiões mais abastadas, ou seja na América do Norte, Oceania e Europa. Por sua vez as taxas de mortalidade tendem a ser maiores nas regiões menos desenvolvidas, incluindo partes da América do Sul, Caribe e África Sub-Saariana ${ }^{(4,8-10)}$. As taxas de incidência de câncer de próstata são muito menores nos paises asiáticos, tais como China e Japão (50 a 60 vezes menor em comparação com as taxas dos Estados Unidos), embora também tenham se elevado, possivelmente em parte como decorrência da ocidentalização dos costumes nestas regiões ${ }^{(2,11)}$.

\subsection{Tratamento do câncer de próstata localizado}

Pacientes com câncer de próstata têm modernamente sido estratificados em 3 diferentes grupos de risco: baixo, intermediário e alto risco. Estes grupos se definem a partir de 3 parâmetros: score de Gleason, valor do PSA e estadiamento clínico ${ }^{(12)}$. Os pacientes que têm risco baixo e intermediário são em geral tratados com prostatectomia radical ou radioterapia. Pacientes com doença de alto risco podem ser tratados por prostatectomia radical, porém são preferencialmente tratados com radioterapia externa em associação com supressão androgênica por 3 anos ${ }^{(13,14)}$. Nestes tratamentos com intenção curativa, os índices de cura estão ao redor de 60 a $80 \%$. 


\subsection{Tratamento do câncer de próstata metastático}

O câncer de próstata apresenta uma relação íntima com os hormônios sexuais masculinos. Tanto as células sadias da glândula prostática como as tumorais têm o crescimento estimulado por androgênios. A descrição do importante papel que a estimulação androgênica desempenhava no crescimento do câncer de próstata, em 1941, permitiu estabelecer a terapia de privação androgênica (TDA) como o principal tratamento para o câncer de próstata avançado ${ }^{(15)}$ sendo que 77 a $90 \%$ dos pacientes respondem a TDA inicial, com controle de sintomas, aumento de sobrevida e melhora na qualidade de vida, incluindo diminuição de dor óssea e complicações (redução de fraturas patológicas e compressão medular) ${ }^{(16)}$. A hormonioterapia se tornou um dos principais focos de estudo no tratamento da doença metastática, com o desenvolvimento de várias drogas. Dentre elas temos a abiraterona e a enzalutamida, que na atualidade são os tratamentos padrão para os pacientes que apresentam piora da doença após um período mais ou menos prolongado de TODA ${ }^{(17,18)}$. Além destes tratamentos, os pacientes podem também ser tratados com quimioterapia (Docetaxel${ }^{(19)}$, Cabazitaxel ${ }^{(20)}$ ), radiofármacos ${ }^{(21)}$ ou mesmo imunoterapia ${ }^{(22)}$.

\subsection{Câncer de próstata e imunidade}

Há anos investiga-se sobre o inter-relacionamento entre câncer e imunidade. Sabe-se que tanto as formas inatas como as adquiridas, da imunidade, são capazes de prover atividade antitumoral competente. Assim como a maioria dos tumores em geral, o câncer de próstata é capaz de desenvolver-se em meio ambiente imuno- 
competente. Esta tolerância imunológica à presença dos tumores no organismo ocorre por uma variedade de mecanismos, incluindo a indução de linfócitos $\mathrm{T}$ supressores reguladores, e algumas vezes até oriundos de linfócitos $\mathrm{T}$ efetores ${ }^{(23)}$. Esta mesma característica de imunossupressão no câncer de próstata pode ser evidenciada, por exemplo, pelo achado de aumento no número de linfócitos $\mathrm{T}$ reguladores $\mathrm{CD} 4+\mathrm{Foxp} 3+$ no sangue periférico e em tumores de pacientes com câncer de próstata, corroborando em parte a atividade imunosupressora antitumoral (24).

Várias são as razões que tornam o câncer de próstata um modelo interessante para as estratégias de imunomodulação. Em primeiro lugar o câncer de próstata é em geral uma neoplasia de crescimento lento e com uma longa história natural, de tal maneira a ser um modelo ideal no qual há tempo suficiente para que possa ser gerada uma resposta imune ótima ${ }^{(25)}$. Em segundo lugar o câncer da próstata expressa vários antígenos-associados ao tumor relativamente órgão-específicos tais como PSA, PAP e PSMA. Outros antígenos importantes relacionados a vários tipos de câncer e também ao câncer da próstata são os antígenos chamados cancer/testis antigen (CTA) ${ }^{(26)}$. Os CTAs são antígenos tipicamente restritos ao tecido testicular normal do homem adulto e expressam-se de forma aberrante em diversos tipos de câncer ${ }^{(27)}$. Existem tumores que são fortemente expressores de CTAs como, por exemplo, câncer de bexiga, pulmão não-pequenas células e melanoma ${ }^{(28-30)}$. Nestes tumores a presença de transcriptos identificados por RT-PCR comparece em 55\%, $51 \%$ e $53 \%$ das vezes, respectivamente. Esta gradação é dada quando pelo menos 20\% dos espécimes analisados possuem a expressão dos CTAs. O adenocarcinoma usual da próstata e o câncer da mama podem ser considerados expressores 
moderados ${ }^{(31,32)}$. Trabalhos identificam a presença de transcriptos de CTAs em $37 \%$ e 30\%, respectivamente, nestes tumores. Outro CTA que se mostrou altamente restrito e prevalente em amostras de melanoma (59\%), câncer de próstata (58\%) e câncer de pulmão (57\%) é o CTSP-1 ${ }^{(33)}$. CTSP-1 é na verdade parte de uma família de genes, sendo que os membros desta família mostram-se bastante restritos tanto em sua expressão, bem como na similaridade de sua estrutura proteica. Quando foram checados títulos de anticorpos anti-CTSP-1 em pacientes com câncer de próstata se encontrou presença de anticorpos em $20 \%$ dos casos. Este mesmo grupo de trabalho veio posteriormente demonstrar num estudo envolvendo 147 pacientes com câncer de próstata localizado, que a resposta humoral contra este antígeno poderia ser usada como marcador prognóstico especialmente nos pacientes com escore de Gleason elevado. Anticorpos anti-CTSP-1 foram detectados em 25\% dos pacientes ${ }^{(34)}$.

Estas evidências colocam, de certa forma, o câncer de próstata como um modelo oncológico válido para tratamentos que envolvam imunomodulação ${ }^{(35,36)}$. Talvez o primeiro desafio seja a busca de antígenos associados ao câncer de próstata que sejam suficientemente imunogênicos, de tal maneira a serem explorados como alvos de imunomodulação ${ }^{(37)}$. Outro aspecto fundamental é justamente a necessidade de suprimir mecanismos de tolerância que limitam a resposta imune contra os antígenos tumorais. Neste sentido, antígenos virais podem ser mais adequados para desencadear melhores respostas de células $\mathrm{T}$ antitumorais devido a sua natureza “non-self" $(38,39)$. No entanto apenas alguns cânceres humanos são associados até o momento a uma etiologia viral. Evidências recentes indicam que retrovírus endógenos silenciados sob condições normais ao longo de nossa evolução, são induzidos em células cancerígenas e podem ser uma nova fonte de antígenos de 
tumores com características de antígenos virais (40). Este é o escopo onde se insere nossa proposta de pesquisa.

\subsection{Retrovirus endógenos}

Os cromossomos de todos os mamíferos e da maioria dos vertebrados estão repletos de retrovírus ancestrais que inicialmente se inseriram no genoma como retrovírus exógenos ${ }^{(41)}$. A colonização de células germinativas fizeram com que estes fragmentos retrovirais passassem a ser transmitidos pelas gerações subsequentes obedecendo em grande parte a forma de herança mendeliana. Esse é um processo extremamente longo, de tal maneira que após dezenas de milhões de anos, $8 \%$ do genoma humano consiste dos chamados retroelementos (partículas virais que se inseriram no genoma através da enzima transcriptase reversa). Estes são compostos de LTRs (Long Terminal Repeats), ou seja as partes terminais nãocodificantes dos retrovírus endógenos que foram inseridas de forma fragmentada em diferentes partes do genoma e que também contém o restante do gene que consiste no retrovírus endógeno ${ }^{(42,43)}$. Durante todo este período, desde a inserção cromossômica, houve extensas mutações/deleções e fragmentações diversas, fazendo com que a maior parte deste material genético não seja capaz de transcrever proteínas. Todavia existem especulações e evidências de que estas partículas virais podem exercer função reguladora de partes do genoma, impedindo ou facilitando a expressão de certos genes ${ }^{(44-48)}$. Estes genes são compostos por 2 LTRs e 3 exons melhor definidos, a exemplo dos retrovírus exógenos, sendo o mais famoso deles o 
vírus do HIV. O desenho esquemático dos retrovírus pode ser visto na Figura 1 abaixo:

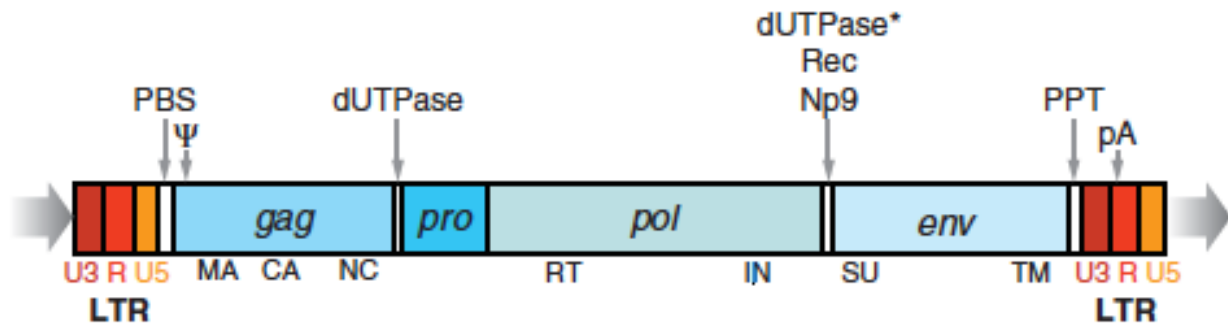

Figura 1 - Desenho esquemático de um gene de um retrovírus endógeno. Os elementos essenciais de interesse são as extremidades designadas por LTR (long terminal repeat), que podem estar isoladamente copiadas no genoma e quando rastreadas são identificadas como pertencentes a genes tipo retrovírus endógenos. Os exons de interesse são aqui representados por gag, pol e env. São os 3 exons principais dos retrovírus tanto exógenos como endógenos e responsáveis pela transcrição de genes relacionados com a formação da matrix viral, cápside/nucleocápside e envelope viral, respectivamente.

\subsection{Retro-elementos endógenos humanos (HERE) no câncer}

HERE inclui Retrovírus Endógenos Humanos (HERV) e Elementos

Nucleares Longos Intercalados (LINE). HERVs são remanescentes de antigas infecções retrovirais que infectaram a linhagem germinativa de nossos ancestrais e se tornaram fixas na população ${ }^{(42)}$. Retrovírus são tradicionalmente divididos em transmitidos entre hospedeiros (exógenos) e nos transmitidos pela linhagem germinativa (endógenos). Eles compõem aproximadamente $8 \%$ do genoma humano. LINE são retrotransposons. Esta importante categoria genômica compõem $3 \%$ do genoma humano. São sequências gênicas que se "movem"pelo DNA por um mecanismo de "cut and paste"envolvendo a transcrição reversa de um intermediário de RNA e a inserção de sua cópia de DNA complementar em um sítio diferente no 
genoma. Eles têm o promotor de RNA polimerase II e codificam uma transcriptase reversa e uma endonuclease que lhes permitem se "mover" no genoma, através da cópia de si próprios. Eles representam aproximadamente $20 \%$ do genoma humano. Diferentes estudos têm demonstrado a hipometilação de elementos LINE1 em diferentes cânceres ${ }^{(49-51)}$, sugerindo um aumento em sua expressão. Um estudo recente mostrou que a hipometilação de LINE1 ocorre em câncer de próstata primário (quando comparado a tecidos normais) e é significantemente mais pronunciado em câncer de próstata metastático ${ }^{(51)}$.

Sequências retrovirais endógenas são expressas em cânceres humanos. Por exemplo, a expressão aumentada de transcritos de env HERV-K foi demonstrada em melanoma ${ }^{(52)}$ em câncer de mama ${ }^{(53)}$ e de ovário ${ }^{(54)}$ quando comparada à expressão em tecidos normais. A antigenicidade de elementos HERV foi demonstrada séricamente e pelo reconhecimento de células T CD8+. Anticorpos contra HERV-K gag e env foram detectados em pacientes portadores de tumor de células germinativas ${ }^{(55)}$ e câncer de mama ${ }^{(56)}$.

A associação entre resposta de anticorpo e melhor prognóstico foi constatada em análise exploratória neste trabalho em pacientes com tumores germinativos. Utilizando-se clones da expressão de cDNA recombinantes séricos (SEREX), um antígeno HERV-K gag e sua imunogenicidade foi identificado em câncer de próstata (57). Isso sugere que os produtos do gene retroviral são capazes de atuar como antígenos associados ao tumor, ativando respostas tanto de células $\mathrm{T}$ quanto $\mathrm{B}$, como visto com o HER2/neu ${ }^{(58)}$ ou NY-BR-1 ${ }^{(59)}$. Esta propriedade pode também ser demonstrada em relação à imunidade celular a partir de alguns estudos em humanos com diferentes tipos de câncer epitelial, como citaremos a seguir. Mullins e cols 
estudaram sequências de retrovírus endógenos da família HERV-H em um grupo de cânceres do aparelho digestivo. Nestes tumores houve evidência de forte expressão gênica. Os autores demonstraram sensibilidade para resposta celular medida por ensaio ELISPOT-Interferon-Gama. Além disso procederam à expansão destes linfócitos sensibilizados e demonstraram capacidade citolítica em $40 \%$ de linhagens celulares de carcinoma coloretal endogenamente expressores de HERV-H Xp22.3 ORF ${ }^{(60)}$. Rakoff-Nahoum e cols também encontraram linfócitos $\mathrm{T}$ sensibilizados para peptídeos de família HERV-K em pacientes com antecedentes de seminoma, utilizando ensaio ELISPOT interferon-gama. Estas achados foram encontrados também em uma minoria de indivíduos sem antecedente de câncer ${ }^{(61)}$. Um último exemplo da reatividade imune foi demonstrado em pacientes com câncer de ovário. Rycaj e cols estudaram resposta humoral e celular contra peptídeos de HERV-K env, e compararam com mulheres portadoras de patologia ovariana benigna e mulheres sem neoplasias. Neste estudo pode-se demonstrar aumento de transcrição gênica de HERV-K nas pacientes com câncer de ovário, bem como presença de anticorpos contra proteína de HERV-K-env e presença de linfócitos sensibilizado contra estas mesmas proteínas, por ensaio de ELISPOT-interferon gama. Demonstrou-se também que estes linfócitos sensibilizados mostraram atividade citolítica aumentada ${ }^{(62)}$.

\subsection{HERV e androgênios}

O genoma HERV-K é homólogo ao vírus do tumor de mama em camundongos (MMTV) ${ }^{(63)}$. A transcrição do genoma HERV é mediada por elementos da região U3 da repetição terminal longa 5' (LTR). Muitos retrovírus 
contêm elementos que respondem a glicocorticóides (GRE-Glucocorticoids Response Elements) na região U3, incluindo HERV e outros gama-retrovírus como o MMTV (64, 65). GREs virais são geralmente homólogos ao clássico Elemento Responsivo a Andrógeno (ARE), um sítio de ligação para dímeros do receptor de andrógeno ${ }^{(66)}$. Há homologia entre esses GREs virais e os AREs em alguns genes de mamíferos. Por exemplo, no câncer de mama, a expressão de HERV-K é aumentada pelos hormônios esteróides femininos ${ }^{(67)}$. Recentemente, Rec, uma proteína HERV$\mathrm{K}$, demonstrou formar um complexo trimérico com a proteína testicular "Zinc Finger" (TZFP) e com o AR. Rec é capaz de aliviar a repressão mediada por TZFP da transativação induzida por AR (receptor de androgênio), sugerindo que isso pode funcionar como uma oncoproteína por "des-reprimir" fatores de transcrição oncogênicos como os AREs ${ }^{(68)}$. Baseado nestas observações é possível especularmos que a expressão de HEREs pode ser aumentada por androgênio, no caso dos pacientes com câncer de próstata e eventualmente tornar estes transcritos "visíveis" ao sistema imune, constituindo possíveis alvos para imunomodulação em pacientes recém-diagnosticados com câncer de próstata. 


\section{JUSTIFICATIVA DO ESTUDO}

Este estudo se insere no escopo geral da pesquisa de antígenos associados ao câncer, no caso o câncer da próstata. Este tipo de investigação pode ter como fruto a maior compreensão dos aspectos inerentes à imunogenicidade do câncer, ou seja a capacidade do organismo reagir à presença de antígenos produzidos pelo genoma tumoral. No caso especifico da próstata, existe a peculiaridade de haver interação entre o sistema imunológico e o sistema hormonal em suas diversas facetas e complexidades, como sugerido anteriormente. Hodiernamente a imunomodulação é uma das estratégias mais promissoras no tratamento de câncer através de utilização de drogas capazes de estimular a imunidade dos pacientes, fazendo com que estes passem a reagir de forma competente contra o tumor, através de linfócitos $\mathrm{T}$ citotóxicos. A imunomodulação tem sido explorada com medicamentos que têm por intuito amplificar o combate imunológico, reduzindo os mecanismos de “desligamento" do sistema imune, tornando-o assim mais "atento" e vigilante ${ }^{(24,69)}$. São tratamentos que reduzem a ação de células do sistema imune que funcionam como contra-reguladores negativos da atividade inflamatória, de tal maneira a controlar reações exacerbadas ou mesmo impedir mecanismos de auto-imunidade ${ }^{\text {(70- }}$

72). Estas células ao serem "desligadas" podem permitir ação citotóxica mais eficiente e continuada sobre as células tumorais. Neste sentido, a busca de antígenos associados ao câncer pode ajudar a fornecer instrumentos adicionais na confecção de vacinas que podem se aliar a estas medicações imuno-potencializadoras.

Em relação aos retrovírus endógenos, há muito pouco estudo sobre sua expressão dentro do genoma do câncer de próstata, embora existam algumas 
evidências de que eles se expressam com formação de proteínas e que podem até estimular a formação de anticorpos específicos, pela ativação da imunidade humoral (57). Em relação à imunidade celular, fenômeno este que inicia a resposta imune através do primeiro encontro entre um antígeno e seu linfócito T-naïve respectivo, há quase nada estudado até agora. Há motivos bastante racionais para que este tipo de antígeno seja estudado, seja por ser originalmente viral e portanto exógeno e vindo do lado-de-lá, do "estrangeiro" e por conseguinte com qualidades de non-self, e também por poder ser estimulado através de hormônios sexuais como já mencionado anteriormente, característica tão específica e para nós oportuna no caso do câncer da próstata, um exemplo máximo de uma biologia hormônio-modulável ${ }^{(73)}$. À semelhança do modelo de investigação citado anteriormente, referente ao trabalho de Mullins e cols em câncer gastrointestinal ${ }^{(60)}$, entendemos que nosso trabalho pode trazer adição e colaboração para aumentar o repertório de antígenos-associados ao câncer de próstata, que poderão eventualmente ser explorados para fins terapêuticos. 


\section{HIPÓTESE}

A hipótese deste projeto é que pacientes com câncer de próstata teriam expressão aumentada de retrovirus endógenos e que neste sentido possuiriam dentro de si repertório de linfócitos $\mathrm{T}$ citotóxicos sensibilizados por peptídeos oriundos desta expressão. E também temos por hipótese de que, se isto é verdade, a resposta imune seria diferente ao compararmos pacientes com doença localizada e pacientes com doença disseminada. 


\section{OBJETIVOS}




\section{OBJETIVOS}

\subsection{Objetivo geral}

Avaliar a resposta celular contra peptídeos de retrovírus endógenos em pacientes com câncer de próstata localizado e metastático à luz de sua expressão gênica e perfil de ativação celular em sangue periférico.

\subsection{Objetivos específicos}

a) Extrair através de análise genômica in silico no banco de dados do TCGA dados de expressão gênica de retrovirus endógenos da família HERV-K HML-2 ( análise de RNAseq).

b) Caracterizar resposta imune celular contra peptídeos de HERV-K em amostras de sangue periférico de pacientes com câncer de próstata localizado e pacientes com doença disseminada submetidos à castração.

c) Caracterizar perfil de ativação celular (análise de linfócitos T) em sangue periférico de pacientes com câncer de próstata localizado e pacientes com doença disseminada submetidos à castração. Esta análise permite fornecer um pano de fundo do estado imunológico atual destes pacientes em relação às células envolvidas nos estágios mais importantes da resposta imune dos pacientes. 
5 MATERIAL E MÉTODOS 


\section{MATERIAL E MÉTODOS}

\subsection{Material}

\subsubsection{Casuística e considerações éticas}

No serviço de cirurgia urológica do Instituto do Câncer do Estado de São Paulo são operados aproximadamente de 360 a 480 casos novos por ano. Sessenta e cinco pacientes com câncer de próstata localizado e normais em seu estado hormonal e 24 pacientes com câncer de próstata metastático e com estado hormonal de supressão androgênica tratados e em seguimento nesta instituição foram convidados para participar deste estudo. Amostras de sangue foram coletadas, no período de janeiro de 2015 a outubro de 2016, e encaminhadas imediatamente para o laboratório (Laboratório de Investigação Médica, LIM-60. Departamento de Alergia e Imunopatologia da Faculdade de Medicina da Universidade de São Paulo sob a supervisão do Prof. Dr. Esper Georges Kallás) para centrifugação, separação de Células Mononucleares Periféricas e devida criopreservação. Os pacientes com doença localizada foram coletados na noite anterior de sua operação de vesiculoprostatectomia radical. Os pacientes com câncer metastático foram coletados no ambulatório de Oncologia Clínica do Aparelho Geniturinário. Para controle foram aproveitados amostras de células mononucleares de 12 indivíduos normais. Todos consentiram antes da coleta do material mediante leitura e assinatura de Consentimento Livre e Esclarecido. O projeto foi aprovado pelo Comitê de Ética da Universidade de São Paulo (Nº Processo CAPPesq\#0525/10). 


\subsection{Métodos}

\subsection{1- Análise genômica - Dados Públicos (TCGA)}

Para identificar expressão de retrovírus endógenos humanos (HERVs) da família K do banco público TCGA, utilizou-se uma plataforma pública: i) referência de Genoma Humano (versão hg19,GRCh37) obtida de UCSC (Universidade da Califórnia-Santa Cruz) [Genome Res. 2002 Jun;12(6):996-1006]; ii) informação obtida de transcriptoma humano do GENCODE (the reference human genome annotation for The ENCODE Project-v19)[ Genome Res. 2012 Sep;22(9):1760-74]. iii) localização genômica (versão hg19/GRCh37) de HERV-K definido por RepeatMasker (www.repeatmasker.org), informação obtida a partir da página da UCSC. Apenas as sequências de HERV-K e/ou seus respectivos LTRs (Long Terminal Repeats) foram usados nesta triagem de expressão gênica. Baseado nos dados de RepeatMasker, foram obtidos 107 HERV-K ( e LTRs-solo) localizados no cromossomo 22. Em seguida foi construída uma pipeline bioinformática baseada em escritos de samtools, shell e Perl (www.perl.org) de tal maneira a poder fazer a checagem da localização genômica de HERV-Ks/LTRs no mapeamento genômico de todos os dados de RNAseq (RNA sequenciado) das amostras de próstata. Os achados (reads) mapeados exatamente na posição genômica de HERV-K/LTRs foram filtrados de tal maneira a se evitar alinhamentos falso-positivos. Apenas os achados únicos mapeados e com controle de qualidade superior a 20 (Q>20) foram considerados (Figura 2). Esta pesquisa foi realizada para todas as 496 amostras de tumor de próstata do TCGA. Foi considerado positivo o achado de expressão de 
HERV-K (ou LTR) quando houvesse mais de 1 achado em mais de uma amostra, como esquematizado na Figura 2.

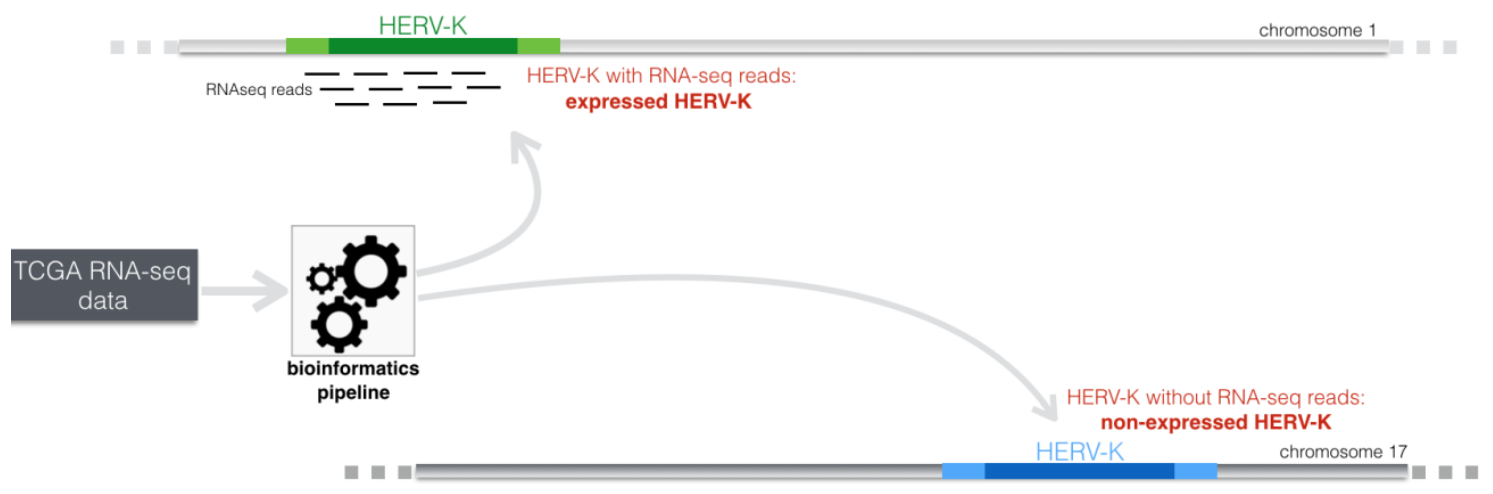

Figura 2 - Esquema mostrando pareamento de leituras de RNA-seq expressas diretamente com o DNA

\subsubsection{Separação de CMSP (Células Mononucleares de Sangue Periférico)}

As CMSP foram separadas através do processo de diferença de gradiente de densidade por solução de Ficoll-Paque Plus (GE Healthcare). Em resumo, amostras de sangue total coletado em tubos de EDTA, Heparina ou ACD foram transferidas para tubos Falcon de $50 \mathrm{ml}$ e diluídas em solução de HANK'S na proporção 1:1. Os homogeinados foram transferidos para tubos Falcon contendo solução de Ficoll na proporção 1:3 de forma lenta e com a inclinação do tubo contendo solução de Ficoll em um ângulo de $30^{\circ}$. Em seguida os tubos foram centrifugados por 30 minutos a $2.300 \mathrm{rpm}$ em temperatura de 18 a $23{ }^{\circ} \mathrm{C}$ com aceleração e desaceleração 1 . Após a centrifugação, a fase intermediária, contendo as CMSP, foi coletada e transferida 
para um único tubo cônico de $50 \mathrm{ml}$. Ao conteúdo do tubo foi diluído em solução de HANK'S (q.s.p. $45 \mathrm{ml}$ ) e centrifugados por $10 \mathrm{~min}$ a $1700 \mathrm{rpm}$ com aceleração e desaceleração 9. O sobrenadante foi descartado e o botão celular ressuspendido em 45 ml de HANK'S para lavagem. Após centrifugação, o sobrenadante foi descartado e o pellet de células foi submetido à lise das hemácias pela adição de $3 \mathrm{ml}$ de solução de ACK, e incubação de 2 min à temperatura ambiente. Em seguida, a lise foi bloqueada pela adição de solução de HANK'S (q.s.p. $45 \mathrm{ml}$ ) e o tubo novamente centrifugado. Após o descarte, o botão celular foi ressuspendido em $5 \mathrm{ml}$ de HANK'S, para a contagem de células. Uma alíquota de 10 microlitros da suspensão celular foi misturada em 90 microlitros de solução de Azul de Tripan 0,4\%; 10 microlitros dessa mistura foi transferida para a Câmara de Newbauer, e 4 quadrantes foram contados. Após o cálculo [(Total de células $/ \mathrm{n}^{\circ}$ quadrantes) x vol. suspensão x fator de diluição (10) x fator de correção da câmara $\left(10^{4}\right)$ ] obteve-se a quantidade de células viáveis totais. $\mathrm{O}$ tubo contendo as células foi centrifugado novamente, $\mathrm{o}$ sobrenadante desprezado e o botão celular ressuspendido em solução de congelamento em uma concentração de $10 \times 10^{6}$ de células $/ \mathrm{ml}$. Cada alíquota de $1 \mathrm{ml}$ foi armazenada no freezer $-80^{\circ} \mathrm{C}$ dentro de um suporte de resfriamento progressivo (stratacooler) e após 24 horas foram transferidos para o tanque de nitrogênio líquido.

\subsubsection{Avaliação de Resposta Imune Celular por ELISPOT}

Quinze peptídeos sobrepostos por 11 aminoácidos correspondentes a respectivos consensos de proteínas da estrutura gag e env HERV-K foram usados na concentração final de $10 \mathrm{mcg} / \mathrm{ml}$ (fornecidos pela Divisão de Imunologia do 
Departamento de medicina da Universidade de Toronto - vide sequência dos peptídeos no apêndice). Placas de nitrocelulose com 96 poços de base plana (Multiscreen, Milipore, Bedford,MA) foram semeadas com 0,5 mcg de anticorpo monoclonal anti-Interferon-Gama (Mabtech, Nacka, Suécia) incubados durante 1 hora a $4^{\circ}$ C. As placas foram lavadas com PBS x 1 e então receberam $1.0 \times 10^{5}$ CMSP suspensas em meio RPMI 1640 suplementadas com penicilina, streptomicina e adicionadas de $10 \%$ de soro fetal bovino (R10), dentro dos poços. O R10 também continha peptídeos gag e env p24, Ionomicina $1 \mathrm{mg} / \mathrm{ml}$ (controle positivo) e, 2,0 microlitros de $100 \%$ de DMSO em 5,0 microlitros (controle negativo). As placas foram incubadas por 16 horas na temperatura de $37^{\circ} \mathrm{C}$ em $\mathrm{CO}_{2} 5 \%$. Após este processo as células foram desprezadas fora. Pós 5 processos de lavagem das placas com PBST (1x PBS contendo 0,05\% de Tween 20), 0,05 microgramas de anticorpo monoclonal biotinilado anti Interferon-Gama (Mabtech) foi adicionado e as placas foram incubadas por posterior 2 horas em temperatura ambiente. Após 5 novas lavagens com PBST, 0,07 microgramas de fosfatase alcalina por poço (Vector Laboratories Inc., Burlingame,CA) em 50 microlitros de PBS foi adicionado por 1 hora em temperatura ambiente. Após 5 lavagens adicionais com PBST, 50 microlitros de BCIP/NBT (\%-Bromo-4-Chloro-3-Indolyl Phosphato/Nitro Blue tetrazolium) de solução por poço foi adicionado e as placas foram reveladas por aproximadamente 30 minutos. Após este tempo se processou à contagem de pontos (spots) utilizando-se um leitor AID (AID, Alemanha), de tal maneira que as respostas específicas contra peptídeos de HERV-K foram consideradas como sendo o número

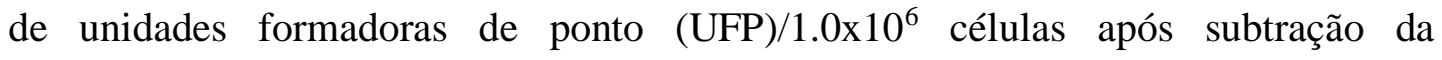
quantidade residual de Interferon-Gama. As respostas foram consideradas positivas 
quando o número de UFP excedesse 50 UFP por $1.0 \times 10^{6}$ células e fosse pelo menos 4 vezes o nível dos poços sem peptídeo HERV-K.

\subsubsection{Citometria de Fluxo-Imunofenotipagem-Perfil de Ativação e Senescência celular}

Para garantir a qualidade e bom controle dos experimentos, cada lote de experimento foi composto das três coortes pré-planejadas de pacientes com câncer de próstata localizado, câncer de próstata disseminado e grupo controle de indivíduos sadios, sendo que todo o experimento foi realizado no mesmo dia em todos estes coortes. Os painéis de anticorpos utilizados nestas análises foram definidos considerando as propriedades de cada molécula de anticorpo (Tabela 1).As populações linfocitárias foram selecionadas imunofenotipicamente com base na expressão das moléculas CD3, CD4 e CD8. O perfil ontogênico dos linfócitos foi determinado pela presença ou ausência de moléculas CD27, CD45RA e CCR7 e a ativação definida com base na expressão das moléculas CD38, CCR5 e HLA-DR na superfície celular dos linfócitos T CD4 e CD8 (Figura 3 A, B e C; e Tabela 2). O perfil de Senescência e Exaustão dos linfócitos $\mathrm{T}$ foram definidos com base na expressão das moléculas de superfície CD28, CD57, CD95 e PD1. Foi também examinado o perfil de células que expressam PD-L1 como um elemento muito importante de contra-regulação da inflamação e que na atualidade tem sido bastante explorado como agente de desligamento do sistema imune nas situações de escape tumoral e imunomodulação. O perfil de ontogenia linfocitária, ou seja o estudo das sub-populações envolvidas no processo de resposta imune, foi realizado com a 
expressão combinada dos marcadores CD45RA+CD27+CCR7+, ficando as seguintes classificações: células naive (CD45RA+CD27+CCR7+); células de memória central (CD45RA-CD27+CCR7+); células de memória efetora (CD45RA-CD27-CCR7-); células de memória transitória (CD45RACD27+CCR7-); células de memória intermediária (CD45RA+CD27+CCR7-) e células efetoras terminais (CD45RA+CD27-CCR7-). A avaliação do status de ativação e senescência foi avaliada em cada um destes estágios de ontogenia celular, tanto na população de células CD4+ como CD8+. Ou seja, cada fenótipo foi sobreposto na análise isoladamente e em combinação, de tal maneira a examinar-se a participação de cada um destes elementos no processo imune em relação à sua situação de ativação (processo agudo, resposta inflamatória em curso, local de trânsito dentro do processo, etc) bem como à sua situação de senescência (término da resposta imune, instalação de estado crônico de inflamação, desligamento da resposta imune, apoptose linfocitária, estado de tolerância, etc).

\subsubsection{Marcação de Superfície Celular}

As CMSP criopreservadas em nitrogênio líquido foram descongeladas em banho-maria a $37^{\circ} \mathrm{C}$ e transferidas para tubos de $15 \mathrm{ml}$ contendo $9 \mathrm{ml}$ de meio RPMI enriquecido (10\% de Soro fetal Bovino, $2 \mathrm{mM}$ de L-glutamina, $1 \mathrm{mM}$ de piruvato de sódio, $1 \mathrm{mM}$ de penicilina/estreptomicina, 55 microM de 2-Mercaptoetanol, e $10 \mathrm{mM}$ da solução de HEPES); estes foram centrifugados a $1700 \mathrm{rpm}$ por 10 minutos. O sobrenadante foi descartado e as células foram suspensas em $2 \mathrm{ml}$ de RPMI enriquecido para contagem em azul de tripan 0,4\% (10 microlítros de 
amostra+10 microlítros do reagente). Após a contagem, foram separadas $1 \times 10^{6}$ células de cada paciente para cada painel de imunofenotipagem em alíquotas de 100 microlitros que foram distribuídas em uma placa de 96 poços com fundo "V". A suspensão celular foi submetida a duas etapas de lavagem pela adição de 100 microl de solução tampão MACS [solução de PBS 1x contendo albumina de soro bovino $(0,5 \%)$ e EDTA $(2 \mathrm{mM})]$ seguida de centrifugação a $1.700 \mathrm{rpm}$ por 10 minutos. Após o descarte do sobrenadante, o botão de células foi homogeneizado com 100 microlitros da mistura de anticorpos monoclonais referente ao painel de ativação celular (Tabela 3) e de senescência (Tabela 4) e incubado a $4^{\circ} \mathrm{C}$ por 30 minutos, protegido da luz. Após incubação, foram realizadas duas etapas de lavagem com solução Tampão MACS, conforme descrito anteriormente. As amostras do painel de ativação celular foram fixadas com 200 microl de paraformaldeido (PFA) $1 \%$ e armazenadas no escuro a $4^{\circ} \mathrm{C}$. As amostras foram adquiridas no citômetro de fluxo BD LSRII Fortessa (Becton Dickinson Immunodiagnostic Systems, San Jose, CA, EUA). A compensação foi realizada com beads positiva e negativas (BD Biosciences), em que as beads positivas foram marcadas individualmente para cada fluorcromo utilizado.

\subsubsection{Estratégias de Análise dos Dados de Citometria de Fluxo}

Os dados gerados da aquisição no citômetro de fluxo foram analisados no programa Flowjo (TreeStar, San Caros, California,USA). A definição dos gates foi baseada na análise dos tubos de FMO. Para o painel de ativação foram utilizados 6 tubos de FMO (CD27, CD38, CD45RA, HLA-DR, CCR5 e CCR7). Para o painel de 
senescência foram utilizados 4 tubos de FMO (CD28, CD57, CD95 e PD1). As estratégias de análise utilizadas para o painel de ativação, senescência e diferenciação ontogênica dos linfócitos T estão apresentadas na Figura 3.

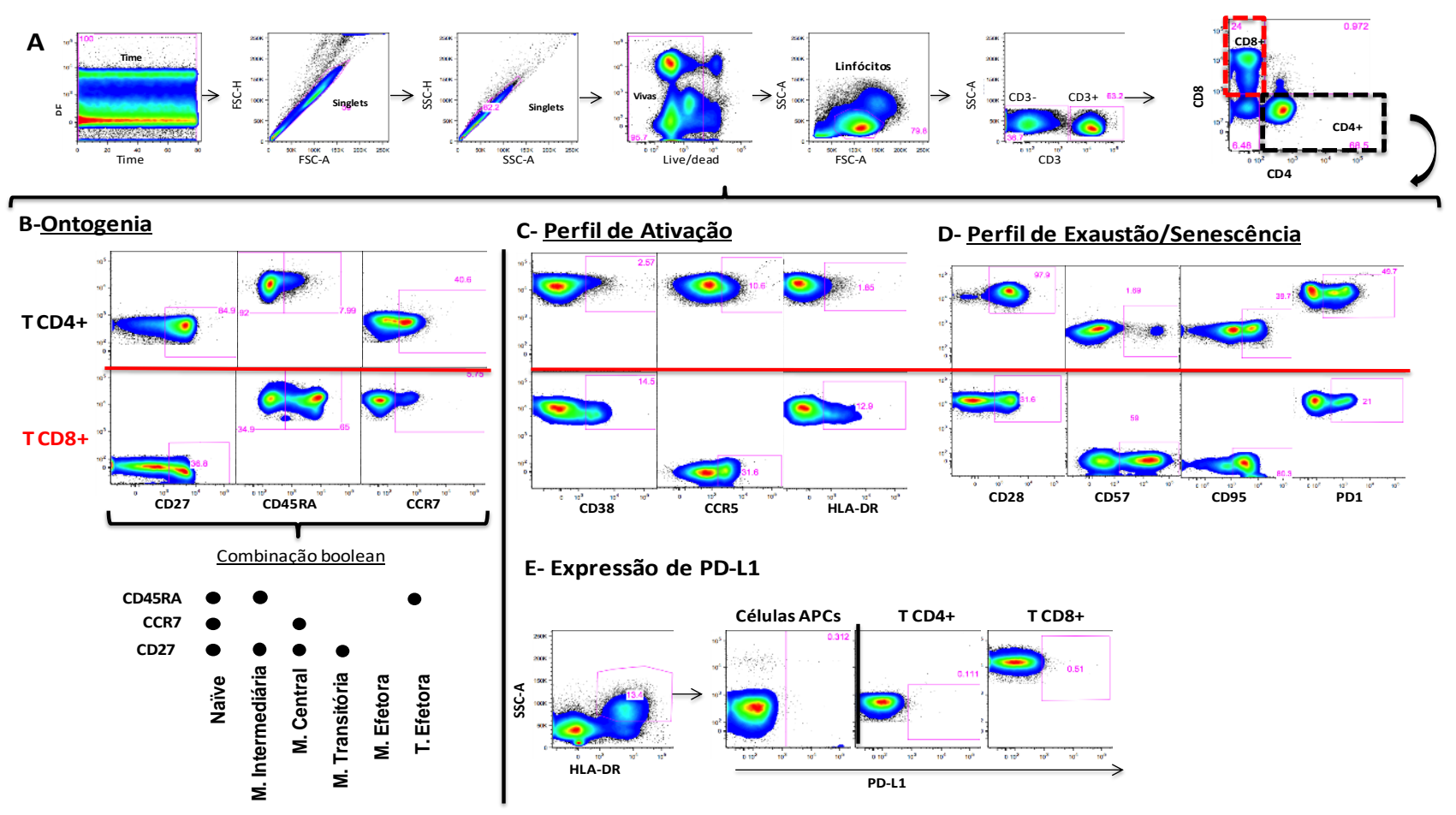

Figura 3 - Estratégia de análise de células TCD4+ e CD8+. Os dados foram analisados em gráficos pseudocolor plot, baseados nos seguintes parâmetros: A) parâmetros de qualidade-Time, Singlets, Vivas, Linfócitos T (CD3+), CD4 e CD8; B) o perfil de ontogenia, foi definido através da combinação booleana da expressão de CD27, CD45RA e CCR7 para identificar as diferentes subpopulações; C) o perfil de ativação foi analisado através da expressão de CD38, CCR5 e HLADR; D) o perfil de exaustão/ senescência através da expressão de CD28, CD57, CD95, PD1; E) a expressão de PD-L1 foi observada nas células apresentadoras de antígenos identificadas por HLA-DR x SSC-A, células T CD4+ e CD8+ 


\subsubsection{Análise Estatística}

O objetivo principal deste estudo foi determinar a resposta imune celular de pacientes com câncer de próstata contra peptídeos de retrovírus endógenos da família HERV-K comparando 3 coortes: 1-câncer de próstata localizado e sensível à castração; 2-câncer de próstata disseminado e resistente à castração e 3-grupo controle composto de indivíduos saudáveis e sem diagnóstico de câncer de próstata.

Como estudo auxiliar foi feita análise genômica da expressão de retrovírus endógeno da família HERV-K por bioinformática.

Como estudo correlato foi também analisado o estado de ativação celular e senescência celular de forma comparativa entre as diferentes coortes, com a hipótese de que haveria alguma diferença na resposta imune de HERV-K entre as diferentes coortes e que de alguma forma isso poderia estar correlacionado com possíveis diferenças nos estados de ativação ou senescência. Uma hipótese inicial seria a de encontrar correlação entre estados de maior ativação, menor senescência e maior probabilidade de se encontrar resposta imune celular, de tal maneira a compor um quadro coerente. Para tanto seriam feitas análises não-pareadas e pareadas entre os grupos em relação aos diferentes perfis de ativação e senescência de acordo com os agrupamentos ontogenéticos (designados posteriormente como sub-populações), segundo os marcadores de superfície celular analisados na citometria de fluxo, já descritos anteriormente. Para tanto utilizou-se o teste U de MannWhitney/Wilcoxon bi-caudal para a análise de significância estatística na comparação entre os 3 grupos, em análise não-paramétrica. A regressão logística univariada estava planejada para que se houvesse positividade relevante e significante na resposta imune, esta seria 
correlacionada com as diferenças entre as populações linfocitárias nas 3 diferentes coortes de pacientes.

Esta análise tinha por objetivo obter dados para geração de novas hipóteses, por entendermos que este estudo ainda teria caráter exploratório e porque o desfecho de análise mais importante em relação aos pacientes com doença localizada seria a sobrevida-livre de elevação do PSA. Com esta premissa consideramos ter estudado pacientes em número suficiente. No entanto este desfecho é relacionado ao tempo de seguimento, queneste momento ainda é, e portanto seria precoce qualquer outro estudo de correlação prognóstica. Neste sentido temos planejado no futuro reanalizar prospectivamente os achados de ativação e senescência linfocitárias como possíveis biomarcadores de sobrevida. Nesta ocasião tentaremos uma análise multivariada, levando-se em conta outros aspectos potencialmente confundidores dentro da equação, sobretudo as características prognósticas clássicas no câncer de próstata localizado, tais como grau de Gleason e estadiamento cirúrgico ${ }^{(74)}$. Em relação aos pacientes com doença disseminada, julgamos ser uma coorte pequena para análises multivariadas já que o desfecho mais importante aqui seria sobrevida global. No momento desta análise, a maioria destes pacientes ainda está viva. Também num futuro próximo, quando o desfecho de sobrevida estiver maduro, vamos arriscar uma análise de fatores prognósticos baseada no estado de ativação e senescência linfocitárias em sua correlação com a eficácia do tratamento de supressão androgênica, tempo para atingimento do estado de resistência à castração, benefício clínico e tempo de sobrevida destes pacientes.

$\mathrm{Na}$ análise realizada, então, diferenças intra e inter-grupos foi considerada estatisticamente significante quando $\mathrm{p}<0,05$. As análises seriam feitas utilizando 
programa Stata versão 12 (StataCorp, College Station, TX), Graph Pad Prism7.0 e SPICE. A construção das tabelas e gráficos foi feita pelos programas Graph Pad Prism 7.0 e SPICE. 
Tabela 1 - Informações descrevendo a função e a finalidade de cada molécula caracterizada através dos painéis de citometria de fluxo

\begin{tabular}{|c|c|c|}
\hline $\begin{array}{l}\text { Marcadores de } \\
\text { membrana }\end{array}$ & Funções & Finalidade \\
\hline CD3 & $\begin{array}{l}\text { Proteína de superfície associadas ao Receptor de } \\
\text { Células T (TCR). }\end{array}$ & $\begin{array}{l}\text { Caracterização de } \\
\text { linfócitos T }\end{array}$ \\
\hline $\mathrm{CD} 4$ & $\begin{array}{l}\text { Proteína que participa da sinalização e adesão celular } \\
\text { sendo um co-receptor de MHC de classe II. }\end{array}$ & $\begin{array}{l}\text { Caracterização de } \\
\text { linfócitos T CD4 } \\
\text { auxiliares }\end{array}$ \\
\hline CD8 & $\begin{array}{l}\text { Proteína que participa da sinalização e adesão celular } \\
\text { sendo um co-receptor de MHC de classe I }\end{array}$ & $\begin{array}{l}\text { Caracterização de } \\
\text { linfócitos T CD8 } \\
\text { citotóxicos }\end{array}$ \\
\hline $\mathrm{CD} 27$ & $\begin{array}{l}\text { Proteína ligante do CD70, atua como co-estimulador } \\
\text { para ativação de células T e B }\end{array}$ & Diferenciação ontogênica \\
\hline CD45RA & $\begin{array}{l}\text { Isoforma de CD45. Contém o exon A, que é uma } \\
\text { tirosina fosfatase que participa do processo de } \\
\text { sinalização celular }\end{array}$ & Diferenciação ontogênica \\
\hline CCR7 & $\begin{array}{l}\text { Receptor das quimiocinas CCL19 e CCL21, } \\
\text { participando do processo de migração das células para } \\
\text { órgãos linfoides secundários }\end{array}$ & Diferenciação ontogênica \\
\hline CD38 & $\begin{array}{l}\text { Ectoenzima multifuncional, glico-hidrolase NAD onde } \\
\text { catalisa a Nicotinamida-adenina-dinucleotideo. } \\
\text { Participa no processo de adesão celular, transdução de } \\
\text { sinais e vias de sinalização }\end{array}$ & Ativação celular \\
\hline HLA-DR & $\begin{array}{l}\text { Molécula do Complexo de Histocompatibilidade } \\
\text { Maior (MHC) Classe II. Se liga a peptídeos } \\
\text { antigênicos de forma estável e apresenta-os na } \\
\text { superfície celular }\end{array}$ & Ativação celular \\
\hline CCR5 & $\begin{array}{l}\text { Proteina expressa em linfócitos T. Está associado a } \\
\text { mecanismos mais gerais de ativação celular }\end{array}$ & Ativação celular \\
\hline CD57 & $\begin{array}{l}\text { Rotineiramente usado para identificar células } \\
\text { senescentes com reduzida capacidade proliferativa }\end{array}$ & Senescência e Exaustão \\
\hline CD28 & $\begin{array}{l}\text { Receptor de membrana responsável pelo desligamento } \\
\text { da resposta imune celular. Neste sentido é um receptor } \\
\text { inibitório associado com perfis de exaustão celular }\end{array}$ & Senescência e Exaustão \\
\hline CD95 & $\begin{array}{l}\text { Receptor da superfamília do TNF. Recebe o ligante de } \\
\text { FAS e inicia apoptose celular }\end{array}$ & $\begin{array}{l}\text { Senescência e Exaustão- } \\
\text { apoptose }\end{array}$ \\
\hline PD1 & $\begin{array}{l}\text { Um receptor do tipo check-point que atua inibindo a } \\
\text { resposta celular continuada nas inflamações em geral. } \\
\text { Importante nos mecanismos de redução da intensidade } \\
\text { das respostas imunológicas anti-tumorais. Presente em } \\
\text { populações de linfócitos T citotóxicos. }\end{array}$ & $\begin{array}{l}\text { Senescência e Exaustão- } \\
\text { apoptose }\end{array}$ \\
\hline PD-L1 & $\begin{array}{l}\text { Ligante de PD1. Receptor de superfície que pode estar } \\
\text { expresso em linfócitos e em células tumorais de vários } \\
\text { tipos de tumores incluindo o câncer de próstata }\end{array}$ & $\begin{array}{l}\text { Senescência e Exaustão- } \\
\text { apoptose }\end{array}$ \\
\hline
\end{tabular}

*Fonte: Janeway 2002

Abbas 2007 
Tabela 2 - Informações dos anticorpos e reagentes utilizados no painel de citometria de fluxo

\begin{tabular}{lcccc}
\hline & Fluorcromo & Clone & Catalogo & Empresa \\
\hline CD3 & PE CF594 & UCHT1 & 562280 & BD \\
CD4 & APC H7 & RPA-T4 & 560158 & BD \\
CD8 & BV 510 & SK1 & 563919 & BD \\
CD27 & PE & M-T271 & 340425 & BD \\
CD38 & PerCP Cy 5.5 & HIT2 & 551400 & BD \\
CD45RA & FITC & HI100 & 555488 & BD \\
CCR7 & PE Cy7 3D12 & 3D12 & 557648 & BD \\
HLA-DR & Alexa fluor 700 & G46-6 & 560743 & BD \\
CCR5 & BV 711 & 2D7/CCR5 & 563395 & BD \\
CD57 & BV 605 & NK-1 & 563895 & BD \\
CD28 & APC & CD28.2 & 559770 & BD \\
CD95 & PE Cy5 & DX2 & 559773 & BD \\
PD1 & & & & \\
PD-L1 & & & & \\
Viabilidade & UV & - & L34957 & Invitrogen \\
\hline
\end{tabular}




\section{RESULTADOS}

\subsection{Análise demográfica e clínica das coortes pesquisadas}

Tabela 3 - Características Demográficas dos pacientes e Grupo Controle

\begin{tabular}{lccc}
\hline & $\begin{array}{c}\text { Doença Localizada } \\
\mathbf{n = 6 5}\end{array}$ & $\begin{array}{c}\text { Doença Disseminada } \\
\mathbf{N = 2 4}\end{array}$ & $\begin{array}{c}\text { Grupo Controle } \\
\text { N=12 }\end{array}$ \\
\hline Idade (mediana) & $64(45-81)$ & $68(52-80)$ & $68(51-79)$ \\
Estadiamento & & & \\
pT3apN0 & $44 \%$ & - & - \\
pT3bpN1 & $16 \%$ & & \\
pT2cpN0 & $20 \%$ & & \\
pT3apN1 & $8 \%$ & & \\
pT3bpN0 & $8 \%$ & & - \\
pT3bpNx & $2 \%$ & $12(0,002-343)$ & \\
pT2apN0 & $2 \%$ & & - \\
PSA & $14,9(3-99)$ & $8,3 \%$ & - \\
Grupos Étnicos & & $75 \%$ & - \\
Afro-descendentes & $11,7 \%$ & $12,5 \%$ & \\
Caucasianos & $60 \%$ & $4,17 \%$ & \\
Mestiços & $27,4 \%$ & & \\
Asiáticos & - & & \\
\hline
\end{tabular}

*Nota: Pacientes com doença disseminada apresentam predominantemente metástases ósseas e linfonodais 


\subsection{Resultados de Análise genômica da expressão gênica de HERV-K}

Para identificar os loci potencialmente ativos de HERV-K (transcritos), foi utilizada uma lista dos retrovírus endógenos mais recentemente integrados (e fixos) no genoma humano. HERV-K e solo-LTRs (LTR5_Hs). Através de um pipeline computacional atravessando coordenadas RepeatMasker no genoma de referência humano (GRCh37) e sequência de dados de RNAm, foi possível identificar um grupo HERVs potencialmente transcritos: aproximadamente $17 \%$ da coorte de câncer de próstata localizado, analizados do TCGA (257 no total), apresentou pelo menos 2 ou mais achados de RNAseq provenientes de regiões contendo genes de HERV-K, sugerindo fortemente sua transcrição ou atividade. Para se evitar candidatos falso-positivos, apenas resultados positivos em elementos exclusivamente em HERV-K/LTR5_Hs foram utilizados. 


\subsection{Resultado de ELISPOT-Interferon gama contra peptídeos de HERV-K}

Todos os pacientes e participantes do Grupo Controle foram analisados para ELISPOT-interferon Gama. Quase nenhuma resposta foi vista, dentro de nossos critérios de mais de 50 spots por paciente tanto em relação aos peptídeos relacionados ao exon gag ou env, da família de HERV-K, utilizando controles positivos e negativos. Este quadro está mostrado nas figuras 4 e 5 . Pode-se notar apenas a presença de 50 spots em 2 pacientes para peptídeo de gag e env e 1 paciente com 80 spots para env. Estes achados em meio à maioria daqueles que atingiram menos de 20 spots, caracterizam um resultado negativo, ou pelo menos muito baixa responsividade ou ainda nenhuma responsividade podendo ser atribuídos os resultados apenas a achados falso-positivos, provavelmente. 


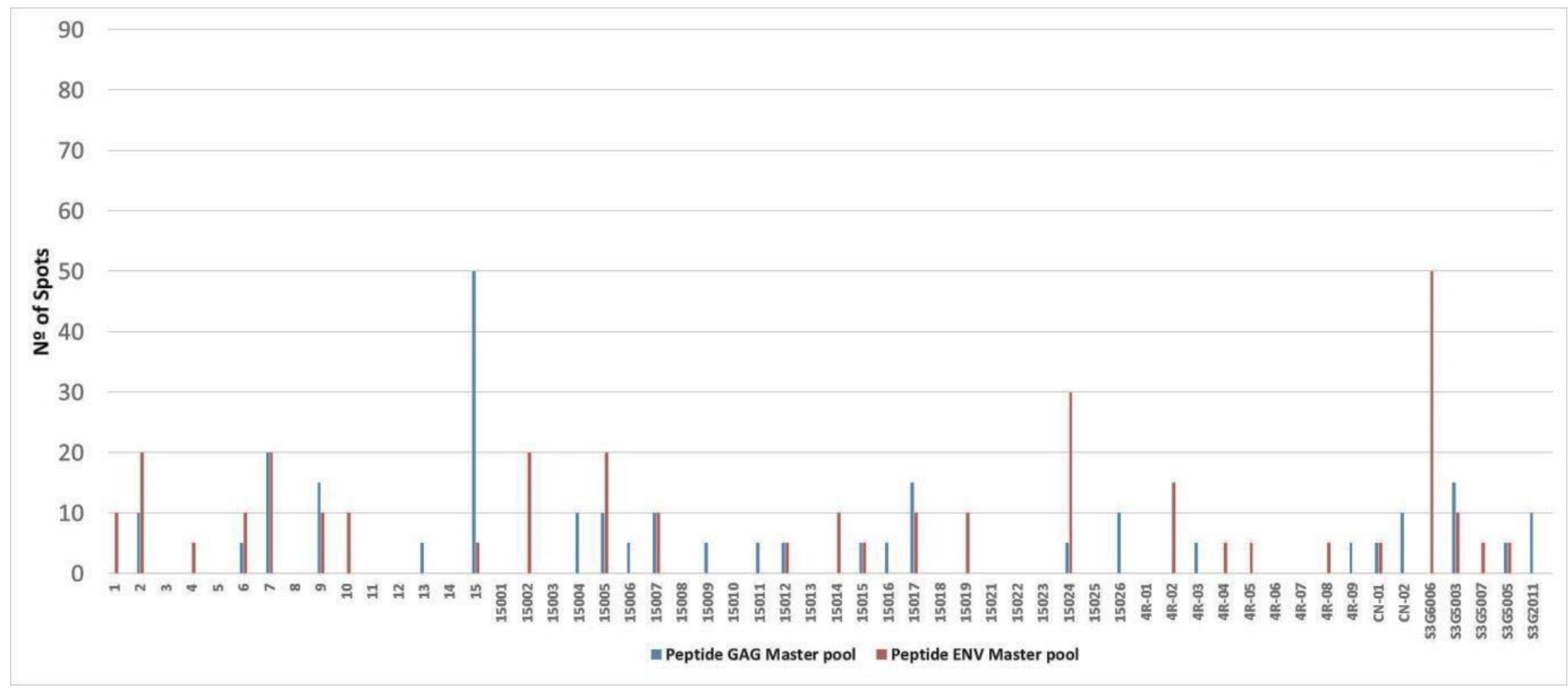

Figura 4 - Eixo $\mathrm{Y}=\mathrm{N}^{\mathrm{o}}$ de spots. Eixo $\mathrm{X}=$ pacientes. Neste gráfico encontramos contagens de 50 spots em 2 pacientes, apenas. Um com doença localizada para gag (\#15) e outro do grupo controle para env (\#S3G6006) 


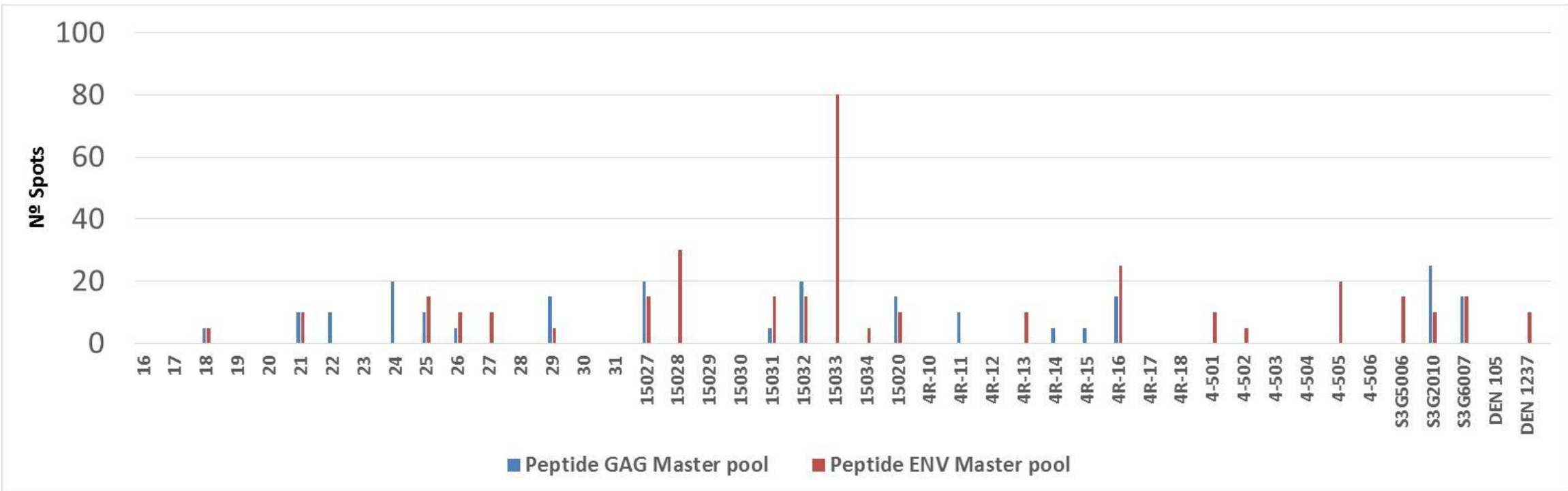

Figura 5 - Eixo $\mathrm{Y}=\mathrm{N}^{0}$ de spots. Eixo $\mathrm{X}=$ pacientes. Neste gráfico encontramos contagens acima do limiar de positividade -80 spotscontra env em um paciente com doença localizada 


\subsection{Resultado de avaliação de ativação e senescência linfocitária por citometria de fluxo}

\section{*Nota explicativa:}

1- Foi realizada análise em toda a população de linfócitos T CD4 e CD8 de forma regrada na seguinte sequência:

i- Prevalência das células com os diferentes marcadores isoladamente, em relação à ativação (CD38, CCR5 e HLA-DR) em toda a população de linfócitos. Posteriormente a mesma análise analisando co-expressão entre os diferentes marcadores.

ii- Prevalência das células com os diferentes marcadores isoladamente, em relação ao perfil de senescência/exaustão (CD28, CD57, CD95 e PD-1) em toda a população de linfócitos. Posteriormente a mesma análise analisando co-expressão entre os diferentes marcadores.

iii- Distribuição de cada grupamento de células com os marcadores específicos (isolados e em combinação) em relação às sub-populações de linfócitos em relação à sua ontogenia (Naïve, Memória Central, Memória transitória, Memória Intermediária, Memória Efetora e Memória Terminal Efetora) nas diferentes coortes estudadas.

2- Nesta sessão inicial estarão relatados apenas os achados estatisticamente significantes. $O$ restante das tabelas e gráficos estarão dispostos no apêndice final. 


\subsubsection{Perfil de Diferenciação dos Linfócitos T CD4+}
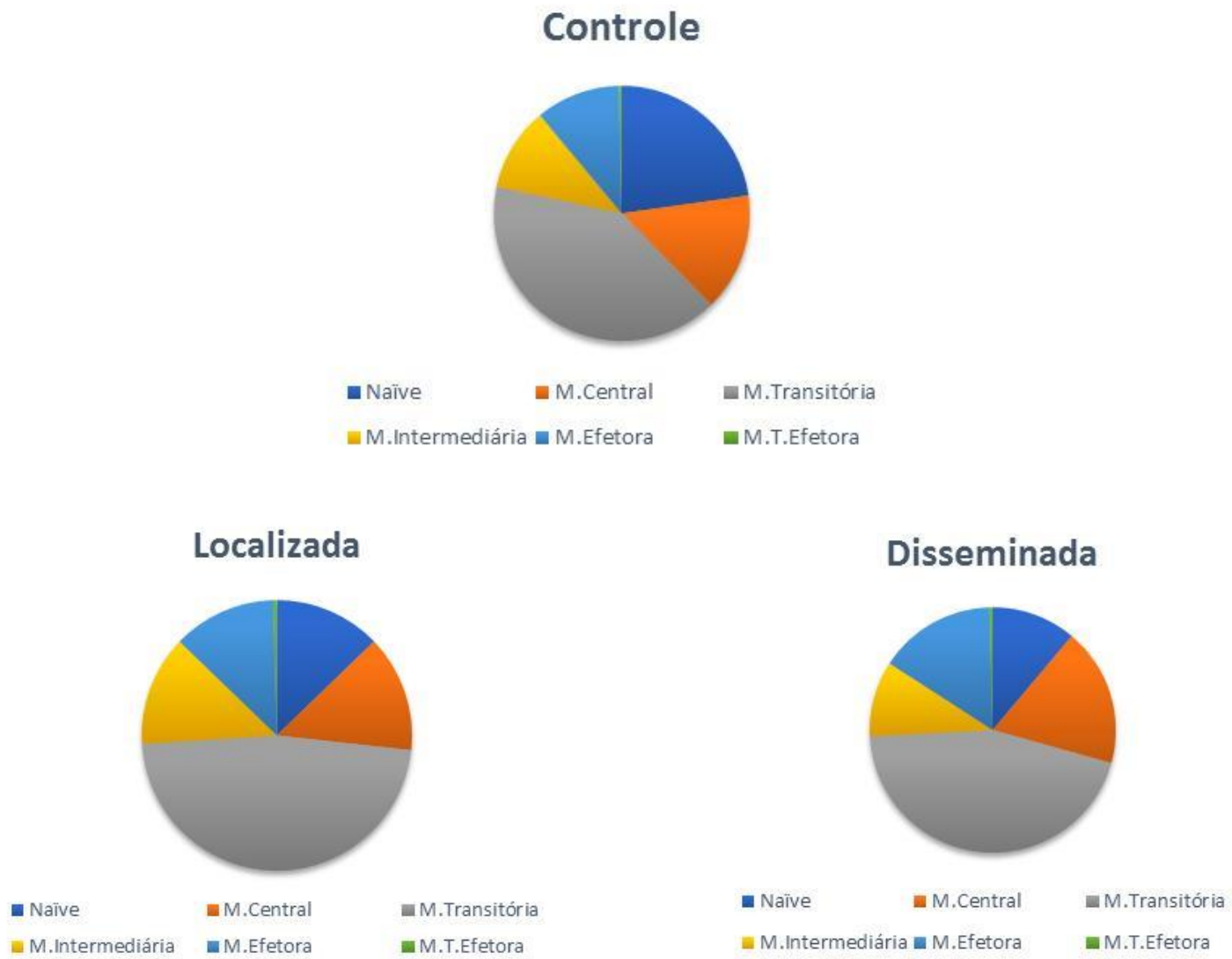

Figura 6 - Distribuição dos diferentes imunofenótipos entre as coortes , na população global de CD4

Tabela 4 - Distribuição dos diferentes imunofenótipos entre as coortes na população global de CD4

\begin{tabular}{lcccc}
\hline & Controle & Localizada & Disseminada & $\begin{array}{c}\text { Valor P entre } \\
\text { Localizada e } \\
\text { Disseminada }\end{array}$ \\
\hline Naïve & 20,7 & 11,7 & 10,6 & 0,75 \\
M.Central & 13,6 & 12,8 & 17,4 & 0,046 \\
M.Transitória & 37 & 43,3 & 42,8 & 0,36 \\
M.Intermediária & 9,63 & 12,1 & 9,5 & 0,0079 \\
M.Efetora & 9,71 & 11,3 & 14,7 & 0,12 \\
M.T.Efetora & 0,33 & 0,42 & 0,42 & 0,44 \\
\hline
\end{tabular}


Figura 6 e Tabela 4: Distribuição dos diferentes imunofenótipos em cada coorte analisada, mostrando que há diferença na participação de cada sub-população na ontogenia linfocitária, entre as diferentes coortes, sendo estas diferenças atribuíveis às diferenças nas subpopulações de Memória Central e Memória Intermediária. A comparação mostrou diferença estatisticamente significante na comparação entre Controle e Localizada $(p=0,04)$. Comparação entre Controle e Disseminada $(\mathrm{p}=0,01)$ e comparação entre Localizada e Disseminada $(\mathrm{p}=0,001)$. Uma análise inicial para examinarmos os diferentes estados de ativação nas diferentes coortes. Mann-Whitney U test, bicaudal. 


\subsubsection{Perfil de Ativação de Linfócitos T CD4+}

A- Presença de maior ativação nas coortes de doença localizada versus doença disseminada para a marcação isolada de CD38 analisados na expressão individual dos marcadores CD38, CCR5 e HLA-DR

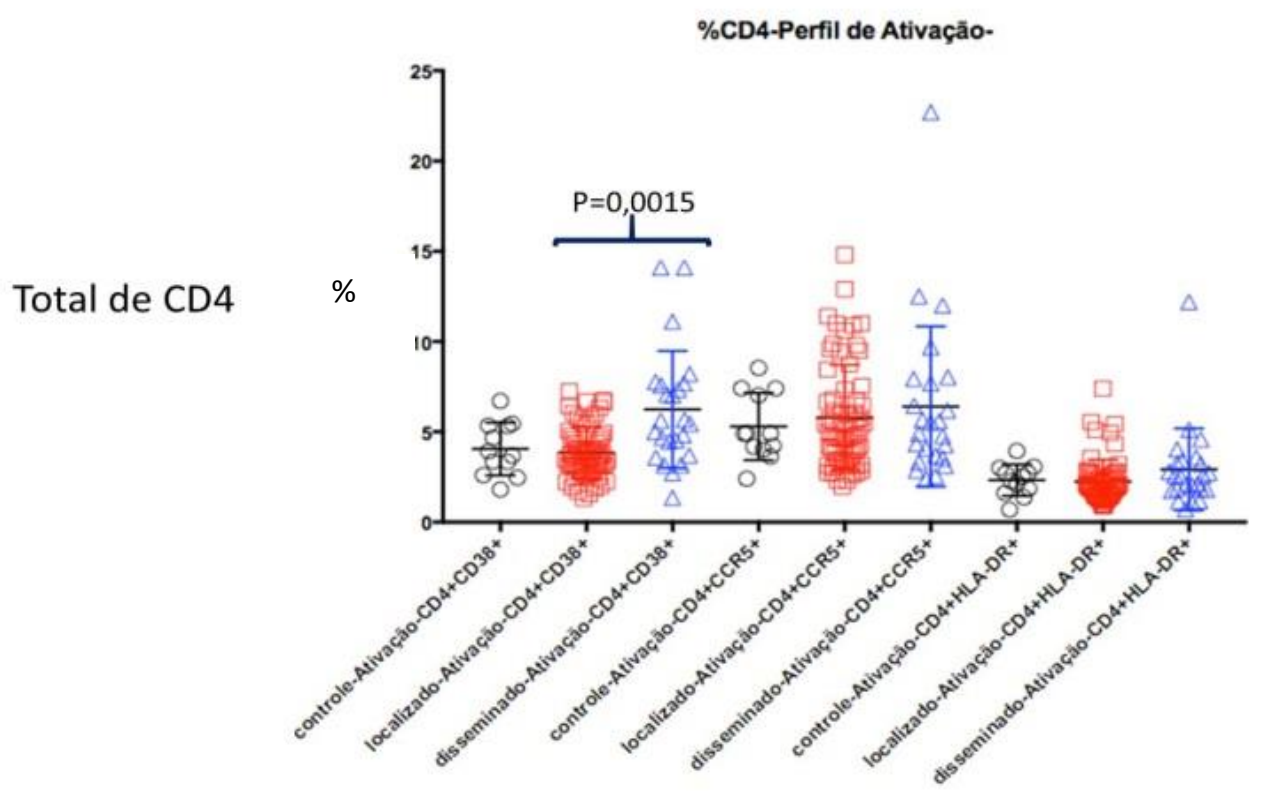

Gráfico 1 - Perfil de CD4 total, quando selecionado isoladamente por marcadores de ativação celular, na comparação entre as coortes

Tabela 5 - Comparação das medianas das porcentagens de linfócitos T CD4 selecionados para marcadores de senescência e exaustão, isoladamente.

\begin{tabular}{lccc}
\hline & CD38+ & CCR5+ & HLA-DR+ \\
\hline Controle & $\mathbf{3 , 8}$ & 4,9 & 2,39 \\
Localizado & $\mathbf{3 , 6}$ & 4,8 & 1,9 \\
Disseminado & $\mathbf{5 , 5 3}$ & 5,21 & 2,54 \\
Valor $\boldsymbol{p}$ entre Local. e dissem. & $\mathbf{0 , 0 0 0 1}$ & 0,77 & 0,09 \\
\hline
\end{tabular}

Gráfico 1 e Tabela 5: Mediana da porcentagem de células com os marcadores isoladamente analisados na população total de linfócitos T CD4+. Mann-Whitney U test bicaudal. Mostrando significância estatística com $p<0,0015$ para os grupos de marcação isolada de CD38+ 
B- Maior prevalência de ativação linfocitária baseada em CD38 em todas as sub-populações linfocitárias, no grupo de doença disseminada

Gráfico 2 - Imunofenótipo selecionado isoladamente para CD38 na população global de CD4

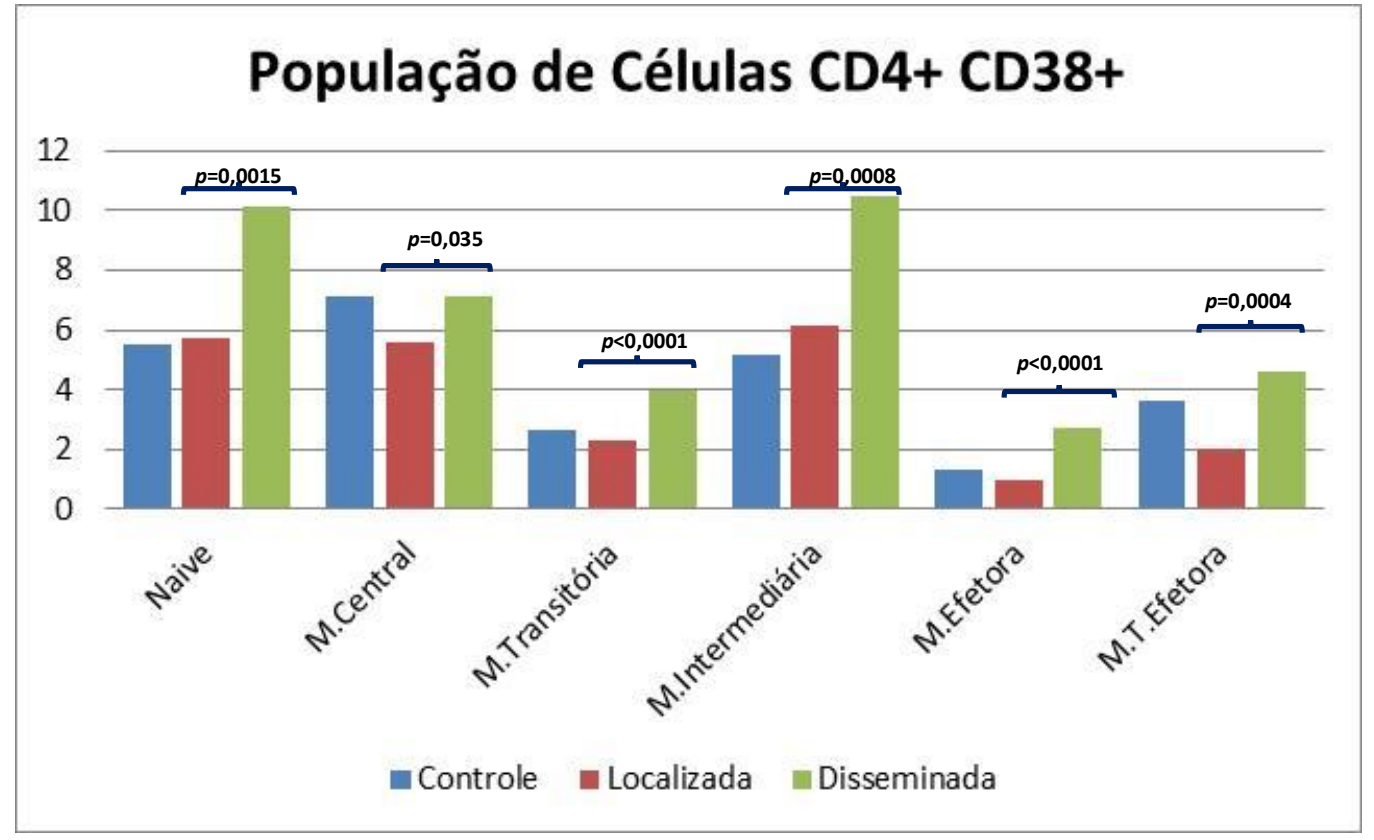

Tabela 6 - Imunofenótipo selecionado isoladamente para CD38 na população global de CD4

\begin{tabular}{lcccc}
\hline & Controle & Localizada & Disseminada & $\begin{array}{c}\text { Valor } \boldsymbol{p} \text { entre local. e } \\
\text { disseminada }\end{array}$ \\
\hline Naive & $\mathbf{5 , 5}$ & $\mathbf{5 , 6 9}$ & $\mathbf{1 0 , 1 5}$ & $\mathbf{0 , 0 0 1 5}$ \\
M. Central & $\mathbf{7 , 0 9}$ & 5,57 & $\mathbf{7 , 1 3}$ & $\mathbf{0 , 0 3 5}$ \\
M. Transitória & $\mathbf{2 , 6 5}$ & $\mathbf{2 , 3}$ & $\mathbf{3 , 9 9}$ & $<\mathbf{0 , 0 0 0 1}$ \\
M. Intermed. & $\mathbf{5 , 1 6}$ & $\mathbf{6 , 1 1}$ & $\mathbf{1 0 , 4 5}$ & $\mathbf{0 , 0 0 0 8}$ \\
M. Efetora & $\mathbf{1 , 3 3}$ & $\mathbf{0 , 9 8}$ & $\mathbf{2 , 7 0}$ & $<\mathbf{0 , 0 0 0 1}$ \\
M. Term. Efetora & $\mathbf{3 , 6 1}$ & $\mathbf{2 , 0}$ & $\mathbf{4 , 6 1}$ & $\mathbf{0 , 0 0 0 4}$ \\
\hline
\end{tabular}

Gráfico 2 e Tabela 6: Diferenças estatisticamente significantes, mostrando aumento de ativação na coorte de doença disseminada quando examinadas pela marcação individual de CD38 em praticamente todas as sub-populações. Isoladamente, as coortes de Controle e Doença Localizada são muito parecidas e iguais do ponto de vista estatístico. Mann-Whitney U test bicaudal. 
Quando examinamos a concomitância de CD38 com outros marcadores de ativação testadas (CCR5+HLA-DR; CD38+HLA-DR e CD38+CCR5), vemos o mesmo padrão de maior ativação nas coortes de doença disseminada, com significância estatística na maioria das sub-populações testadas, como mostrados nas figuras e tabelas colocadas no apêndice. 


\subsubsection{Perfil de Senescência/Exaustão de Linfócitos T CD4+}

A- Presença de predominância de linfócitos $\mathbf{T}$ em perfil de senescência na coorte de doença disseminada, com significância estatística nos perfis que marcam CD57 e PD1. Expressão individual dos marcadores CD28, CD57, CD95 e PD-1

Gráfico 3 - Perfil de CD4 total, quando selecionado isoladamente por marcadores de senescência e exaustão, na comparação entre as coortes

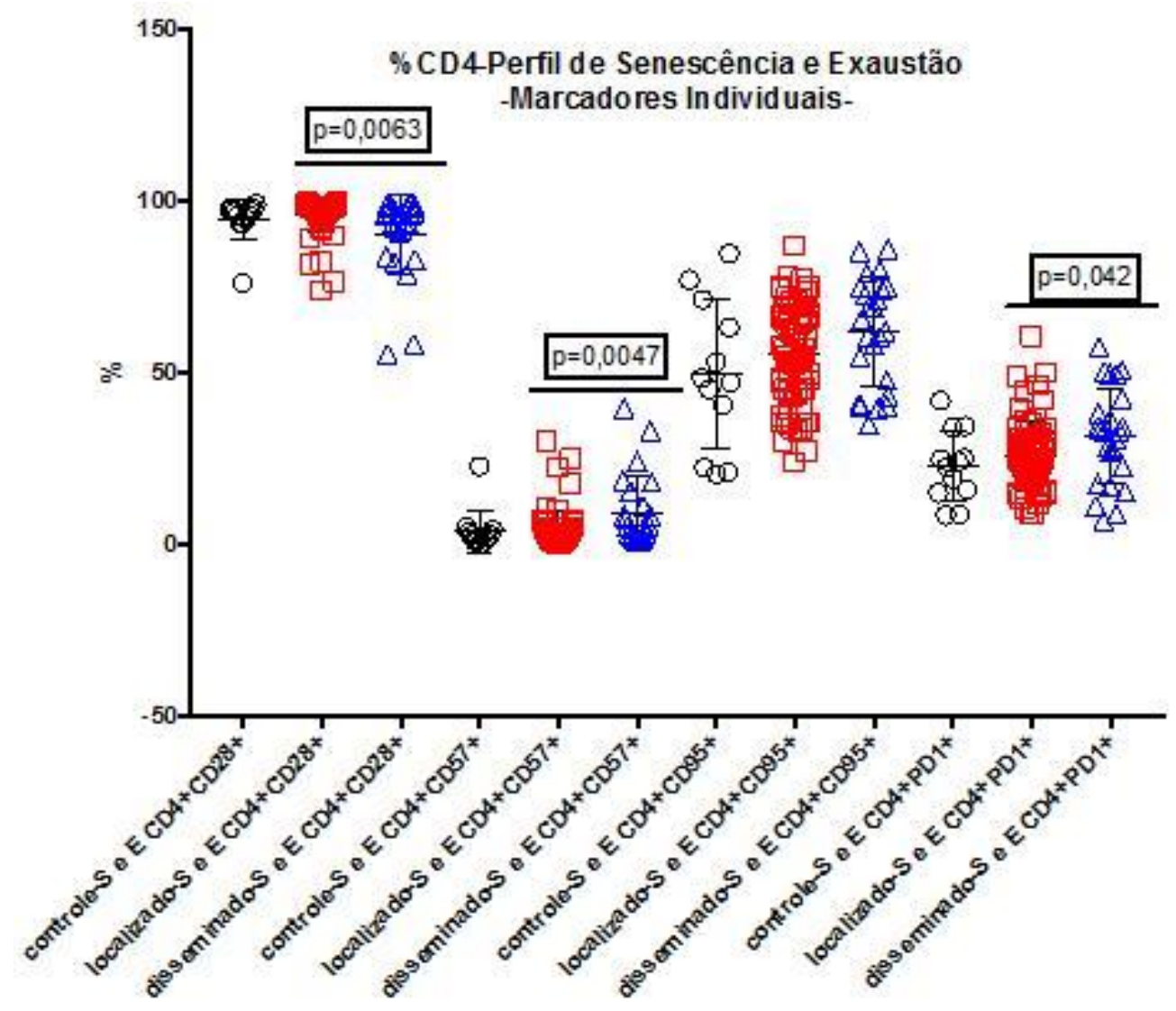


Tabela 7 - Comparação das medianas das porcentagens de linfócitos T CD4 selecionados para marcadores de senescência e exaustão, isoladamente

\begin{tabular}{lcccc}
\hline & CD28+ & CD57+ & CD95+ & PD1+ \\
\hline Controle & 96,45 & 2,52 & 47,85 & 23,5 \\
Localizada & 97,6 & 2,24 & 54,8 & 24,3 \\
Valor $\boldsymbol{p}$ & 0,15 & 0,91 & 0,34 & 0,42 \\
& & & & \\
Controle & 96,45 & 2,52 & 47,85 & 23,5 \\
Disseminada & 94,65 & 4,86 & 63,85 & 33 \\
Valor $\boldsymbol{p}$ & 0,34 & 0,053 & 0,14 & 0,07 \\
& & & & \\
Localizada & $\mathbf{9 7 , 6}$ & $\mathbf{2 , 2 4}$ & 54,8 & $\mathbf{2 4 , 3}$ \\
Disseminada & $\mathbf{9 4 , 6}$ & $\mathbf{4 , 8 6}$ & 63,85 & $\mathbf{3 3}$ \\
Valor $\boldsymbol{p}$ & $\mathbf{0 , 0 0 6 3}$ & $\mathbf{0 , 0 0 4 7}$ & 0,06 & $\mathbf{0 , 0 4 2}$ \\
\hline
\end{tabular}

Gráfico 3 e Tabela 7: Mediana da porcentagem de células com os marcadores isoladamente na população total de linfócitos T CD4+, mostrando significância estatística com $p<0,05$ para a maioria dos marcadores de superfície com fenótipo de senescência e exaustão, também priviliegiando a coorte de doença disseminada. Mann-Whitney U test bicaudal. 
B- Estudo baseado em CD28 isoladamente mostrou maior senescência e exaustão na coorte de doença localizada em comparação com a doença disseminada

Gráfico 4 - Diferenças entre as sub-populações linfocitárias de CD4, quando selecionado isoladamente para CD28

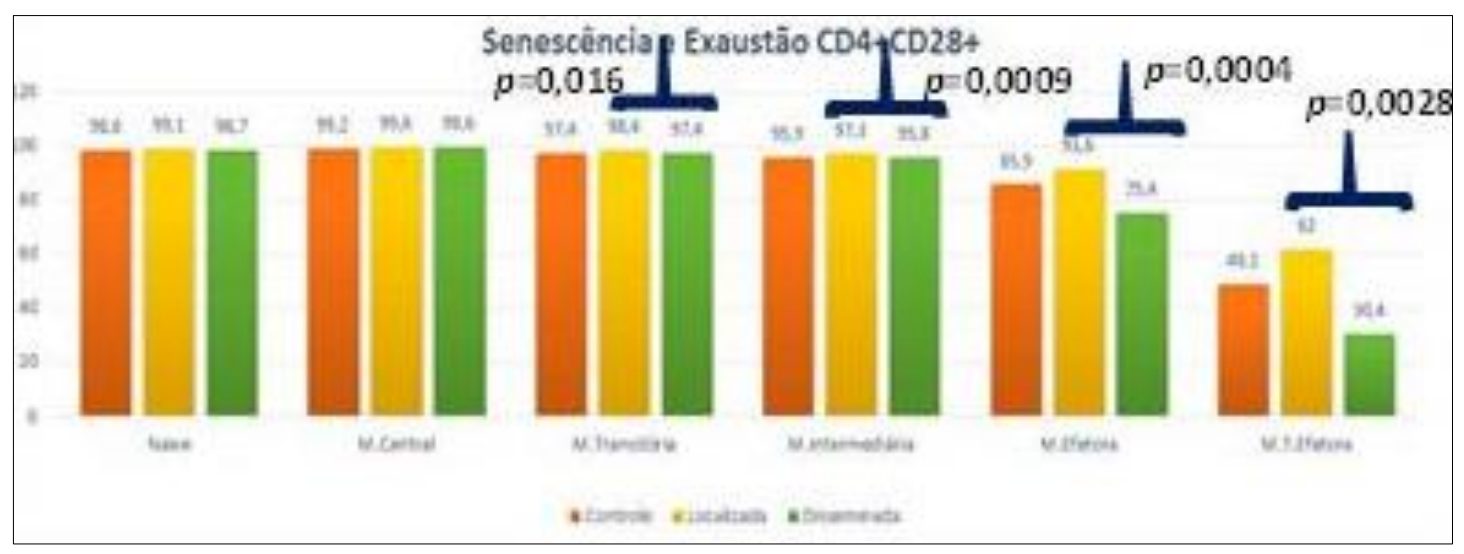

Tabela 8 - Diferenças entre as sub-populações linfocitárias de CD4, quando selecionado isoladamente para CD28

\begin{tabular}{lcccc}
\hline & Controle & Localizada & Disseminada & $\begin{array}{c}\text { Valor } \boldsymbol{p} \text { entre local. } \\
\text { disseminada }\end{array}$ \\
\hline Naive & 98,6 & 99,1 & 98,7 & 0,66 \\
M.Central & 99,2 & 99,6 & 99,6 & 0,39 \\
M.Transitória & $\mathbf{9 7 , 4}$ & $\mathbf{9 8 , 4}$ & $\mathbf{9 7 , 4}$ & $\mathbf{0 , 0 1 6}$ \\
M.Intermed. & $\mathbf{9 5 , 9}$ & $\mathbf{9 7 , 3}$ & $\mathbf{9 5 , 8}$ & $\mathbf{0 , 0 0 9}$ \\
M.Efetora & $\mathbf{8 5 , 9}$ & $\mathbf{9 1 , 6}$ & $\mathbf{7 5 , 4}$ & $\mathbf{0 , 0 0 0 4}$ \\
M.Term.Efetora & $\mathbf{4 9 , 1}$ & $\mathbf{6 2}$ & $\mathbf{3 0 , 4}$ & $\mathbf{0 , 0 0 2 8}$ \\
\hline
\end{tabular}

Gráfico 4 e Tabela 8: Comparação das medianas em todas as sub-populações mostra maior porcentagem de linfócitos T CD4+CD28+ na coorte de doença localizada em comparação com a doença disseminada. Mann-Whitney U test, bicaudal para significância estatística de $p<0,05$. 


\section{C- Estudo baseado em CD57 isoladamente mostrou maior senescência e exaustão na coorte de doença disseminada em comparação com a doença localizada}

Gráfico 5 - Diferenças entre as sub-populações linfocitárias de CD4, quando selecionado isoladamente para CD57

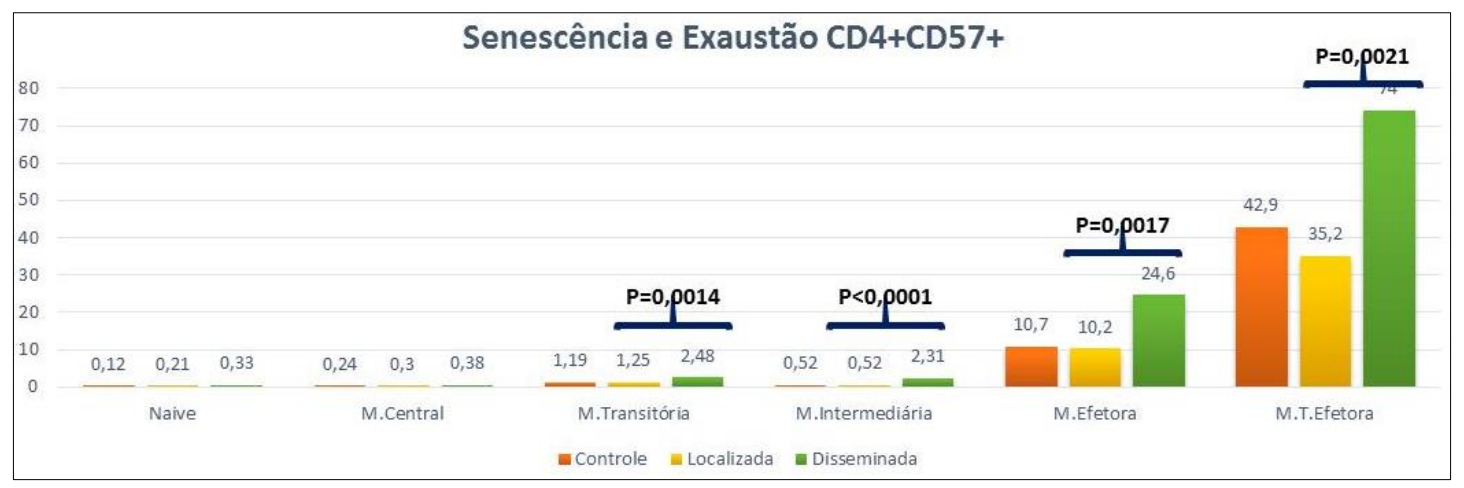

Tabela 9 - Diferenças entre as sub-populações linfocitárias de CD4, quando selecionado isoladamente para CD57

\begin{tabular}{lcccc}
\hline & Controle & Localizada & Disseminada & $\begin{array}{c}\text { Valor } \boldsymbol{p} \text { entre local. e } \\
\text { disseminada }\end{array}$ \\
\hline Naive & 0,12 & 0,21 & 0,33 & 0,07 \\
M. Central & 0,24 & 0,30 & 0,38 & 0,21 \\
M. Transitória & 1,19 & 1,25 & 2,48 & 0,0014 \\
M. Intermed. & 0,52 & 0,52 & 2,31 & $<0,0001$ \\
M. Efetora & 10,7 & 10,2 & 24,6 & 0,0017 \\
M. Term. Efetora & 42,9 & 35,2 & 74 & 0,021 \\
\hline
\end{tabular}

Gráfico 5 e Tabela 9: Comparação das medianas em todas as sub-populações mostra maior porcentagem de linfócitos T CD4+CD57+ na coorte de doença disseminada em comparação com a doença localizada. Mann-Whitney U test, bicaudal para significância estatística de $p<0,05$. 
D- Estudo baseado em CD95 isoladamente mostrou maior senescência e exaustão na coorte de doença disseminada em comparação com a doença localizada

Gráfico 6 - Diferenças entre as sub-populações linfocitárias de CD4, quando selecionado isoladamente para CD95

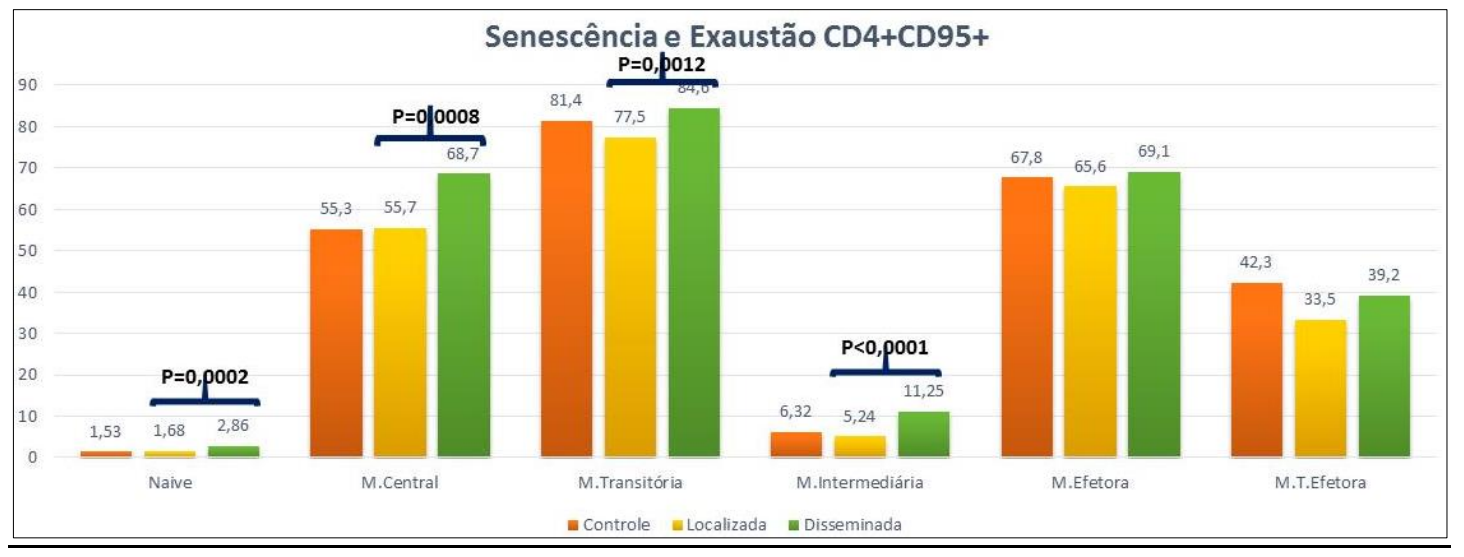

Tabela 10 - Diferenças entre as sub-populações linfocitárias de CD4, quando selecionado isoladamente para CD95

\begin{tabular}{lcccc}
\hline & Controle & Localizada & Disseminada & $\begin{array}{c}\text { Valor } \boldsymbol{p} \text { entre local. e } \\
\text { disseminada }\end{array}$ \\
\hline Naive & 1,53 & 1,68 & 2,86 & 0,0002 \\
M. Central & 55,3 & 55,7 & 68,7 & 0,0008 \\
M. Transitória & 81,4 & 77,5 & 84,6 & 0,0012 \\
M. Intermed. & 6,32 & 5,24 & 11,25 & $<0,0001$ \\
M. Efetora & 67,8 & 65,6 & 69,1 & 0,91 \\
M. Term. Efetora & 42,3 & 33,5 & 39,2 & 0,32 \\
\hline
\end{tabular}

Gráfico 6 e Tabela 10: Comparação das medianas em todas as sub-populações mostra maior porcentagem de linfócitos T CD4+CD95+ na coorte de doença disseminada em comparação com a doença localizada. Mann-Whitney U test, bicaudal para significância estatística de $p<0,05$ 
E- Estudo baseado em PD1 isoladamente mostrou maior senescência e exaustão na coorte de doença disseminada em comparação com a doença localizada

Gráfico 7 - Diferenças entre as sub-populações linfocitárias de CD4, quando selecionado isoladamente para PD1

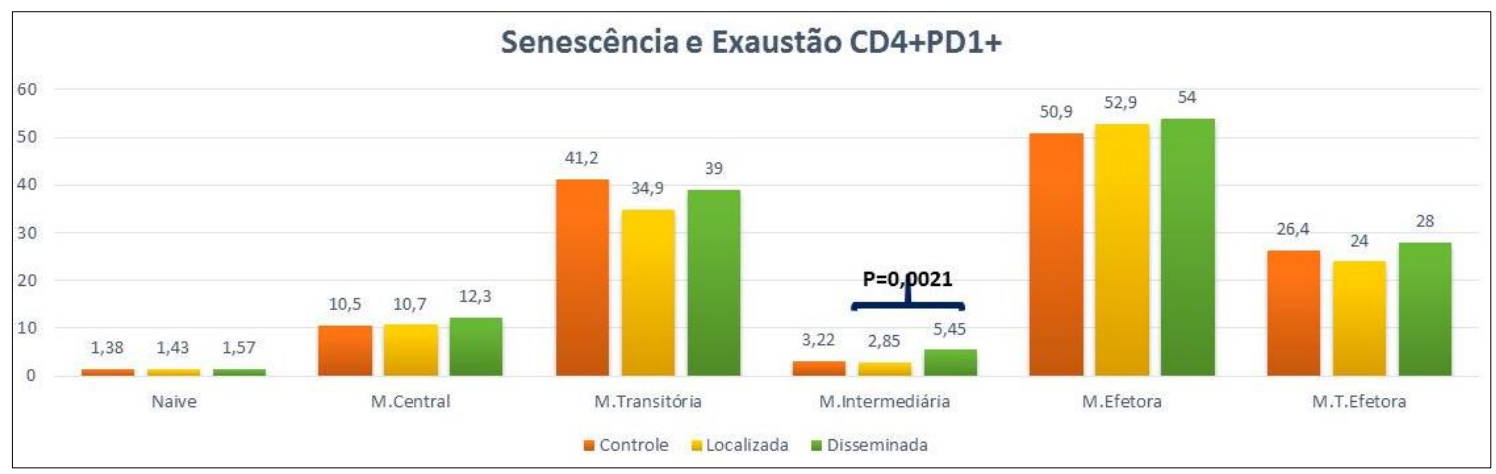

Tabela 11- Diferenças entre as sub-populações linfocitárias de CD4, quando selecionado isoladamente para PD1

\begin{tabular}{lcccc}
\hline & Controle & Localizada & Disseminada & $\begin{array}{c}\text { Valor } \boldsymbol{p} \text { entre local. } \\
\text { disseminada }\end{array}$ \\
\hline Naive & 1,38 & 1,43 & 1,57 & 0,19 \\
M. Central & 10,5 & 10,7 & 12,3 & 0,11 \\
M. Transitória & 41,2 & 34,9 & 39 & 0,18 \\
M. Intermed. & $\mathbf{3 , 2 2}$ & $\mathbf{2 , 8 5}$ & $\mathbf{5 , 4 5}$ & $\mathbf{0 , 0 0 2 1}$ \\
M. Efetora & 50,9 & 52,9 & 54 & 0,65 \\
M. Term. Efetora & 26,4 & 24 & 28 & 0,59 \\
\hline
\end{tabular}

Gráfico 7 e Tabela 11: Comparação das medianas em todas as sub-populações mostra maior porcentagem de linfócitos T CD4+PD1+ na coorte de doença disseminada em comparação com a doença localizada. Mann-Whitney U test, bicaudal para significância estatística de $p<0,05$. Nota-se, contudo, que somente houve significância estatística na subpopulação de Memória Intermediária. No restante das sub-populações houve também a mesma tendência mas em escala bem menor se comparamos com os marcadores CD57 e CD95. Mann-Whitney U test bi-caudal para significância de $p<0,05$. 
Também na análise das sub-populações com co-expressão dos diferentes marcadores de senescência e exaustão, CD28, CD57, CD95 e PD1, houve basicamente manutenção dos padrões de maior porcentagem na coorte de doença disseminada e poucas alterações na comparação entre controle e doença localizada. Estes diferentes gráficos e tabelas podem ser encontrados na sessão de apêndice. 


\subsubsection{Perfil de Diferenciação dos Linfócitos T CD8+}

Figura 7 - Distribuição dos diferentes imunofenótipos entre as coortes, na população global de CD8

\section{Controle}

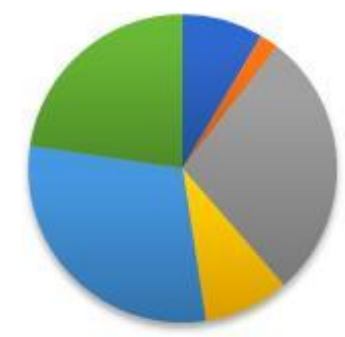

- Naïve M.Central $\quad$ M.Transitória

a. M. Intermediária = M.Efetora $\mathbf{a}$ M.T.Efetora

\section{Localizada}

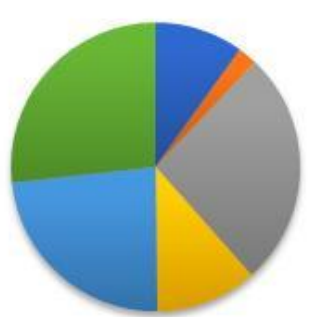

naïve

M.Central

= M.Intermediária $=$ M.Efetora
- M.Transitória

‥ M.T.Efetora
Disseminado

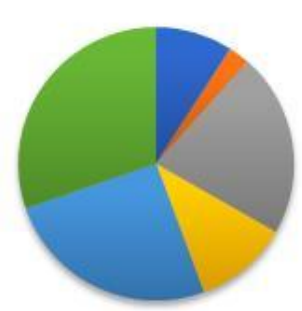

m.Central

M.Transitória

M.Intermediária

M.Efetora

M.T.Efetora 
Tabela 12 - Distribuição dos diferentes imunofenótipos entre as coortes, na população global de CD8

\begin{tabular}{lcccc}
\hline & Controle & Localizada & Disseminada & $\begin{array}{c}\text { Valor } \boldsymbol{p} \text { entre local. e } \\
\text { disseminada }\end{array}$ \\
\hline Naive & 7,54 & 9,01 & 8,4 & 0,74 \\
M. Central & 1,75 & 1,94 & 2,3 & 0,82 \\
M. Transitória & 25 & 24 & 20 & 0,49 \\
M. Intermed. & 7,92 & 10,3 & 10,2 & 0,37 \\
M. Efetora & 26,4 & 21,3 & 23,5 & 0,43 \\
M. Term. Efetora & 20,1 & 24,3 & 27,9 & 0,53 \\
\hline
\end{tabular}

Figura 7 e Tabela 12: Distribuição dos diferentes imunofenótipos em cada coorte analisada, mostrando que há diferença na participação de cada sub-população na ontogenia linfocitária, entre as diferentes coortes. No entanto na análise estatística não houve diferença significante em nenhuma sub-população que poderia explicar melhor esta distribuição distinta entre as coortes, como mostra a tabela acima. Uma análise inicial para examinarmos os diferentes estados de ativação nas diferentes coortes. Mann-Whitney U test, bicaudal. 


\subsubsection{Perfil de Ativação dos Linfócitos T CD8+}

A- Maior ativação linfocitária na coorte de doença disseminada quando selecionados os linfócitos T CD8 isoladamente para CD38

Gráfico 8 - Perfil de CD8 total, quando selecionado isoladamente por marcadores de ativação celular, na comparação entre as coortes

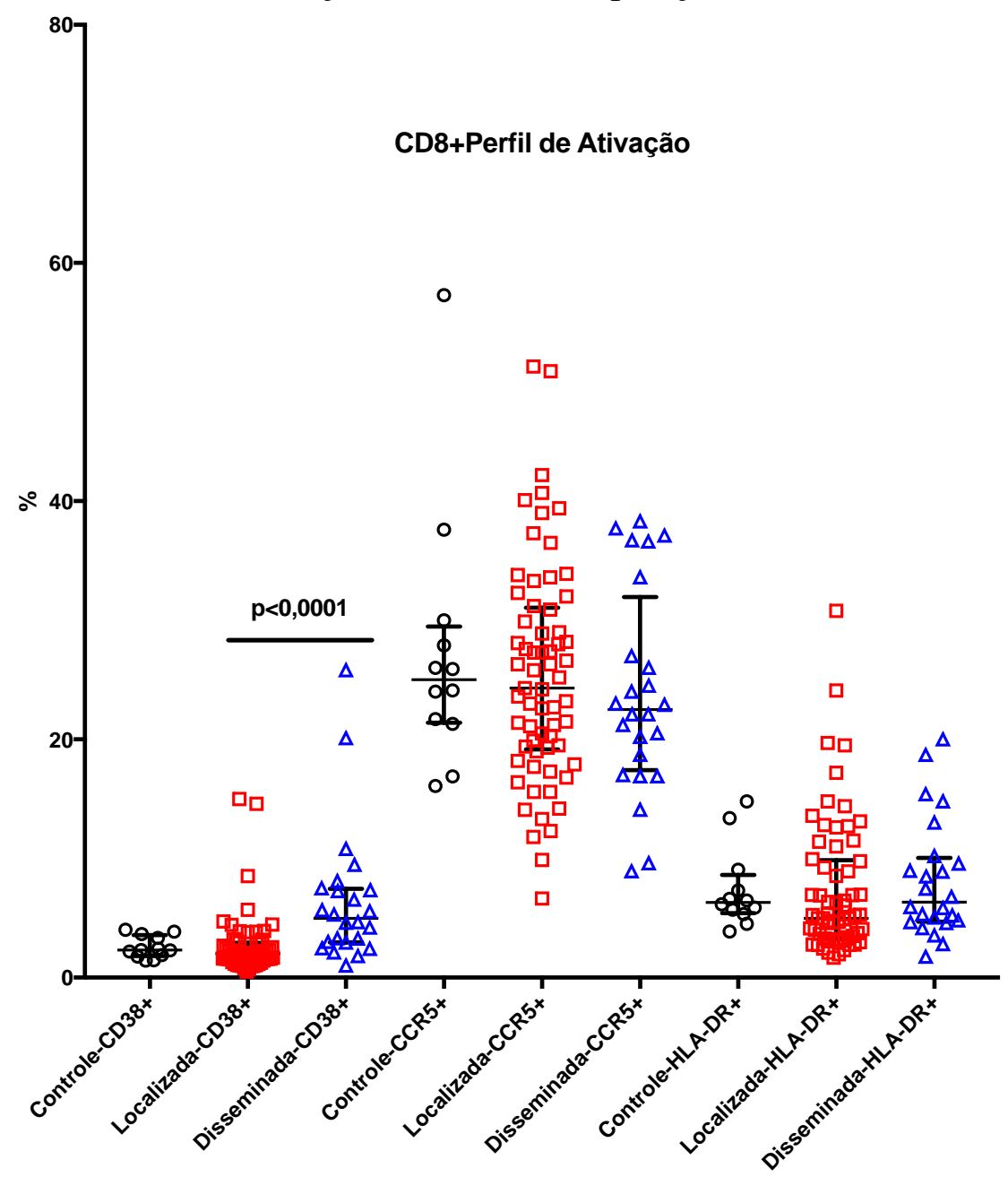


Gráfico 9 - Perfil de CD8 total, quando selecionado isoladamente por marcadores de ativação celular, na comparação entre as coortes

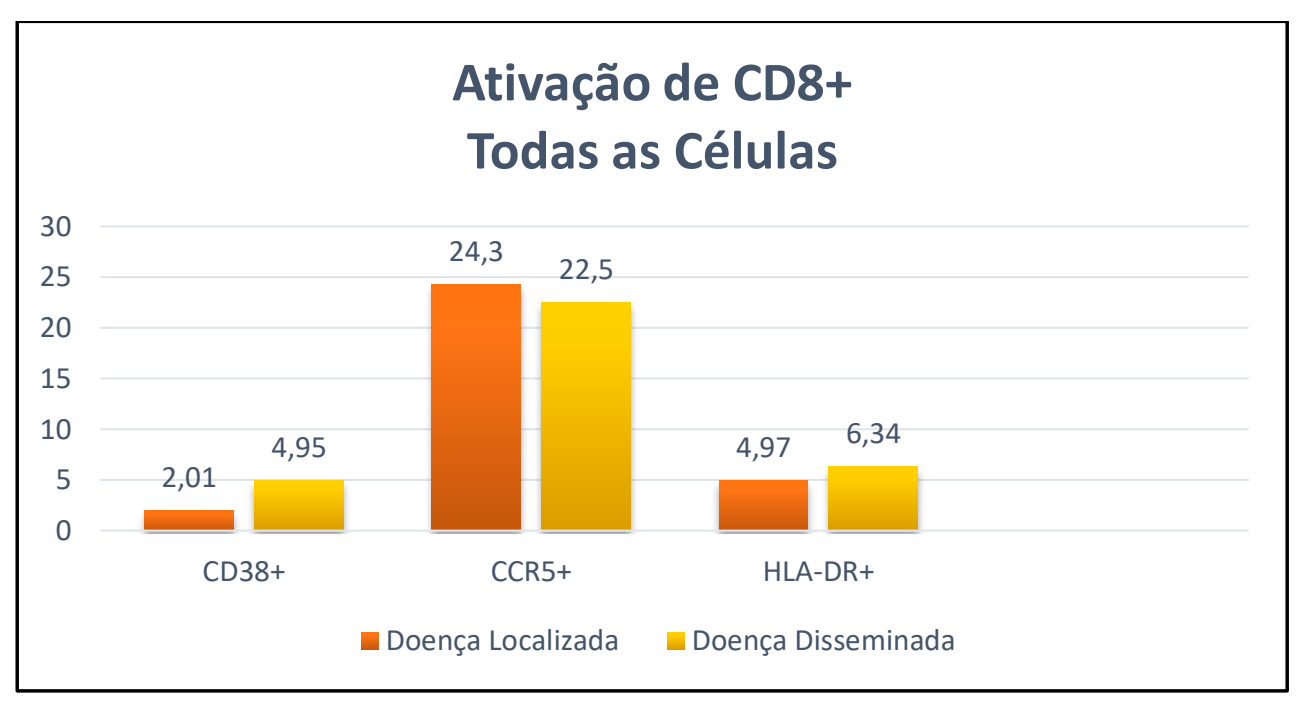

Tabela 13 - Perfil de CD8 total, quando selecionado isoladamente por marcadores de ativação celular, na comparação entre as coortes

\begin{tabular}{lccc}
\hline & CD38+ & CCR5+ & HLA-DR+ \\
\hline Localizada & $\mathbf{2 , 0 1}$ & 24,3 & 4,97 \\
Disseminada & $\mathbf{4 , 9 5}$ & 22,5 & 6,34 \\
Valor $\boldsymbol{p}$ & $<\mathbf{0 , 0 0 0 1}$ & 0,50 & 0,16 \\
\hline
\end{tabular}

Gráfico 8, Gráfico 9 e Tabela 13: Comparação entre as medianas de porcentagem de linfócitos T CD8 selecionados para marcadores individuais de ativação, mostrando significância estatística favorecendo maior ativação na coorte de doença disseminada. MannWhitnau U test bicaudal para significância de $p<0,05$. 
B- Distribuição da ativação linfocitária por marcador individual dentro das sub-populações

Gráfico 10 - Diferenças entre as sub-populações linfocitárias de CD8, quando selecionado isoladamente para CD38

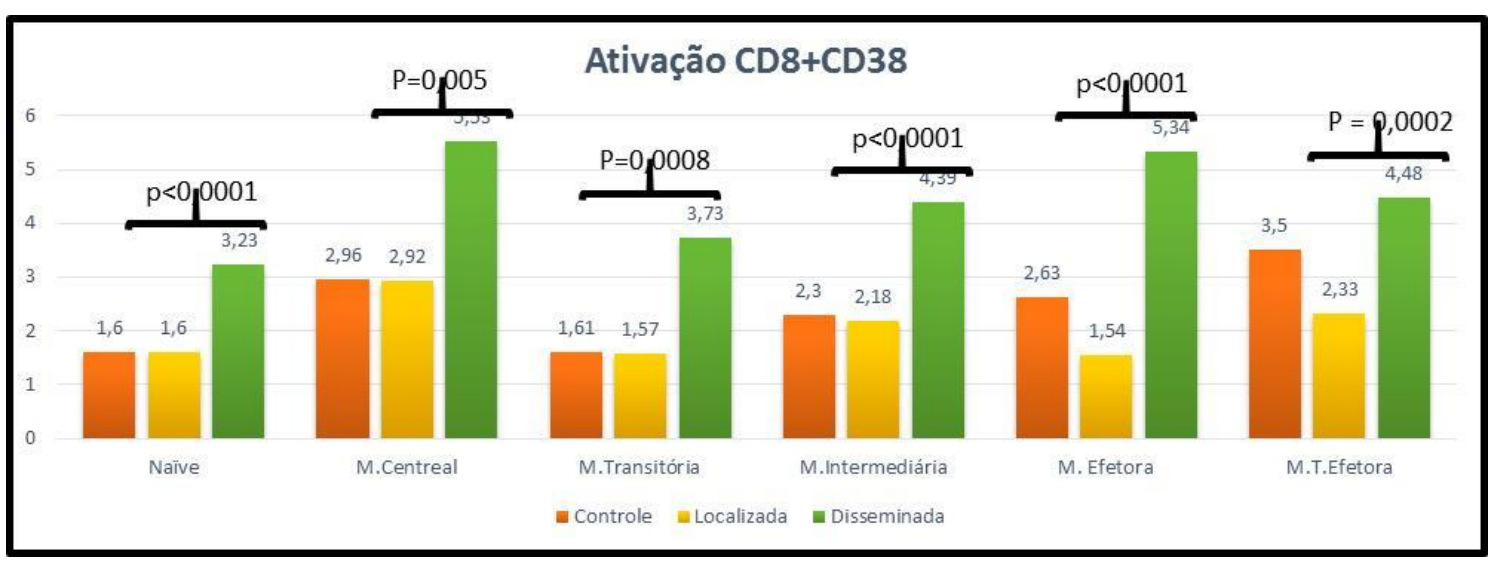

Tabela 14 - Medianas da porcentagem dos linfócitos T CD8 marcados por CD38, distribuídos pelas sub-populações ontogenéticas

\begin{tabular}{lcccc}
\hline CD38 & Controle & Localizada & Disseminada & $\begin{array}{c}\text { Valor } \boldsymbol{p} \text { entre local. } \\
\text { disseminada }\end{array}$ \\
\hline Naive & $\mathbf{1 , 6}$ & $\mathbf{1 , 6}$ & $\mathbf{3 , 2}$ & $<\mathbf{0 , 0 0 0 1}$ \\
M. Central & 2,9 & $\mathbf{2 , 9}$ & $\mathbf{5 , 5}$ & $\mathbf{0 , 0 0 5}$ \\
M. Transitória & 1,6 & 1,5 & 3,7 & $\mathbf{0 , 0 0 0 8}$ \\
M. Intermed. & $\mathbf{2 , 3}$ & $\mathbf{2 , 1}$ & $\mathbf{4 , 3}$ & $<\mathbf{0 , 0 0 0 1}$ \\
M. Efetora & $\mathbf{2 , 6}$ & $\mathbf{1 , 5}$ & $\mathbf{5 , 3}$ & $<\mathbf{0 , 0 0 0 1}$ \\
M. Term. Efetora & $\mathbf{3 , 5}$ & $\mathbf{2 , 3}$ & $\mathbf{4 , 4}$ & $\mathbf{0 , 0 0 0 2}$ \\
\hline
\end{tabular}

Gráfico 10 e Tabela 14: Dados mostrando que a maior ativação celular na coorte de doença disseminada apenas selecionados por CD38 se distribui por todos os imunofenótipos com significância estatística. Mann-Whitney $\mathrm{U}$ test bicaudal com $p<0,005$ 
*No restante das avaliações das diferenças entre as medianas das porcentagens dos linfócitos T CD8 das diferentes coortes selecionados por co-expressão dos marcadores de ativação, apareceram mais evidências de maior ativação na coorte de pacientes com doença disseminada. Estes gráficos e tabelas também podem ser vistos em seus detalhes na parte de apêndice. 


\subsubsection{Perfil de Senescência/Exaustão de Linfócitos T CD8+}

A- Maior perfil de senescência e exaustão na coorte de doença disseminada, quando selecionamos a análise por marcação apenas de CD95

Gráfico 11 - Perfil de CD8 total, quando selecionado isoladamente por marcadores de senescência e exaustão, na comparação entre as coortes

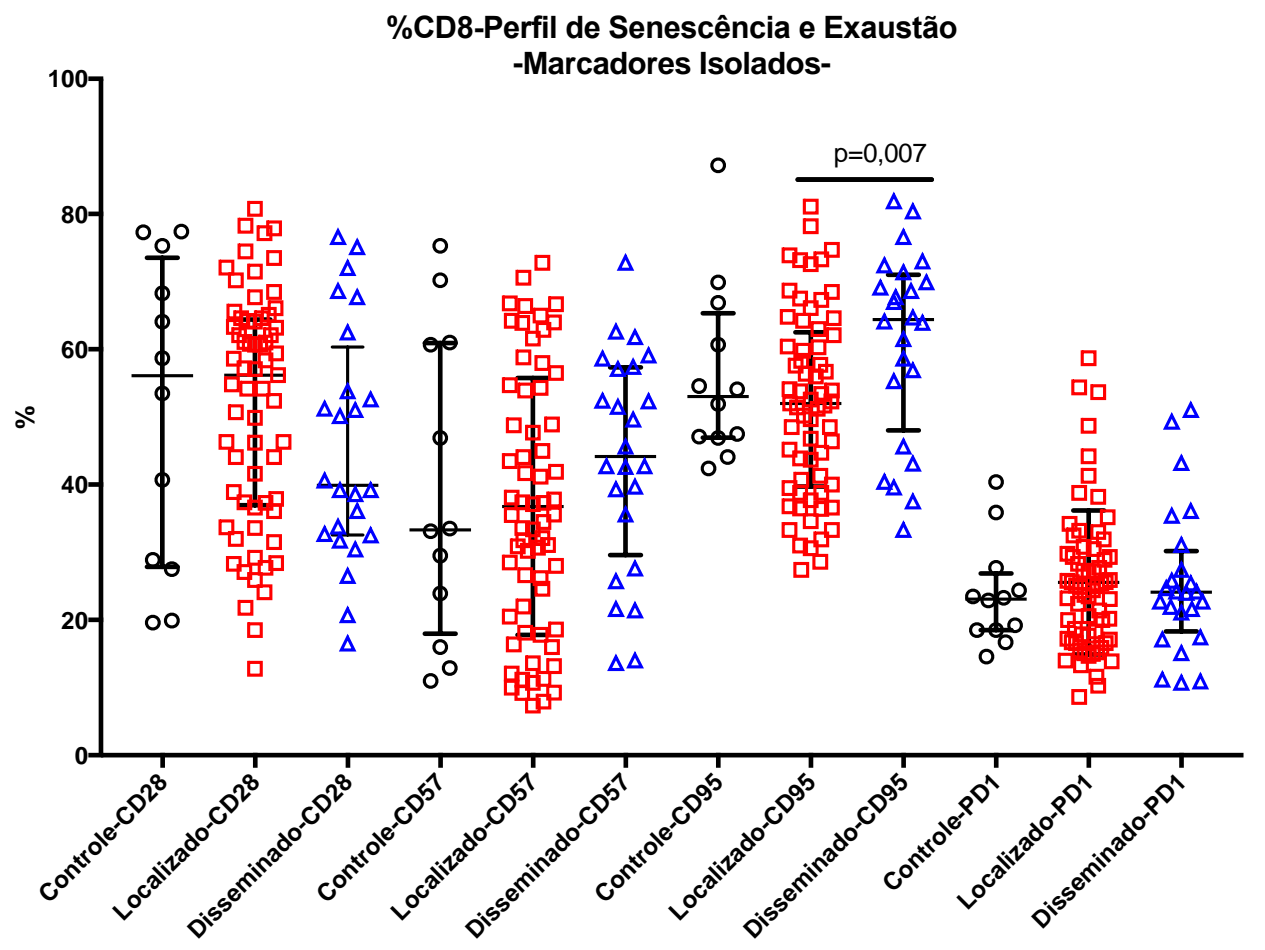


Tabela 15 - Comparação das medianas das porcentagens de linfócitos T CD8 selecionados para marcadores de senescência e exaustão, isoladamente

\begin{tabular}{lcccc}
\hline & CD28+ & CD57+ & CD95+ & PD1+ \\
\hline Controle & 56 & 33 & 52 & 23 \\
Localizada & 56 & 35 & 53 & 24 \\
Valor $\boldsymbol{p}$ & 0,97 & 0,66 & 0,41 & 0,65 \\
& & & & \\
Controle & 56 & 33 & 53 & 23 \\
Disseminada & 39 & 44 & 64 & 24 \\
Valor $\boldsymbol{p}$ & 0,47 & 0,68 & 0,24 & 0,67 \\
& & & & \\
Localizada & 56 & 35 & $\mathbf{5 2}$ & 24 \\
Disseminada & 39 & 44 & $\mathbf{6 4}$ & 24 \\
Valor $\boldsymbol{p}$ & 0,18 & 0,11 & $\mathbf{0 , 0 0 7}$ & 0,92 \\
\hline
\end{tabular}

Gráfico 11 e Tabela 15: Mediana da porcentagem de células com os marcadores isoladamente na população total de linfócitos T CD8+ mostrando significância estatística com $p<0,05$ para apenas CD95, priviliegiando a coorte de doença disseminada. MannWhitney U test bicaudal. 
Gráfico 12 - Comparação entre a mediana das porcentagens dos linfócitos T CD8, selecionados para marcação de CD95

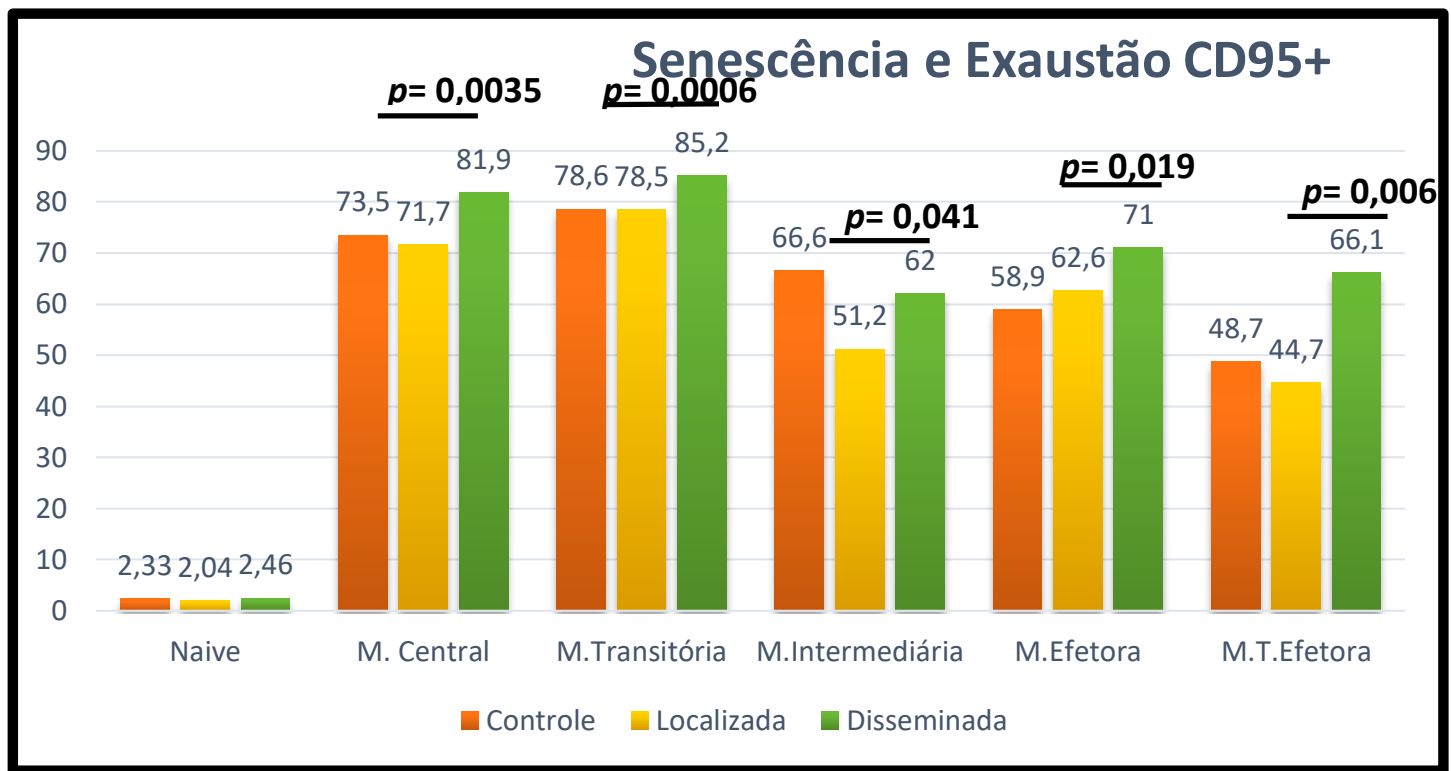

Tabela 16 - Dados da comparação entre a mediana das porcentagens dos linfócitos T CD8, selecionados para marcação de CD95

\begin{tabular}{lcccc}
\hline \multicolumn{1}{c}{ CD95 } & Controle & Localizada & Disseminada & $\begin{array}{c}\text { Valor } \boldsymbol{p} \text { entre local. } \\
\text { e disseminada }\end{array}$ \\
\hline Naive & 2,33 & 2,04 & 2,46 & 0,12 \\
M.Central & 73,50 & $\mathbf{7 1 , 7 0}$ & $\mathbf{8 1 , 9 0}$ & $\mathbf{0 , 0 0 3 5}$ \\
M.Transitória & 78,60 & $\mathbf{7 8 , 5 0}$ & $\mathbf{8 5 , 2 0}$ & $\mathbf{0 , 0 0 0 6}$ \\
M.Intermed. & 66,60 & $\mathbf{5 1 , 2 0}$ & $\mathbf{6 2 , 0}$ & $\mathbf{0 , 0 4 1}$ \\
M.Efetora & 58,90 & $\mathbf{6 2 , 6 0}$ & $\mathbf{7 1 , 0}$ & $\mathbf{0 , 0 1 9}$ \\
M.Term.Efetora & 48,70 & $\mathbf{4 4 , 7 0}$ & $\mathbf{6 6 , 1 0}$ & $\mathbf{0 , 0 0 6}$ \\
\hline
\end{tabular}

Gráfico 12 e Tabela 16: Os dados mostram que na comparação das medianas há evidência de maiores índices de senescência e exaustão para a coorte de doença disseminada em praticamente todas as sub-populações linfocitárias, exceto as células naive. Mann-Whitney U test, com significância para $p<0,05$. 
$\mathrm{Na}$ análise de co-expressão dos marcadores de senescência e exaustão na população de linfócitos CD8+ não houve a mesma regularidade em termos de predominância na corte disseminada ou localizada. Na verdade houve um padrão misto onde conforme a co-expressão estudada houve predomínio na coorte localizada e às vezes juntamente predomínio na coorte disseminada em diferentes subpopulações. Novamente estas tabelas e gráficos estão dispostos na sessão de apêndice. 


\subsubsection{PDL-1 está mais expresso nas coortes de Linfócitos T CD4 e em CD8 mas} não em APCs e ocorrem em maior quantidade na coorte de doença disseminada

Gráfico 13 -Comparação entre as coortes quando selecionadas apenas para PD-L1 nas populações de linfócitos T CD4, CD8 e nas APCs
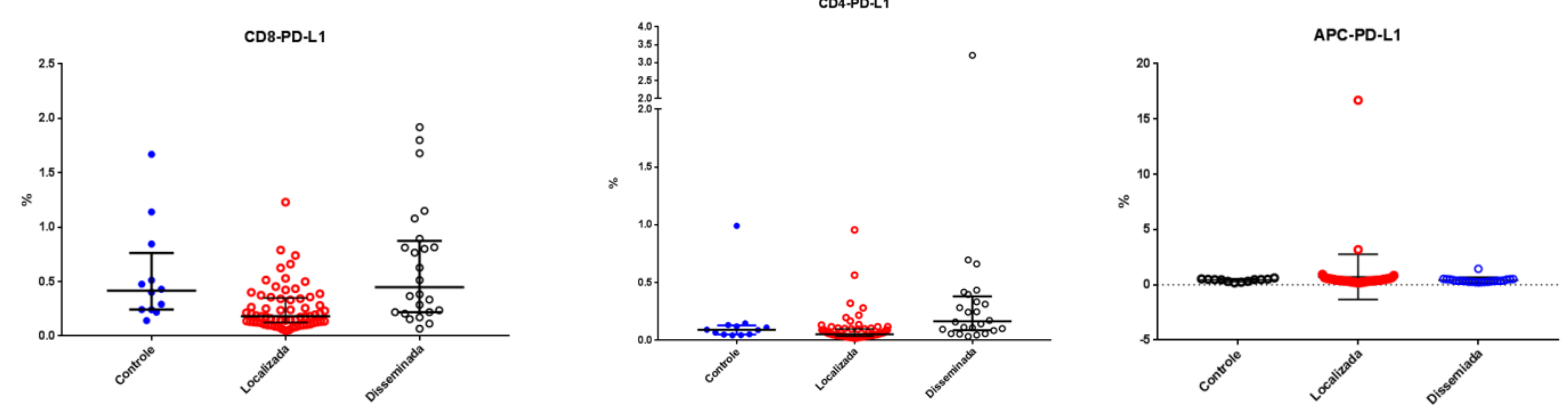

Tabela 17 - Comparação entre as coortes quando selecionadas apenas para PD-L1 nas populações de linfócitos T CD4, CD8 e nas APCs

\begin{tabular}{llll}
\hline & CD8 & CD4 & APC \\
\hline Controle & $\mathbf{0 . 4 1}$ & $\mathbf{0 . 0 0 9}$ & 0.46 \\
Localizada & $\mathbf{0 . 1 8}$ & $\mathbf{0 . 0 5}$ & 0.39 \\
valor p & $\mathbf{0 . 0 0 2}$ & $\mathbf{0 . 0 4}$ & 0.89 \\
Controle & 0.41 & 0.09 & 0.46 \\
Disseminada & 0.44 & 0.166 & 0.36 \\
valor p & 0.908 & 0.053 & 0.45 \\
Localizada & $\mathbf{0 . 1 8}$ & $\mathbf{0 . 0 5}$ & 0.39 \\
Disseminada & $\mathbf{0 . 4 4}$ & $\mathbf{0 . 1 6 6}$ & 0.36 \\
valor p & $<\mathbf{0 . 0 0 1}$ & $<\mathbf{0 . 0 0 1}$ & 0.24 \\
\hline
\end{tabular}

Valor significante de $p<0,05$. Teste de Mann-Whitney bicaudal 


\section{DISCUSSÃO}

O objetivo principal deste estudo foi interrogar se o sistema imune é capaz de reconhecer peptídeos de HERV-K em pacientes com câncer de próstata tanto em estágios precoces como em estágios avançados da doença, se de fato aceitarmos as evidências existentes de que há alguma expressão do gene da família HML-2 de HERV-K em linhagens celulares de câncer de próstata como sugerido pela literatura ${ }^{(75)}$ e de alguma forma corroborado por nosso estudo preliminar de análise genômica computacional de pacientes com câncer de próstata sequenciados e colocados no banco de dados publico do TCGA. Existe pesquisa que mostra haver sítios de ligação hormonal nos LTRs de retrovírus endógenos em vários LTRs de HERV-K em tumor de próstata bem como em linhagem celular de $\operatorname{LNCaP}(76,77)$. Pesquisa estudando retroelementos em linhagem celular de câncer de próstata e em tecido tumoral de câncer de próstata encontrou expressão de HERV-K17 e HERVK_22q11.23 especialmente restritos às linhagens celulares hormônio-sensíveis. Estes autores demonstraram que a expressão e a regulação androgênica requeria um segmento em seus Elementos Responsivos a Esteróides em seus LTRs. Nestes casos a ligação dos dímeros de receptor de androgênio com seu ligante nesta região fazia com que a expressão destes genes fosse androgênio-dependente. O mesmo fenômeno, aliás, acontece com câncer de mama ${ }^{(53)}$ e pode explicar os achados de maior expressão de HERV nestes tumores hormônio-sensíveis. Este aspecto tem especial relevância em nosso estudo porque tivemos a oportunidade de checar a resposta imune em duas coortes diferentes no que diz respeito à sensibilidade hormonal. 
A coorte de pacientes com doença localizada tem seu status hormonal intacto com níveis normais de testosterona, ao passo que no grupo de pacientes com doença disseminada ocorre o contrário, ou seja, a supressão androgênica, exatamente como característica fundamental de seu tratamento. Teoricamente teríamos maior interação dos dímeros de androgênio com seus respectivos AREs (Androgen Responsive Elements) tanto nos genes relacionados à proliferação celular e todos os outros aspectos de funcionamento da célula prostática tumoral, assim como em relação aos promotores de HERV ao nível nuclear, como explicado anteriormente.

Um outro aspecto que necessita ser lembrado é que as mudanças do estado androgênico podem ter impacto diferencial na capacidade de resposta imune antiHERV. Esta questão tem óbvia implicação conceitual em nosso estudo já que nosso objetivo principal é justamente testar a resposta imune. Mercader e cols. (78) mostraram em um estudo prospectivo e randomizado que pacientes com câncer de próstata sendo tratados com supressão androgênica antes da prostatectomia radical, tinham infiltração pronunciada de linfócitos $\mathrm{T}$ na próstata, principalmente na contagem de células CD4+ quando comparado com pacientes não-castrados. Este mesmo estudo mostrou que esta população de linfócitos $\mathrm{T}$ não parece ser inespecífica. Estudos de restrição de TCR (T Cell Receptor) mostrou tratar-se de infiltração oligoclonal, sugestiva de ser direcionada a antígenos associados ao câncer de próstata. Tem também sido demonstrado que mesmo na supressão androgênica de longo-prazo antes da prostatectomia radical, ocorria infiltração linfocitária, após supressão androgênica de até 9 meses de duração ${ }^{(79,80)}$. Estudos mostram que em até $29 \%$ dos pacientes com câncer de próstata há comprovação de resposta imune contra vários antígenos-associados ao câncer após supressão hormonal ${ }^{(81)}$. Respostas imune 
humoral e celular contra receptor de androgênio têm sido também encontradas em 13 a $18 \%$ de pacientes com câncer de próstata independente do estadiamento e do status hormonal ${ }^{(82)}$, trazendo inclusive o conceito de que mesmo o receptor de androgênio pode ser um antígeno a ser explorado em protocolos de imunoterapia. Encontramos também outras evidências de acionamento de resposta imune específica após radioterapia, com ou sem supressão androgênica associada ${ }^{(81,83)}$.

Portanto há evidência suficiente que dê suporte ao conceito do câncer de próstata como sendo um modelo a ser explorado em relação à imunomodulação na medida em que pacientes são capazes de desencadear resposta humoral e celular contra antígenos-associados ao câncer. Com a intenção de testar o mesmo fenômeno contra peptídeos associados ao HERV-K-HML-2, realizamos nosso estudo testando imunidade celular pelo método de medir a secreção de interferon-gama através de ELISPOT. Nossos resultados foram negativos em todas as coortes, o que então significa que neste experimento não há resposta imune contra os peptídeos de HERV-K, ou seja, mesmo que HERV-K tenha algum grau de expressão em câncer de próstata, nesta análise exploratória não houve reconhecimento imunológico, sendo improvável que HERV-K seja um bom candidato para exploração de medidas de imunomodulação. Uma conclusão equivalente a isso seria dizer que na realidade trata-se de um antígeno pouco imunogênico, ou pouco sensível para desencadear resposta imune. Uma outra consideração seria indagar se haveria necessidade de seleção de pacientes com determinadas classes restritas de HLA de classe I, exigindo conformação de moléculas MHC específicas. Em nosso estudo não fizemos restrição de HLA. Dos poucos estudos que levantamos, nominalmente em tumores germinativo ${ }^{(61)}$, câncer de mama ${ }^{(56)}$, câncer de ovário ${ }^{(62)}$ e mesmo câncer de 
próstata ${ }^{(57)}$, o único que selecionou pacientes por restrição de HLA foi o estudo em câncer germinativo. Mesmo assim selecionou pacientes com fenótipos HLA bastante prevalentes. Portanto neste sentido não tínhamos percebido nenhuma necessidade de fazermos nenhum tipo de restrição para HLA/Sistema MHC.

Alguns comentários críticos devem ser feitos em relação a estes resultados, a começar pelo método escolhido-ELISPOT. ELISPOT juntamente com o método de coloração intracitoplasmática de citoquinas com análise por Citometria de Fluxo, são os dois métodos mais importantes para medir a presença de citoquinas em linfócitos $\mathrm{T}$ ou qualquer outra célula que participe da resposta imune, após exposição a um determinado antígeno. Em ambos os métodos, a ativação induzida pelo antígeno e posterior diferenciação das células $\mathrm{T}$ ocorre supostamente in vivo. CMSP destes indivíduos é re-estimulado na presença destes antígenos e testado para a produção de citoquinas in vitro. No caso de ELISPOT, estas CMSP são isoladas de sangue fresco, cultivadas em poços de plástico preenchidos por anticorpo específico contra a citoquina que se quer medir. Posteriormente submete-se a um segundo cultivo com anticorpo marcado para haver então a contagem dos spots ${ }^{\left({ }^{84}, 85\right)}$. Algumas premissas importantes devem constar. Quando se estuda a citoquina interferon-gama, assumese que o tipo de resposta imune seja do tipo Th1, ou seja aquela resposta que justamente depende da secreção de Interferon-gama pelo linfócito T. Este fenômeno ocorre, de acordo com o conhecimento da imunologia básica, justamente no processo imune contra patógenos intracelulares, sobretudo partículas virais e também tumores. Na literatura é o ensaio que se utiliza no seguimento de resposta após vacinação contra infecções virais (influenza, p.ex.) ou mesmo na investigação de vacinas contra o HIV ${ }^{(86-88)}$. Em estudos com animais as citoquinas Th1 parecem promover resposta 
celular anti-tumoral ${ }^{\left({ }^{89}\right)}$. Este tipo de estudo corrobora seguir nesta linha e pesquisar secreção de interferon-gama como evidência de resposta imune anti-tumoral, sobretudo porque se tratam de peptídeos de retrovírus endógenos, que guardam semelhança com HIV, uma infecção viral passível de ser avaliada em sua resposta por INF-Gama-ELISPOT. No entanto há uma série de estudos em humanos que mostram que a resposta imune antitumoral ocorre via perfil Th2 com secreção de outras citoquinas (IL-4, IL-5 e IL-13) ${ }^{(90)}$. Este fenômeno tem sido estudado em tumores de pâncreas e tumores renais, com predominância de resposta Th2 no sangue periférico destes pacientes ${ }^{(91,92)}$. Estudos como este apontam para o fato de que este viés em direção à resposta Th2 pode tornar avaliação com ELISPOTInterferon gama indetectável ou frustro em certas circunstâncias. Não sabemos se esta seria uma possível explicação para termos obtido resultado praticamente desprezível em nossas coortes. Uma hipótese nestes casos é que há participação de TGF-beta, que consegue desviar para Th2 através de IL-10 como citoquina intermediária e que talvez em uma situação de menor estímulo, seria uma citoquina mais importante. Isto é parte, inclusive do mecanismo imunossupressor de TGF-beta $(89,93)$. Existem vários mecanismos pelos quais o câncer da próstata pode evadir-se do sistema imunológico. Pode haver perda gradual de antígenos, promoção de apoptose linfocitária precoce através da ação de células Treguladoras ou mesmo acúmulo de células que expressam PD-L1 ${ }^{(94)}$. Uma outra consideração muito atual deve ser cogitada como uma das explicações de nossa falta de resposta imune celular. Tratase do fenômeno conhecido como o de maior expressão de checkpoints (CTLA-4 e PD-L1) nas células imunológicas. Estas moléculas de superfície são responsáveis pelo freio da resposta imune. Miller e cols. mostraram que o câncer da próstata se 
associa com acúmulo de linfócitos T reguladores no sangue e no ambiente tumoral e este fato se correlaciona inversamente aos estádios mais avançados do câncer bem como a sobrevida dos pacientes ${ }^{(24)}$. Outras células potencialmente responsáveis pelo fenômeno de escape tumoral do sistema imune são as MDSC (myeloid-derived supressor cells), que estão aumentadas nas situações de tumores de próstata mais avançados e que podem tornar os tumores não-responsivos aos antígenos que são pertinentes ${ }^{(95)}$. Todos estes elementos podem estar por trás desta espécie de anergia linfocitária contra os antígenos de HERV-K. Em relação ao nosso estudo de ativação celular, não pudemos fazer nenhuma correlação com o resultado da resposta imune, na medida em que esta foi praticamente irrelevante. Mas mesmo assim pudemos observar um aspecto interessante quando comparamos as diferentes coortes. As subpopulações linfocitárias referem-se aos diferentes estágios dentro do espectro da resposta imune, começando pelo linfócito $\mathrm{T}$ naïve, como sendo a célula que habita preferencialmente os órgãos linfóides onde faz o primeiro contato com seu antígeno cognato ${ }^{(96)}$. A partir deste contato, os linfócitos se diferenciam em células efetoras, quando há o antígeno presente a ser "combatido", ou então em células de memória, que mantém a capacidade de expandir rapidamente quando entram em contato novamente com o seu antígeno que a sensibilizou ${ }^{(97)}$. As diferentes fases deste processo podem ser identificadas pela presença dos diferentes marcadores celulares de superfície, que foram estudados por citometria de fluxo, de tal maneira a didaticamente poderem ser classificados nas células de memória central, memória transitória, memória intermediária e mais tardiamente nas células de memória efetora e terminal efetora, já nas fases finais de execução dos fenômenos responsáveis pelo êxito desta resposta imune $(98,99)$. Em nosso experimento de imunofenotipagem 
linfocitária encontramos aumento dos marcadores de ativação, incluindo células de memória transitória e intermediária, assim como memória efetora e terminal efetora, caracterizada por um ambiente de ativação imunológica geral, maior na coorte de doença disseminada, caracterizando bem a situação de grande oferta antigênica associada ao câncer de próstata nesta situação como ilustrada na Figura 6, no caso da população de linfócitos T CD4. No caso dos fenótipos de senescência e exaustão caracterizados pela marcação individual de CD57, CD95, CD28 e PD1, observamos um quadro mais misto embora ainda com maior porcentagem destes imunofenótipos também na coorte de doença disseminada. Neste caso o raciocínio seria de que estas células após período de constante ativação caminhariam para fenótipos de exaustão, marcando o final da resposta imune, com células entrando em apoptose ou em estado já de senescência com reduzida ativação, ou seja reduzida atividade imunológica, a exemplo do que encontramos em infecções crônicas. A verdade é que a presença de células em estado de exaustão contribuem para a tolerância periférica e moderam a resposta imune. São mecanismos fisiológicos importantes contra a auto-imunidade (100) e que também podem contribuir para a insensibilidade linfocitária contra antígenos associados a tumor em geral, e que também poderia incluir insensibilidade às proteínas e retrovírus endógenos. Neste sentido, no contexto de câncer disseminado as células $\mathrm{T}$ se tornam exaustas/disfuncionais, com capacidade de proliferação defeituosa bem como redução na produção de citoquinas ${ }^{(101,102)}$.

Como não houve em nossas análises praticamente nenhuma resposta imune contra proteínas de HERV-K, não pudemos estabelecer nenhuma correlação entre resposta imune e os diferentes estados de ativação celular. Um aspecto muito importante deve ser ressaltado, no entanto, a partir de nossos dados, e que se refere à 
maior expressão de PD-L1 na coorte de doença disseminada em comparação com a doença localizada. Este fenômeno de maior concentração de células que expressam PD-L1 nas fases avançadas podem também ajudar a entender a condição de tolerância ao antígeno de HERV-K e justificar a utilização de metodologias de imunomodulação bloqueadoras de PD-L1 justamente nos pacientes com doença avançada. Neste sentido seria importante fazer-se a análise diferencial dentro da coorte de doença avançada entre os pacientes com situação castração sensível daqueles com castração resistente. Talvez o interesse de utilizar este tipo de imunomodulação pode mudar se houver diferença nesta expressão entre um grupo e outro. Este aspecto permanece para ser melhor elucidado em coortes maiores. Mas tem importante implicação prática na clínica. Uma observação importante que podemos fazer é o fato de vermos maior senescência na doença disseminada. Uma interrogação imediata decorrente desta observação é relacionar uma coisa à outra. $\mathrm{Ou}$ seja, será que o status de senescência é parcialmente responsável pela disseminação ? Será que há algum elo causal nisso, ou seja, quanto maior a senescência, maior a tolerância anti-tumoral e maior a chance de disseminação ? Uma forma de seguirmos nesta indagação será examinarmos este aspecto naqueles pacientes com doença localizada que venham a recair com elevação do PSA. A comparação do grau de senescência na população que recidiva em comparação com a população que não recidiva poderia dar pistas adicionais nesta linha de pesquisa. 


\section{CONCLUSÃO}

1- Existe expressão gênica de HERV-K em genoma de câncer de próstata, como já demonstrado na literatura e por nós corroborado em estudo de análise genômica.

2- Esta expressão gênica, em nossa avaliação não foi suficiente para elicitar resposta célula imune contra proteínas de HERV da família K-HML-2. Neste sentido se há alguma resposta celular citotóxica, esta é fraca seja por mecanismos de imunossupressão mediados por maior expressão de PD-L1 pelas células tumorais ou por células imunes mononucleares, assim como quaisquer dos mecanismos mencionados anteriormente que podem explicar não-responsividade imunológica contra antígenos tumorais.

3- O câncer de próstata se caracteriza, do ponto de vista imunológico periférico, como tendo maior ativação e maior estado de exaustão nas fases mais avançadas de doença. Isso pode ter implicações práticas importantes em função dos mecanismos de ativação e sobretudo de exaustão, se forem baseados em mecanismos que podem ser modulados com imunoterapia, como é o caso da expressão de PD1 e PD-L1, mais pronunciada nas fases avançadas.

4- Interessante será acompanharmos a evolução da doença na coorte de pacientes com doença localizada para vermos se haverá correlação entre senescência e recidiva bioquímica (elevação do PSA). 
9 ANEXOS 


\title{
9 ANEXOS
}

\section{Anexo A - Termo de Consentimento Livre e Esclarecido}

\author{
HOSPITAL DAS CLÍNICAS DA FACULDADE DE MEDICINA DA \\ UNIVERSIDADE DE SÃO PAULO- HCFMUSP
}

TERMO DE CONSENTIMENTO LIVRE E ESCLARECIDO

\section{DADOS SOBRE A PESQUISA}

1. Título do Protocolo de Pesquisa: "Resposta imune ao HERE em pacientes com câncer de próstata"

Pesquisador Principal: DR. ESPER GEORGES KALLÁS, CRM/SP 67395

Pesquisador Executante: Dr. Carlos Dzik

Departamento de Clínica Médica/Disciplina de Imunologia Clínica e Alergia: LABORATÓRIO DE INVESTIGAÇÃO MÉDICA LIM-60

2. AVALIAÇÃO DO RISCO DA PESQUISA:

\section{RISCO MÍNIMO X $\quad$ RISCO MÉDIO $\square \quad$ RISCO BAIXO $\square \quad$ RISCO MAIOR $\square$}

\section{DURAÇÃO DA PESQUISA :}

\section{1 - Desenho do Estudo e Objetivo}

O câncer de próstata é a segunda maior causa de mortalidade relacionada a tumor no homem. Muitos pacientes não se curam pela retirada da próstata por cirurgia ou radioterapia, e seus cânceres voltam ou só são diagnosticados após espalharem pelo corpo. $\mathrm{O}$ crescimento tumoral é inicialmente dependente de hormônios masculinos (andrógenos) e o bloqueio desses hormônios causa sua regressão. Contudo, muitos homens não obtêm sucesso com esse tratamento e morrem de câncer de próstata.

Alguns estudos têm demonstrado que alguns elementos virais, chamados de retro-elementos endógenos humanos (HEREs) são expressos em cânceres, e mais recentemente, foi verificada sua relação com alguns cânceres de próstata.

Baseado em nossos dados preliminares que demonstraram que HEREs são expressos em alguns casos de câncer de próstata e que existe resposta de defesa ao HERE nesses pacientes, pretendemos avaliar a resposta ao HERE (resposta imune) no sangue de pacientes com câncer de próstata e comparando a homens sem câncer de próstata. Desta forma, esperamos encontrar uma maior frequência de resposta imune ao HERE nos pacientes que não respondem ao tratamento.

Nós acreditamos que o estudo aqui proposto contribuirá para uma melhor compreensão dos aspectos imunológicos relacionados com o câncer de próstata contra o HERE com o potencial de ajudar no tratamento.

Para a realização deste estudo precisamos analisar as células imunológicas do sangue periférico bem como o tecido da próstata de pessoas que tem câncer de próstata e comparar com pessoas que não tem câncer de próstata. 
Se você é portador de um câncer de próstata, a sua operação será apenas a da retirada da próstata e o seu caso será analisado no grupo de pacientes com câncer de próstata.

\section{2 - Procedimentos de Pesquisa}

Após ter sido esclarecido sobre o estudo, você poderá decidir se deseja ou não participar. Se decidir participar, você será solicitado a assinar o Termo de Consentimento Livre e Esclarecido ou colocar suas impressões digitais em frente a uma testemunha de sua confiança. Uma cópia deste documento lhe será fornecida. Sua participação consistirá de uma visita médica no dia anterior à sua cirurgia quando você for internado, onde será realizada uma consulta médica para obter dados clínicos a serem analisados conjuntamente com os resultados dos testes laboratoriais de sangue realizados com $80 \mathrm{ml}$ de sangue (equivalente a um terço de um copo de requeijão) coletados por uma agulha esterilizada descartável que será introduzida na veia no braço (procedimento rotineiro).

Você está sendo convidado porque seu médico indicou que será submetido a uma cirurgia onde será retirada a sua próstata. Iremos avaliar um pequeno fragmento da próstata que será retirada e uma amostra de sangue que será colhida se concordar em participar deste estudo, após a assinatura deste Termo de Consentimento Livre e Esclarecido.

\section{3 - Relação dos Procedimentos}

Assinatura do Termo de Consentimento Livre e Esclarecido para coleta de $90 \mathrm{ml}$ de sangue periférico com auxílio de agulha descartável e tubos a vácuo. Também será obtido um fragmento da próstata, logo após a retirada através da cirurgia prevista. A retirada deste pequeno fragmento será realizada por patologista experimentado em técnicas de congelação para assegurar que o fragmento de interesse tenha tecido tumoral que vai ser analisado e ao mesmo tempo para assegurar que não vai haver nenhum prejuízo para a análise final da patologia.

\section{4 - Desconfortos e Riscos Esperados}

Os riscos relacionados com sua participação são mínimos. Algumas pessoas referem dor no local da punção venosa e sensação de desmaio e raramente ocorrem complicações como formação de hematomas ou infecções locais.

\section{5 - Benefícios para o Participante}

Não existe nenhum benefício direto a você por participar neste estudo, mas as informações obtidas de sua participação poderão beneficiar no futuro outras pessoas dependendo das conclusões do estudo. Você não terá despesas pessoais incluindo exames e consultas. Despesas adicionais serão absorvidas pelo orçamento da pesquisa. Não haverá compensação financeira.

6 - Procedimentos Alternativos e/ou Experimentais procedimento experimental neste estudo. Como não se trata de estudo relacionado a possíveis tratamentos, não existem procedimentos alternativos a serem descritos.

\section{7 - Garantia de Acesso aos Pesquisadores}

Você terá acesso aos profissionais responsáveis pela pesquisa para esclarecimento de eventuais dúvidas. O pesquisador do estudo é Esper Georges Kallás, que pode ser encontrado na Rua Dr Arnaldo, 455 3o andar, SP. Tel: 3061-8314 e 3061-8315. Se você tiver alguma consideração ou dúvida sobre a ética da pesquisa, entre em contato com o Comitê de Ética em Pesquisa (CEP) - Rua Ovídio Pires de Campos, 225-5 $5^{\circ}$ andar, tel: 26616442 ramais 16, 17, 18 ou 20, FAX 26616442 ramal 26 São Paulo - SP

e-mail: cappesq.adm@hc.fm.usp.br. 


\section{8 - Voluntariedade}

É garantida a liberdade da retirada de consentimento a qualquer momento e deixar de participar do estudo, sem qualquer prejuízo à continuidade de seu tratamento na Instituição.

\section{9 - Direito de Confidencialidade}

A confidencialidade das informações obtidas nesse estudo será garantida e os dados obtidos serão analisados em conjunto com os de outros voluntários, não sendo divulgada a identificação do voluntário. Sua participação neste estudo é confidencial e sigilosa. A menos que seja exigido por lei, somente a equipe de estudo, Comitês de Ética em Pesquisa e Investigadores das agências regulatórias governamentais poderão ter acesso direto aos registros médicos para verificar as informações do estudo. O material e os dados coletados durante este projeto só serão utilizados para esta pesquisa.

10 - Direito de ser mantido atualizado quanto aos resultados da pesquisa Os dados obtidos com a realização deste estudo estarão à disposição dos voluntários sem que o sigilo de cada participante seja prejudicado.

\section{1 - Despesas e Compensações}

Não há despesas pessoais para o participante em qualquer fase do estudo, incluindo exames e consultas. Também não há compensação financeira relacionada à sua participação. Se existir qualquer despesa adicional, ela será absorvida pelo orçamento da pesquisa. Em caso de dano pessoal com nexo causal comprovado, o participante tem direito a tratamento médico na Instituição, bem como às indenizações legalmente estabelecidas.

\section{Termo de Consentimento Livre e Esclarecido}

Eu discuti com o médico responsável sobre minha decisão em participar nesse estudo.

Ficaram claros para mim quais são os propósitos do estudo, os procedimentos a serem realizados, seus desconfortos e riscos, as garantias de confidencialidade e de esclarecimentos pertinentes. Ficou claro também que minha participação é isenta de despesas e que tenho garantia do acesso a tratamento hospitalar quando necessário. Concordo voluntariamente em participar deste estudo e poderei retirar o meu consentimento a qualquer momento, antes ou durante o mesmo, sem penalidades, prejuízo ou perda de qualquer benefício que eu possa ter adquirido, ou no meu atendimento neste Serviço.

Nome completo do voluntário/representante legal

Assinatura do voluntário/representante legal

Nome completo da testemunha

Assinatura da testemunha para casos de voluntário analfabetos, semi-analfabetos ou portadores. 
Declaro que obtive de forma apropriada e voluntária o Termo de deste paciente ou representante legal para a participação neste estudo.

Prof. Dr. Esper Georges Kallás/Dr. Carlos Dzik

Assinatura do responsável pelo estudo

Data

Data

Data

Data

De deficiência auditiva ou visual.

Consentimento Livre e Esclarecido_____ Data

DADOS DE IDENTIFICAÇÃO DO SUJEITO DA PESQUISA OU RESPONSÁVEL

\section{LEGAL 1.}

NOME.

DOCUMENTO DE IDENTIDADE No :

SEXO : M $\square \mathrm{F} \square[\mathrm{s}$

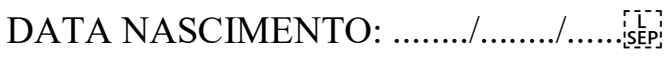

ENDEREÇO

No

APTO:

BAIRRO:

CIDADE

CEP: TELEFONE: DDD

2. RESPONSÁVEL LEGAL

NATUREZA (grau de parentesco, tutor, curador etc.)

DOCUMENTO DE IDENTIDADE : SEXO: $\mathrm{M} \square \mathrm{F} \square$

DATA NASCIMENTO.: .....................

ENDEREÇO:.

No.

APTO:

BAIRRO:

CIDADE:

CEP: TELEFONE: DDD ( ) 


\section{HOSPITAL DAS CLÍNICAS DA FACULDADE DE MEDICINA DA UNIVERSIDADE DE SÃO PAULO- HCFMUSP \\ TERMO DE CONSENTIMENTO LIVRE E ESCLARECIDO \\ DADOS SOBRE A PESQUISA}

1. Título do Protocolo de Pesquisa: "Resposta imune ao HERE em pacientes com câncer de próstata"

Pesquisador Principal: DR. ESPER GEORGES KALLÁS, CRM/SP 67395

Pesquisador Executante: Dr. Carlos Dzik

Departamento de Clínica Médica/Disciplina de Imunologia Clínica e Alergia:

LABORATÓRIO DE INVESTIGAÇÃO MÉDICA LIM-60

\section{AVALIAÇÃO DO RISCO DA PESQUISA: \\ RISCO MÍNIMO X $\quad$ RISCO MÉDIO $\square \quad$ RISCO BAIXO $\square$ RISCO MAIOR $\square$}

\section{DURAÇÃO DA PESQUISA:}

\section{1 - Desenho do Estudo e Objetivo}

O câncer de próstata é a segunda maior causa de mortalidade relacionada a tumor no homem. Muitos pacientes não se curam pela retirada da próstata por cirurgia ou radioterapia, e seus cânceres voltam ou só são diagnosticados após espalharem pelo corpo. O crescimento tumoral é inicialmente dependente de hormônios masculinos (andrógenos) e o bloqueio desses hormônios causa sua regressão. Contudo, muitos homens não obtêm sucesso com esse tratamento e morrem de câncer de próstata.

Alguns estudos têm demonstrado que alguns elementos virais, chamados de retro-elementos endógenos humanos (HEREs) são expressos em cânceres, e mais recentemente, foi verificada sua relação com alguns cânceres de próstata.

Baseado em nossos dados preliminares que demonstraram que HEREs são expressos em alguns casos de câncer de próstata e que existe resposta de defesa ao HERE nesses pacientes, pretendemos avaliar a resposta ao HERE (resposta imune) no sangue de pacientes com câncer de próstata e comparando a homens sem câncer de próstata. Desta forma, esperamos encontrar uma maior frequência de resposta imune ao HERE nos pacientes que não respondem ao tratamento.

Nós acreditamos que o estudo aqui proposto contribuirá para uma melhor compreensão dos aspectos imunológicos relacionados com o câncer de próstata contra o HERE com o potencial de ajudar no tratamento.

Para a realização deste estudo precisamos analisar as células imunológicas do sangue periférico bem como o tecido da próstata de pessoas que tem câncer de próstata disseminado pelo corpo e que está recebendo tratamento hormonal.

\section{2 - Procedimentos de Pesquisa}

Após ter sido esclarecido sobre o estudo, você poderá decidir se deseja ou não participar. Se decidir participar, você será solicitado a assinar o Termo de Consentimento Livre e Esclarecido ou colocar suas impressões digitais em frente a uma testemunha de sua confiança. Uma cópia deste documento lhe será fornecida. Sua participação consistirá de uma visita médica no dia anterior à sua cirurgia quando você for internado, onde será 
realizada uma consulta médica para obter dados clínicos a serem analisados conjuntamente com os resultados dos testes laboratoriais de sangue realizados com $80 \mathrm{ml}$ de sangue (equivalente a um terço de um copo de requeijão) coletados por uma agulha esterilizada descartável que será introduzida na veia no braço (procedimento rotineiro).

Você está sendo convidado porque seu médico indicou que você tem câncer de próstata que se disseminou pelo seu organismo e por esta razão você está recebendo tratamento hormonal. Uma amostra de sangue será colhida se você concordar em participar deste estudo, após a assinatura deste Termo de Consentimento Livre e Esclarecido.

\section{3 - Relação dos Procedimentos}

Assinatura do Termo de Consentimento Livre e Esclarecido para coleta de $90 \mathrm{ml}$ de sangue periférico com auxílio de agulha descartável e tubos a vácuo.

\section{4 - Desconfortos e Riscos Esperados}

Os riscos relacionados com sua participação são mínimos. Algumas pessoas referem dor no local da punção venosa e sensação de desmaio e raramente ocorrem complicações como formação de hematomas ou infecções locais.

\section{5 - Benefícios para o Participante}

Não existe nenhum benefício direto a você por participar neste estudo, mas as informações obtidas de sua participação poderão beneficiar no futuro outras pessoas dependendo das conclusões do estudo. Você não terá despesas pessoais incluindo exames e consultas. Despesas adicionais serão absorvidas pelo orçamento da pesquisa. Não haverá compensação financeira.

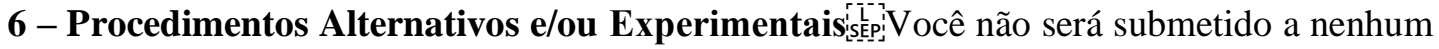
procedimento experimental neste estudo. Como não se trata de estudo relacionado a possíveis tratamentos, não existem procedimentos alternativos a serem descritos.

\section{7 - Garantia de Acesso aos Pesquisadores}

Você terá acesso aos profissionais responsáveis pela pesquisa para esclarecimento de eventuais dúvidas. O pesquisador do estudo é Esper Georges Kallás, que pode ser encontrado na Rua Dr Arnaldo, 455 3o andar, SP. Tel: 3061-8314 e 3061-8315. Se você tiver alguma consideração ou dúvida sobre a ética da pesquisa, entre em contato com o Comitê de Ética em Pesquisa (CEP) - Rua Ovídio Pires de Campos, 225-5 $5^{\circ}$ andar, tel: 26616442 ramais 16, 17, 18 ou 20, FAX 26616442 ramal 26 São Paulo - SP

e-mail: cappesq.adm@hc.fm.usp.br .

\section{8 - Voluntariedade}

É garantida a liberdade da retirada de consentimento a qualquer momento e deixar de participar do estudo, sem qualquer prejuízo à continuidade de seu tratamento na Instituição.

\section{9 - Direito de Confidencialidade}

A confidencialidade das informações obtidas nesse estudo será garantida e os dados obtidos serão analisados em conjunto com os de outros voluntários, não sendo divulgada a identificação do voluntário. Sua participação neste estudo é confidencial e sigilosa. A menos que seja exigido por lei, somente a equipe de estudo, Comitês de Ética em Pesquisa e Investigadores das agências regulatórias governamentais poderão ter acesso direto aos registros médicos para verificar as informações do estudo. O material e os dados coletados durante este projeto só serão utilizados para esta pesquisa. 
10 - Direito de ser mantido atualizado quanto aos resultados da pesquisa Os dados obtidos com a realização deste estudo estarão à disposição dos voluntários sem que o sigilo de cada participante seja prejudicado.

\section{1 - Despesas e Compensações}

Não há despesas pessoais para o participante em qualquer fase do estudo, incluindo exames e consultas. Também não há compensação financeira relacionada à sua participação. Se existir qualquer despesa adicional, ela será absorvida pelo orçamento da pesquisa. Em caso de dano pessoal com nexo causal comprovado, o participante tem direito a tratamento médico na Instituição, bem como às indenizações legalmente estabelecidas.

\section{Termo de Consentimento Livre e Esclarecido}

Eu discuti com o médico responsável sobre minha decisão em participar nesse estudo.

Ficaram claros para mim quais são os propósitos do estudo, os procedimentos a serem realizados, seus desconfortos e riscos, as garantias de confidencialidade e de esclarecimentos pertinentes. Ficou claro também que minha participação é isenta de despesas e que tenho garantia do acesso a tratamento hospitalar quando necessário. Concordo voluntariamente em participar deste estudo e poderei retirar o meu consentimento a qualquer momento, antes ou durante o mesmo, sem penalidades, prejuízo ou perda de qualquer benefício que eu possa ter adquirido, ou no meu atendimento neste Serviço.

Nome completo do voluntário/representante legal

Assinatura do voluntário/representante legal

Nome completo da testemunha

Assinatura da testemunha para casos de voluntário analfabetos, semi-analfabetos ou portadores.

Declaro que obtive de forma apropriada e voluntária o Termo de deste paciente ou representante legal para a participação neste estudo.

\section{Prof. Dr. Esper Georges Kallás/Dr. Carlos Dzik}


Assinatura do responsável pelo estudo

Data

Data

Data

Data

De deficiência auditiva ou visual.

Consentimento Livre e Esclarecido

Data

DADOS DE IDENTIFICAÇÃO DO SUJEITO DA PESQUISA OU RESPONSÁVEL LEGAL 1.

NOME

DOCUMENTO DE IDENTIDADE No :

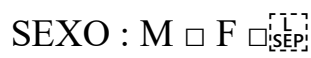

DATA NASCIMENTO

No

APTO:

ENDEREÇO

CIDADE

BAIRRO:

CEP:. TELEFONE: DDD

2. RESPONSÁVEL LEGAL

NATUREZA (grau de parentesco, tutor, curador etc.)

DOCUMENTO DE IDENTIDADE :

SEXO: $\mathrm{M} \square \mathrm{F}$ 口isepp:

DATA NASCIMENTO.: .....................

ENDEREÇO

No

APTO:

BAIRRO:

CIDADE:

CEP: TELEFONE: DDD ( ) 


\title{
Anexo B - APROVAÇÃo PELA COMISSÃo DE ÉTICA PARA ANÁl ISE DE PROJETOS DE PESQUISA CAPPESq
}

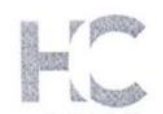

\author{
Hospital das Clinicas da FMUSP \\ Comissão de Ética para Análise de Projetos de Pesquisa \\ CAPPesq
}

N'Protocolo: 0525/10

Título: Resposta Imune do HERE em pacientes com câncer de próstato

Pesquisador Responsável: Esper Georges Kallás

Pesquisador Executante: Esper Georges Kallás

Disciplina: imunologia Clínica e Alergio

Departamento: CLINICA MÉDICA

A Comissão de Ética para Análise de Projetos de Pesquisc -

CApPesa da Diretoria Clinica do Hospital das Clínicas da Facuidade de Medicina da Universidade de São Paulo, APROVOU / TOMOU CIÊNCIA na sessão datada de 00/04/2016, do(s) documento(s) abaixo mencionado(s):

- Carta datada de 16/03/2016- Relatório parcial.

- Carta datada 17/03/2016 - Protocolo versão 3.1 de 16/03/2016 - termo de consentimento livre e esciarecido de 16/03/2016 para doença disseminada.

\footnotetext{
CAPPesq, 06 de Abril de 2016

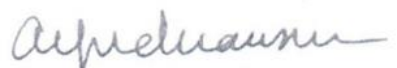

Prof. Dr. Alfredo José Mansur Coordenador

Comissão de Ética para Análise de Projetos de Pesquisa - CAPPesq
} 


\title{
Anexo C - APROVAÇÃO DE EMENDA PELA COMISSÃO DE ÉTICA PARA ANÁLISE DE PROJETOS DE PESQUISA CAPPesq
}

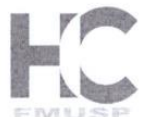

\author{
Hospital das Clínicas da FMUSP \\ Comissão de Ética para Análise de Projetos de Pesquisa \\ CAPPesq
}

No Protocolo: 0525/10

Título: Resposta Imune ao HERE em pacientes com câncer de próstata

Pesquisador Responsável: Esper Georges Kallás

Pesquisador Executante: Esper Georges Kallás

Disciplina: Imunologia Clínica e Alergia

Departamento: CLÍNICA MÉDICA

A Comissão de Ética para Análise de Projetos de Pesquisa CAPPesa da Diretoria Clínica do Hospital das Clínicas da Faculdade de Medicina da Universidade de São Paulo, APROVOU / TOMOU CIÊNCIA na sessão dałada de 16/09/2015, do(s) documento(s) abaixo mencionado(s):

\footnotetext{
- Carta datada de 02.09.15 - Protocolo versão 3.1 de 01.09.15; Termo de Consentimento Livre e Esclarecido versão de 01.09 .15 e Termo de Consentimento Livre e Esclarecido para Biobanco versão de 29.05.15.
}

Em conformidade com a Resolução CNS n 466/12 - cabe ao pesquisador: a) desenvolver 0 projeto conforme delineado; b) elaborar $e$ apresentar relatórios parciais e final; c)apresentar dados solicitados pelo CEP, a qualquer momento; d) manter em arquivo sob sua guarda, por 5 anos da pesquisa, contendo fichas individuais e todos os demais documentos recomendados pelo CEP; e) encaminhar os resultados para publicação, com os devidos créditos aos pesquisadores associados e ao pessoal técnico participante do projeto; f) justificar perante ao CEP interrupção do projeto ou a não publicação dos resultados.

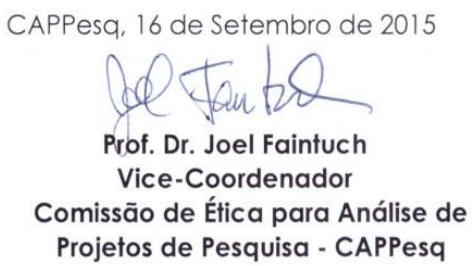

Prof. Dr. Joel Faintuch

Vice-Coordenador

Comissão de Ética para Análise de

Projetos de Pesquisa - CAPPesq 


\section{REFERÊNCIAS}

1. Rebbeck TR, Devesa SS, Chang BL, Bunker CH, Cheng I, Cooney K, et al. Global patterns of prostate cancer incidence, aggressiveness, and mortality in men of african descent. Prostate Cancer. 2013;2013:560857.

2. Hsing AW, Tsao L, Devesa SS. International trends and patterns of prostate cancer incidence and mortality. Int J Cancer. 2000;85(1):60-7.

3. Kvåle R, Auvinen A, Adami HO, Klint A, Hernes E, Møller B, et al. Interpreting trends in prostate cancer incidence and mortality in the five Nordic countries. J Natl Cancer Inst. 2007;99(24):1881-7.

4. Zhou CK, Check DP, Lortet-Tieulent J, Laversanne M, Jemal A, Ferlay J, et al. Prostate cancer incidence in 43 populations worldwide: An analysis of time trends overall and by age group. Int J Cancer. 2016;138(6):1388-400.

5. Neppl-Huber C, Zappa M, Coebergh JW, Rapiti E, Rachtan J, Holleczek B, et al. Changes in incidence, survival and mortality of prostate cancer in Europe and the United States in the PSA era: additional diagnoses and avoided deaths. Ann Oncol. 2012;23(5):1325-34.

6. Bray F, Lortet-Tieulent J, Ferlay J, Forman D, Auvinen A. Prostate cancer incidence and mortality trends in 37 European countries: an overview. Eur J Cancer. 2010;46(17):3040-52.

7. Litwin MS, Tan HJ. The Diagnosis and Treatment of Prostate Cancer: A Review. JAMA. 2017;317(24):2532-42.

8. Center MM, Jemal A, Lortet-Tieulent J, Ward E, Ferlay J, Brawley O, et al. International variation in prostate cancer incidence and mortality rates. Eur Urol. 2012;61(6):1079-92. 
9. Quinn M, Babb P. Patterns and trends in prostate cancer incidence, survival, prevalence and mortality. Part I: international comparisons. BJU Int. 2002;90(2):16273.

10. Baade PD, Youlden DR, Krnjacki LJ. International epidemiology of prostate cancer: geographical distribution and secular trends. Mol Nutr Food Res. 2009;53(2):171-84.

11. Nakata S, Sato J, Imai K, Yamanaka H, Ichinose Y. Epidemiological characteristics of prostate cancer in Gunma Prefecture, Japan. Gunma University Urological Oncology Study Group. Int J Urol. 1995;2(3):191-7.

12. Boorjian SA, Karnes RJ, Rangel LJ, Bergstralh EJ, Blute ML. Mayo Clinic validation of the D'amico risk group classification for predicting survival following radical prostatectomy. J Urol. 2008;179(4):1354-60; discussion 60-1.

13. Bolla M, de Reijke TM, Van Tienhoven G, Van den Bergh AC, Oddens J, Poortmans PM, et al. Duration of androgen suppression in the treatment of prostate cancer. N Engl J Med. 2009;360(24):2516-27.

14. Bolla M, Collette L, Blank L, Warde P, Dubois JB, Mirimanoff RO, et al. Long-term results with immediate androgen suppression and external irradiation in patients with locally advanced prostate cancer (an EORTC study): a phase III randomised trial. Lancet. 2002;360(9327):103-6.

15. Huggins C. Prostatic cancer treated by orchiectomy; the five year results. J Am Med Assoc. 1946;131:576-81.

16. Seidenfeld J, Samson DJ, Hasselblad V, Aronson N, Albertsen PC, Bennett CL, et al. Single-therapy androgen suppression in men with advanced prostate cancer: a systematic review and meta-analysis. Ann Intern Med. 2000;132(7):566-77. 
17. de Bono JS, Logothetis CJ, Molina A, Fizazi K, North S, Chu L, et al. Abiraterone and increased survival in metastatic prostate cancer. N Engl J Med. 2011;364(21):1995-2005.

18. Scher HI, Fizazi K, Saad F, Taplin ME, Sternberg CN, Miller K, et al. Increased survival with enzalutamide in prostate cancer after chemotherapy. N Engl J Med. 2012;367(13):1187-97.

19. Tannock IF, de Wit R, Berry WR, Horti J, Pluzanska A, Chi KN, et al. Docetaxel plus prednisone or mitoxantrone plus prednisone for advanced prostate cancer. N Engl J Med. 2004;351(15):1502-12.

20. de Bono JS, Oudard S, Ozguroglu M, Hansen S, Machiels JP, Kocak I, et al. Prednisone plus cabazitaxel or mitoxantrone for metastatic castration-resistant prostate cancer progressing after docetaxel treatment: a randomised open-label trial. Lancet. 2010;376(9747):1147-54.

21. Parker C, Nilsson S, Heinrich D, Helle SI, O'Sullivan JM, Fosså SD, et al. Alpha emitter radium-223 and survival in metastatic prostate cancer. N Engl J Med. 2013;369(3):213-23.

22. Small EJ, Schellhammer PF, Higano CS, Redfern CH, Nemunaitis JJ, Valone $\mathrm{FH}$, et al. Placebo-controlled phase III trial of immunologic therapy with sipuleucel$\mathrm{T}$ (APC8015) in patients with metastatic, asymptomatic hormone refractory prostate cancer. J Clin Oncol. 2006;24(19):3089-94.

23. Shafer-Weaver KA, Anderson MJ, Stagliano K, Malyguine A, Greenberg NM, Hurwitz AA. Cutting Edge: Tumor-specific CD8+ T cells infiltrating prostatic tumors are induced to become suppressor cells. J Immunol. 2009;183(8):4848-52.

24. Miller AM, Lundberg K, Ozenci V, Banham AH, Hellström M, Egevad L, et al. CD4+CD25high T cells are enriched in the tumor and peripheral blood of prostate cancer patients. J Immunol. 2006;177(10):7398-405. 
25. Becker JT, Olson BM, Johnson LE, Davies JG, Dunphy EJ, McNeel DG. DNA vaccine encoding prostatic acid phosphatase (PAP) elicits long-term T-cell responses in patients with recurrent prostate cancer. J Immunother. 2010;33(6):63947.

26. Scanlan MJ, Simpson AJ, Old LJ. The cancer/testis genes: review, standardization, and commentary. Cancer Immun. 2004;4:1.

27. Simpson AJ, Caballero OL, Jungbluth A, Chen YT, Old LJ. Cancer/testis antigens, gametogenesis and cancer. Nat Rev Cancer. 2005;5(8):615-25.

28. Mengus C, Schultz-Thater E, Coulot J, Kastelan Z, Goluza E, Coric M, et al. MAGE-A10 cancer/testis antigen is highly expressed in high-grade non-muscleinvasive bladder carcinomas. Int J Cancer. 2013;132(10):2459-63.

29. Grah JJ, Katalinic D, Juretic A, Santek F, Samarzija M. Clinical significance of immunohistochemical expression of cancer/testis tumor-associated antigens (MAGE-A1, MAGE-A3/4, NY-ESO-1) in patients with non-small cell lung cancer. Tumori. 2014;100(1):60-8.

30. Xiao J, Chen HS. Biological functions of melanoma-associated antigens. World J Gastroenterol. 2004;10(13):1849-53.

31. Kulkarni P, Uversky VN. Cancer/Testis Antigens: "Smart" Biomarkers for Diagnosis and Prognosis of Prostate and Other Cancers. Int J Mol Sci. 2017;18(4).

32. Ghafouri-Fard S, Shamsi R, Seifi-Alan M, Javaheri M, Tabarestani S. Cancer-testis genes as candidates for immunotherapy in breast cancer. Immunotherapy. 2014;6(2):165-79. 
33. Parmigiani RB, Bettoni F, Vibranovski MD, Lopes MH, Martins WK, Cunha IW, et al. Characterization of a cancer/testis (CT) antigen gene family capable of eliciting humoral response in cancer patients. Proc Natl Acad Sci U S A. 2006;103(48):18066-71.

34. Parmigiani RB, Bettoni F, Grosso DM, Lopes A, Cunha IW, Soares FA, et al. Antibodies against the cancer-testis antigen CTSP-1 are frequently found in prostate cancer patients and are an independent prognostic factor for biochemical-recurrence. Int J Cancer. 2008;122(10):2385-90.

35. Drake CG. Prostate cancer as a model for tumour immunotherapy. Nat Rev Immunol. 2010;10(8):580-93.

36. Gerritsen WR. The evolving role of immunotherapy in prostate cancer. Ann Oncol. 2012;23 Suppl 8:viii22-7.

37. Barve A, Jin W, Cheng K. Prostate cancer relevant antigens and enzymes for targeted drug delivery. J Control Release. 2014;187:118-32.

38. Sultan H, Fesenkova VI, Addis D, Fan AE, Kumai T, Wu J, et al. Designing therapeutic cancer vaccines by mimicking viral infections. Cancer Immunol Immunother. 2017;66(2):203-13.

39. Yang B, Jeang J, Yang A, Wu TC, Hung CF. DNA vaccine for cancer immunotherapy. Hum Vaccin Immunother. 2014;10(11):3153-64.

40. Gonzalez-Cao M, Iduma P, Karachaliou N, Santarpia M, Blanco J, Rosell R. Human endogenous retroviruses and cancer. Cancer Biol Med. 2016;13(4):483-8.

41. Leib-Mösch C, Brack-Werner R, Werner T, Bachmann M, Faff O, Erfle V, et al. Endogenous retroviral elements in human DNA. Cancer Res. 1990;50(17 Suppl):5636S-42S. 
42. Lander ES, Linton LM, Birren B, Nusbaum C, Zody MC, Baldwin J, et al. Initial sequencing and analysis of the human genome. Nature. 2001;409(6822):860921.

43. Dewannieux M, Harper F, Richaud A, Letzelter C, Ribet D, Pierron G, et al. Identification of an infectious progenitor for the multiple-copy HERV-K human endogenous retroelements. Genome Res. 2006;16(12):1548-56.

44. van de Lagemaat LN, Landry JR, Mager DL, Medstrand P. Transposable elements in mammals promote regulatory variation and diversification of genes with specialized functions. Trends Genet. 2003;19(10):530-6.

45. Kurth R, Bannert N. Beneficial and detrimental effects of human endogenous retroviruses. Int J Cancer. 2010;126(2):306-14.

46. Cohen CJ, Lock WM, Mager DL. Endogenous retroviral LTRs as promoters for human genes: a critical assessment. Gene. 2009;448(2):105-14.

47. Isbel L, Whitelaw E. Endogenous retroviruses in mammals: an emerging picture of how ERVs modify expression of adjacent genes. Bioessays. 2012;34(9):734-8.

48. Feschotte C, Gilbert C. Endogenous viruses: insights into viral evolution and impact on host biology. Nat Rev Genet. 2012;13(4):283-96.

49. Takai D, Yagi Y, Habib N, Sugimura T, Ushijima T. Hypomethylation of LINE1 retrotransposon in human hepatocellular carcinomas, but not in surrounding liver cirrhosis. Jpn J Clin Oncol. 2000;30(7):306-9.

50. Wilhelm CS, Kelsey KT, Butler R, Plaza S, Gagne L, Zens MS, et al. Implications of LINE1 methylation for bladder cancer risk in women. Clin Cancer Res. 2010;16(5):1682-9. 
51. Yegnasubramanian S, Haffner MC, Zhang Y, Gurel B, Cornish TC, Wu Z, et al. DNA hypomethylation arises later in prostate cancer progression than $\mathrm{CpG}$ island hypermethylation and contributes to metastatic tumor heterogeneity. Cancer Res. 2008;68(21):8954-67.

52. Büscher K, Trefzer U, Hofmann M, Sterry W, Kurth R, Denner J. Expression of human endogenous retrovirus $\mathrm{K}$ in melanomas and melanoma cell lines. Cancer Res. 2005;65(10):4172-80.

53. Wang-Johanning F, Frost AR, Johanning GL, Khazaeli MB, LoBuglio AF, Shaw DR, et al. Expression of human endogenous retrovirus k envelope transcripts in human breast cancer. Clin Cancer Res. 2001;7(6):1553-60.

54. Wang-Johanning F, Liu J, Rycaj K, Huang M, Tsai K, Rosen DG, et al. Expression of multiple human endogenous retrovirus surface envelope proteins in ovarian cancer. Int J Cancer. 2007;120(1):81-90.

55. Kleiman A, Senyuta N, Tryakin A, Sauter M, Karseladze A, Tjulandin S, et al. HERV-K(HML-2) GAG/ENV antibodies as indicator for therapy effect in patients with germ cell tumors. Int J Cancer. 2004;110(3):459-61.

56. Wang-Johanning F, Radvanyi L, Rycaj K, Plummer JB, Yan P, Sastry KJ, et al. Human endogenous retrovirus $\mathrm{K}$ triggers an antigen-specific immune response in breast cancer patients. Cancer Res. 2008;68(14):5869-77.

57. Ishida T, Obata Y, Ohara N, Matsushita H, Sato S, Uenaka A, et al. Identification of the HERV-K gag antigen in prostate cancer by SEREX using autologous patient serum and its immunogenicity. Cancer Immun. 2008;8:15.

58. Coussens L, Yang-Feng TL, Liao YC, Chen E, Gray A, McGrath J, et al. Tyrosine kinase receptor with extensive homology to EGF receptor shares chromosomal location with neu oncogene. Science. 1985;230(4730):1132-9. 
59. Seil I, Frei C, Sültmann H, Knauer SK, Engels K, Jäger E, et al. The differentiation antigen NY-BR-1 is a potential target for antibody-based therapies in breast cancer. Int J Cancer. 2007;120(12):2635-42.

60. Mullins CS, Linnebacher M. Endogenous retrovirus sequences as a novel class of tumor-specific antigens: an example of HERV-H env encoding strong CTL epitopes. Cancer Immunol Immunother. 2012;61(7):1093-100.

61. Rakoff-Nahoum S, Kuebler PJ, Heymann JJ, E Sheehy M, Ortiz GM, S Ogg $\mathrm{G}$, et al. Detection of $\mathrm{T}$ lymphocytes specific for human endogenous retrovirus $\mathrm{K}$ (HERV-K) in patients with seminoma. AIDS Res Hum Retroviruses. 2006;22(1):526.

62. Rycaj K, Plummer JB, Yin B, Li M, Garza J, Radvanyi L, et al. Cytotoxicity of human endogenous retrovirus K-specific T cells toward autologous ovarian cancer cells. Clin Cancer Res. 2015;21(2):471-83.

63. Ono M. Molecular cloning and long terminal repeat sequences of human endogenous retrovirus genes related to types A and B retrovirus genes. J Virol. 1986;58(3):937-44.

64. Belikov S, Astrand C, Wrange O. Mechanism of histone H1-stimulated glucocorticoid receptor DNA binding in vivo. Mol Cell Biol. 2007;27(6):2398-410.

65. Shaffer PL, Jivan A, Dollins DE, Claessens F, Gewirth DT. Structural basis of androgen receptor binding to selective androgen response elements. Proc Natl Acad Sci U S A. 2004;101(14):4758-63.

66. Ghosh D. Glucocorticoid receptor-binding site in the human immunodeficiency virus long terminal repeat. J Virol. 1992;66(1):586-90. 
67. Ono M, Kawakami M, Ushikubo H. Stimulation of expression of the human endogenous retrovirus genome by female steroid hormones in human breast cancer cell line T47D. J Virol. 1987;61(6):2059-62.

68. Kokontis JM, Hsu S, Chuu CP, Dang M, Fukuchi J, Hiipakka RA, et al. Role of androgen receptor in the progression of human prostate tumor cells to androgen independence and insensitivity. Prostate. 2005;65(4):287-98.

69. Kiniwa Y, Miyahara Y, Wang HY, Peng W, Peng G, Wheeler TM, et al. CD8+ Foxp3+ regulatory $\mathrm{T}$ cells mediate immunosuppression in prostate cancer. Clin Cancer Res. 2007;13(23):6947-58.

70. Franklin C, Livingstone E, Roesch A, Schilling B, Schadendorf D. Immunotherapy in melanoma: Recent advances and future directions. Eur J Surg Oncol. 2017;43(3):604-11.

71. Liu KG, Gupta S, Goel S. Immunotherapy: incorporation in the evolving paradigm of renal cancer management and future prospects. Oncotarget. 2017;8(10):17313-27.

72. Malhotra J, Jabbour SK, Aisner J. Current state of immunotherapy for nonsmall cell lung cancer. Transl Lung Cancer Res. 2017;6(2):196-211.

73. Ryan CJ, Tindall DJ. Androgen receptor rediscovered: the new biology and targeting the androgen receptor therapeutically. J Clin Oncol. 2011;29(27):3651-8.

74. Migowski A, Silva GA. Survival and prognostic factors of patients with clinically localized prostate cancer. Rev Saude Publica. 2010;44(2):344-52.

75. Agoni L, Guha C, Lenz J. Detection of Human Endogenous Retrovirus K (HERV-K) Transcripts in Human Prostate Cancer Cell Lines. Front Oncol. 2013;3:180. 
76. Tomlins SA, Laxman B, Dhanasekaran SM, Helgeson BE, Cao X, Morris DS, et al. Distinct classes of chromosomal rearrangements create oncogenic ETS gene fusions in prostate cancer. Nature. 2007;448(7153):595-9.

77. Goering W, Ribarska T, Schulz WA. Selective changes of retroelement expression in human prostate cancer. Carcinogenesis. 2011;32(10):1484-92.

78. Mercader M, Bodner BK, Moser MT, Kwon PS, Park ES, Manecke RG, et al. $\mathrm{T}$ cell infiltration of the prostate induced by androgen withdrawal in patients with prostate cancer. Proc Natl Acad Sci U S A. 2001;98(25):14565-70.

79. Armas OA, Aprikian AG, Melamed J, Cordon-Cardo C, Cohen DW, Erlandson R, et al. Clinical and pathobiological effects of neoadjuvant total androgen ablation therapy on clinically localized prostatic adenocarcinoma. Am J Surg Pathol. 1994;18(10):979-91.

80. Montironi R, Schulman CC. Pathological changes in prostate lesions after androgen manipulation. J Clin Pathol. 1998;51(1):5-12.

81. Nesslinger NJ, Sahota RA, Stone B, Johnson K, Chima N, King C, et al. Standard treatments induce antigen-specific immune responses in prostate cancer. Clin Cancer Res. 2007;13(5):1493-502.

82. Olson BM, McNeel DG. Antibody and T-cell responses specific for the androgen receptor in patients with prostate cancer. Prostate. 2007;67(16):1729-39.

83. Johnke RM, Edwards JM, Kovacs CJ, Evans MJ, Daly BM, Karlsson UL, et al. Response of $\mathrm{T}$ lymphocyte populations in prostate cancer patients undergoing radiotherapy: influence of neoajuvant total androgen suppression. Anticancer Res. 2005;25(4):3159-66.

84. Janetzki S, Britten CM. The impact of harmonization on ELISPOT assay performance. Methods Mol Biol. 2012;792:25-36. 
85. Scheibenbogen C, Romero P, Rivoltini L, Herr W, Schmittel A, Cerottini JC, et al. Quantitation of antigen-reactive $\mathrm{T}$ cells in peripheral blood by IFNgammaELISPOT assay and chromium-release assay: a four-centre comparative trial. J Immunol Methods. 2000;244(1-2):81-9.

86. Lalvani A, Brookes R, Hambleton S, Britton WJ, Hill AV, McMichael AJ. Rapid effector function in CD8+ memory T cells. J Exp Med. 1997;186(6):859-65.

87. Streeck H, Frahm N, Walker BD. The role of IFN-gamma Elispot assay in HIV vaccine research. Nat Protoc. 2009;4(4):461-9.

88. Lalvani A, Pareek M. Interferon gamma release assays: principles and practice. Enferm Infecc Microbiol Clin. 2010;28(4):245-52.

89. Lucey DR, Clerici M, Shearer GM. Type 1 and type 2 cytokine dysregulation in human infectious, neoplastic, and inflammatory diseases. Clin Microbiol Rev. 1996;9(4):532-62.

90. Paul WE, Zhu J. How are $\mathrm{T}(\mathrm{H}) 2$-type immune responses initiated and amplified? Nat Rev Immunol. 2010;10(4):225-35.

91. Goto S, Sato M, Kaneko R, Itoh M, Sato S, Takeuchi S. Analysis of Th1 and Th2 cytokine production by peripheral blood mononuclear cells as a parameter of immunological dysfunction in advanced cancer patients. Cancer Immunol Immunother. 1999;48(8):435-42.

92. Bellone G, Turletti A, Artusio E, Mareschi K, Carbone A, Tibaudi D, et al. Tumor-associated transforming growth factor-beta and interleukin-10 contribute to a systemic Th2 immune phenotype in pancreatic carcinoma patients. Am J Pathol. 1999;155(2):537-47.

93. Cottrez F, Groux H. Regulation of TGF-beta response during T cell activation is modulated by IL-10. J Immunol. 2001;167(2):773-8. 
94. Miller AM, Pisa P. Tumor escape mechanisms in prostate cancer. Cancer Immunol Immunother. 2007;56(1):81-7.

95. Chi N, Tan Z, Ma K, Bao L, Yun Z. Increased circulating myeloid-derived suppressor cells correlate with cancer stages, interleukin-8 and -6 in prostate cancer. Int J Clin Exp Med. 2014;7(10):3181-92.

96. Appay V, van Lier RA, Sallusto F, Roederer M. Phenotype and function of human T lymphocyte subsets: consensus and issues. Cytometry A. 2008;73(11):97583.

97. Mackay CR. Dual personality of memory $\mathrm{T}$ cells. Nature. 1999;401(6754):659-60.

98. Sallusto F, Lenig D, Förster R, Lipp M, Lanzavecchia A. Pillars article: two subsets of memory $\mathrm{T}$ lymphocytes with distinct homing potentials and effector functions. Nature. 1999. 401: 708-712. J Immunol. 2014;192(3):840-4.

99. Hamann D, Baars PA, Rep MH, Hooibrink B, Kerkhof-Garde SR, Klein MR, et al. Phenotypic and functional separation of memory and effector human CD8+ T cells. J Exp Med. 1997;186(9):1407-18.

100. Nishimura H, Nose M, Hiai H, Minato N, Honjo T. Development of lupuslike autoimmune diseases by disruption of the PD-1 gene encoding an ITIM motifcarrying immunoreceptor. Immunity. 1999;11(2):141-51.

101. Zarour HM. Reversing T-cell Dysfunction and Exhaustion in Cancer. Clin Cancer Res. 2016;22(8):1856-64.

102. Schietinger A, Greenberg PD. Tolerance and exhaustion: defining mechanisms of T cell dysfunction. Trends Immunol. 2014;35(2):51-60. 


\section{APÊNDICES}




\section{APÊNDICES}

\section{APÊNDICES REFERENTES À POPULAÇÃO DE CD4}

\section{Distribuição da Ativação por Marcador Individual dentro dos imunofenótipos de Linfócito T CD4}

\section{-CCR5-}

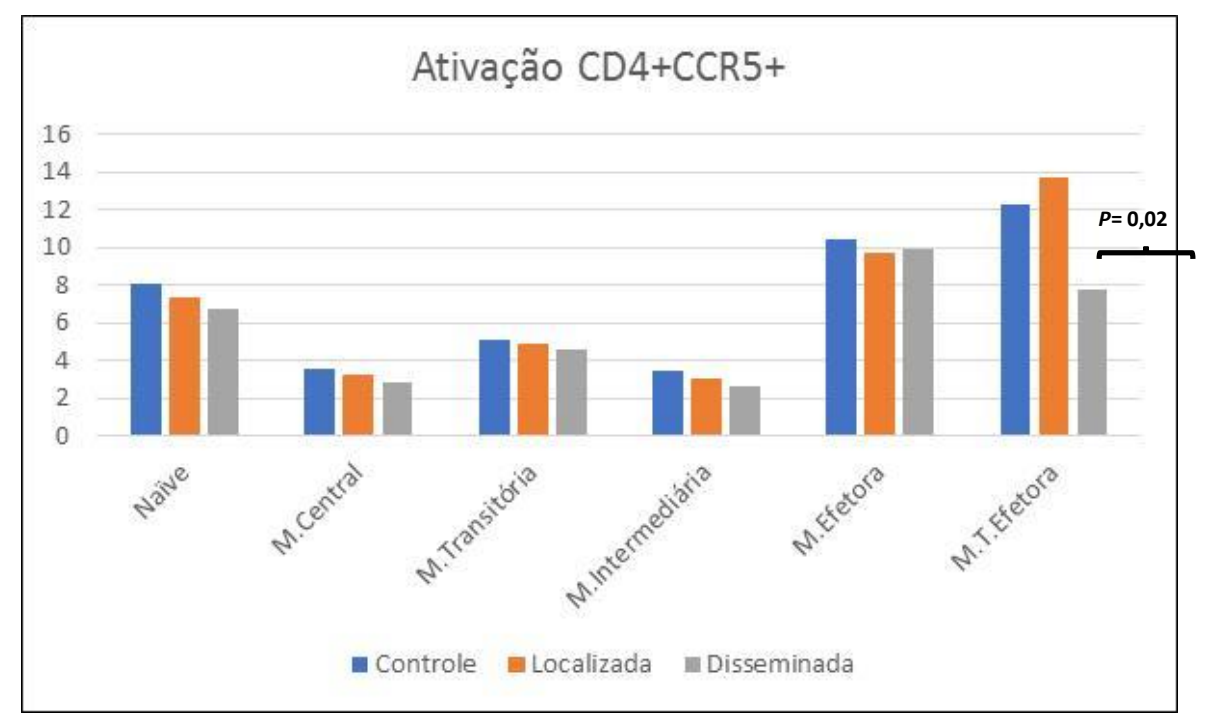

Apêndice-Gráfico 1 Distribuição em histograma mostrando que não ocorre diferença estatisticamente significante nas sub-populações de linfócitos para o marcador CCR5, exceto na sub-população de Memória Terminal Efetora, com redução significativa na quantidade de células CCR5+ na coorte de doença localizada, em comparação com a coorte de doença disseminada.

\begin{tabular}{lcccc}
\hline & Controle & Localizada & Disseminada & $\begin{array}{l}\text { Valor } \boldsymbol{p} \text { entre local. e } \\
\text { disseminada }\end{array}$ \\
\hline Naive & 8,13 & 7,36 & 6,79 & 0,57 \\
M.Central & 3,6 & 3,32 & 2,9 & 0,34 \\
M.Transitória & 5,08 & 4,96 & 4,64 & 0,88 \\
M.Intermed. & 3,45 & 3,12 & 2,65 & 0,32 \\
M.Efetora & 10,49 & 9,76 & 9,93 & 0,75 \\
M.Term.Efetora & 12,3 & 13,7 & 7,74 & 0,02 \\
\hline
\end{tabular}

Tabela: Diferenças estatisticamente significantes, mostrando aumento de ativação na coorte de doença disseminada quando examinadas pela marcação individual de CD38, isoladamente.as coortes de Controle e Doença Localizada são muito parecidas e iguais do ponto de vista estatístico. 
Distribuição da Ativação por Marcador Individual dentro dos imunofenótipos Linfócito T CD4

-HLA DR-

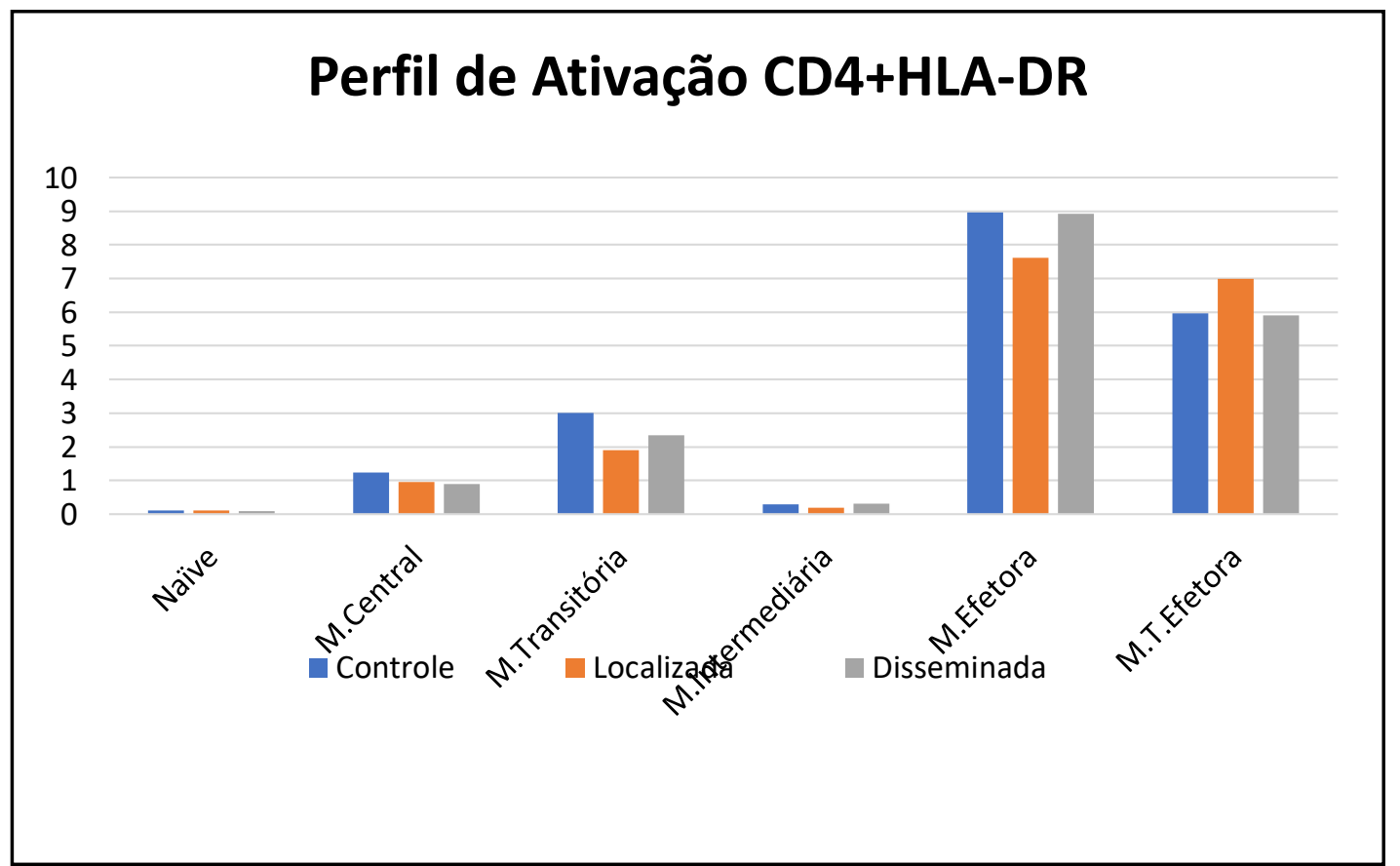

Tabela: Distribuição em histograma mostrando que não ocorre diferença estatisticamente significante nas sub-populações de linfócitos para o marcador HLA DR isoladamente

\begin{tabular}{lcccc}
\hline & Controle & Localizada & Disseminada & $\begin{array}{c}\text { Valor } \boldsymbol{p} \text { entre local. e } \\
\text { disseminada }\end{array}$ \\
\hline Naive & 0,11 & 0,1 & 0,08 & 0,13 \\
M. Central & 1,23 & 0,95 & 0,9 & 0,88 \\
M. Transitória & 3,01 & 1,89 & 2,34 & 0,25 \\
M. Intermed. & 0,28 & 0,18 & 0,31 & 0,061 \\
M. Efetora & 8,97 & 7,61 & 8,93 & 0,43 \\
M. Term. Efetora & 5,97 & 6,99 & 5,91 & 0,81 \\
\hline
\end{tabular}

Tabela: Não há diferença estatisticamente significante nas sub-populações linfocitárias quando examinadas em sua marcação isolada de HLA-DR. 


\section{Distribuição da Ativação por Co-expressão dentro dos imunofenótipos linfócito T CD4. \\ CD38+ HLA-DR+}

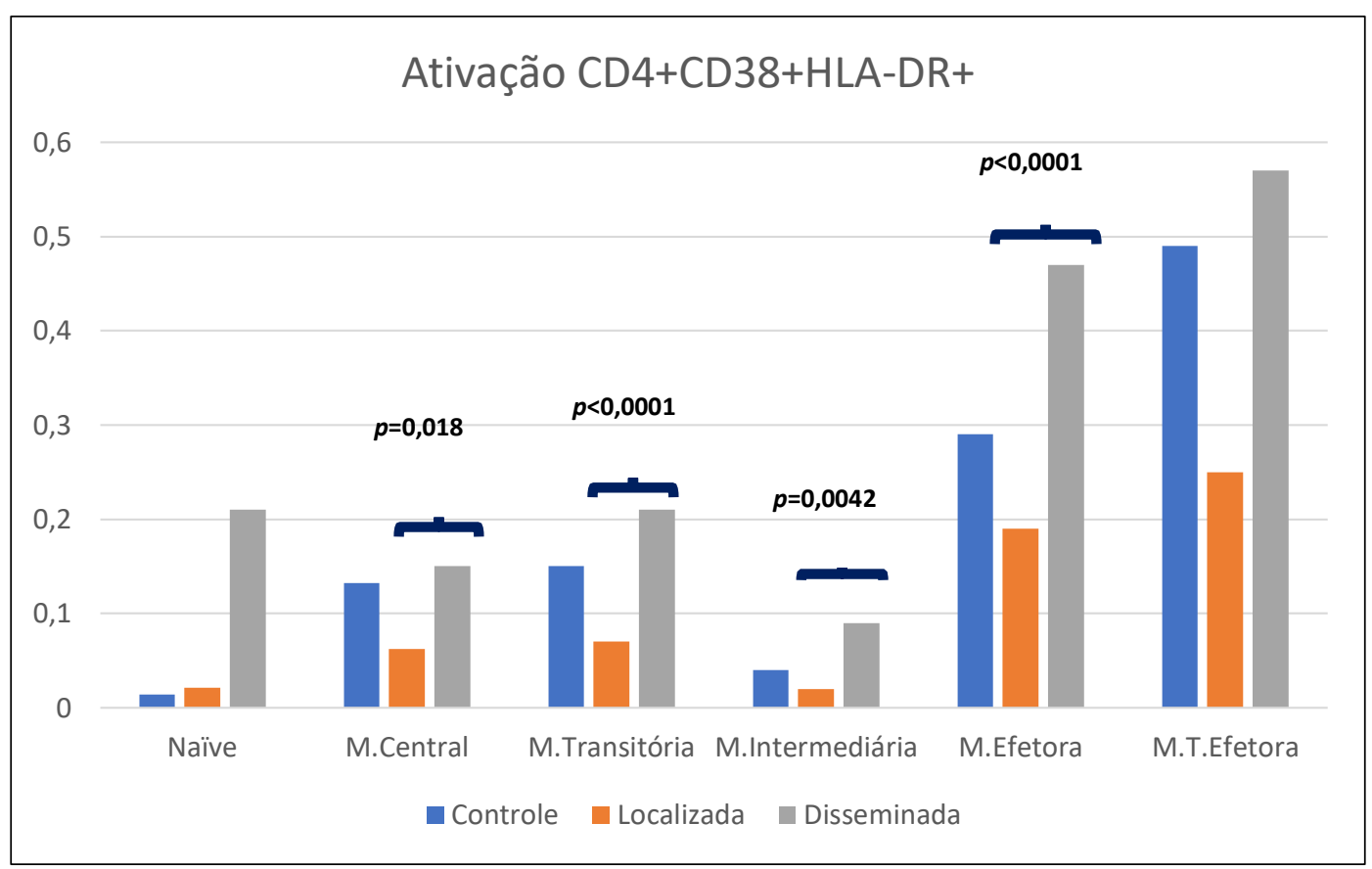

Tabela: Comparações das medianas das porcentagens na análise da co-expressão de CD38+HLA DR com aumento da ativação na coorte de doença disseminada em comparação com doença localizada. Mann-Whitney U test bicaudal

\begin{tabular}{lcccc}
\hline & Controle & Localizada & Disseminada & $\begin{array}{c}\text { Valor } \boldsymbol{p} \text { entre local. e } \\
\text { disseminada }\end{array}$ \\
\hline Naive & 0,014 & 0,021 & 0,21 & 0,91 \\
M. Central & $\mathbf{0 , 1 3 2}$ & $\mathbf{0 , 0 6 2}$ & $\mathbf{0 , 1 5}$ & $\mathbf{0 , 0 1 8}$ \\
M. Transitória & $\mathbf{0 , 1 5}$ & $\mathbf{0 , 0 7}$ & $\mathbf{0 , 2 1}$ & $<\mathbf{0 , 0 0 0 1}$ \\
M. Intermed. & $\mathbf{0 , 0 4}$ & $\mathbf{0 , 0 2}$ & $\mathbf{0 , 0 9}$ & $\mathbf{0 , 0 0 4 2}$ \\
M. Efetora & $\mathbf{0 , 2 9}$ & $\mathbf{0 , 1 9}$ & $\mathbf{0 , 4 7}$ & $<\mathbf{0 , 0 0 0 1}$ \\
M. Term. Efetora & 0,49 & 0,25 & 0,57 & 0,14 \\
\hline
\end{tabular}

Figura e Tabela: Na análise da co-expressão de CD38+HLA DR vemos aumento da ativação na coorte de doença disseminada em comparação com doença localizada em todas as sub-populações, testadas com quase todas apresentando significância estatística pelo teste de Mann-Whitney bicaudal para significância estatística de $p<0,05$. 
Distribuição da Ativação por Co-expressão dentro dos imunofenótipos linfócito T CD4.

\section{CD38+ CCR5+}

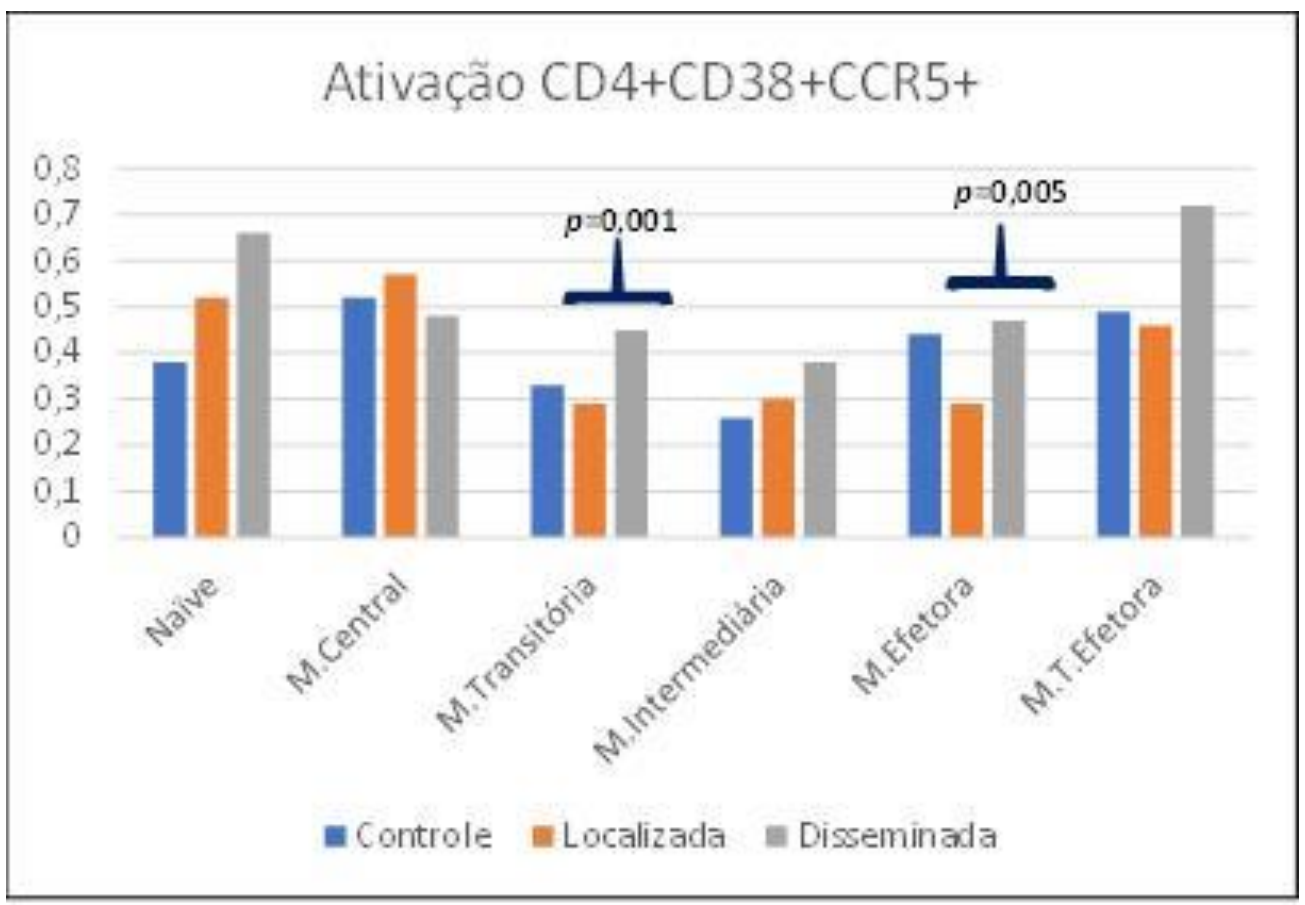

Figura: Na análise da co-expressão de CD38+ CCR5+ vemos aumento da ativação na coorte de doença disseminada em comparação com doença localizada em quase todas as sub-populações, testadas com quase todas apresentando significância estatística pelo teste de Mann-Whitney bicaudal para significância estatística de $p<0,05$.

\begin{tabular}{lcccc}
\hline & Controle & Localizada & Disseminada & $\begin{array}{c}\text { Valor } \boldsymbol{p} \text { entre local. e } \\
\text { disseminada }\end{array}$ \\
\hline Naive & 0,38 & 0,52 & 0,66 & 0,1 \\
M. Central & 0,52 & 0,57 & 0,48 & 0,67 \\
M. Transitória & $\mathbf{0 , 3 3}$ & $\mathbf{0 , 2 9}$ & $\mathbf{0 , 4 5}$ & $\mathbf{0 , 0 0 1}$ \\
M. Intermed. & $\mathbf{0 , 2 6}$ & $\mathbf{0 , 3}$ & $\mathbf{0 , 3 8}$ & $\mathbf{0 , 0 7 6}$ \\
M. Efetora & $\mathbf{0 , 4 4}$ & $\mathbf{0 , 2 9}$ & $\mathbf{0 , 4 7}$ & $\mathbf{0 , 0 0 5}$ \\
M. Term. Efetora & 0,49 & 0,46 & 0,72 & 0,39 \\
\hline
\end{tabular}

Figura : Dados numéricos mostrando a mesma tendência de aumento na ativação, nesta co-expressão de CD38+CCR5+, também analisados em relação às diferenças de medianas pelo teste U de MannWhitney. 


\section{Distribuição da Ativação por Co-expressão dentro dos imunofenótipos linfócito T CD4. \\ CD38+ CCR5+ HLA-DR+}

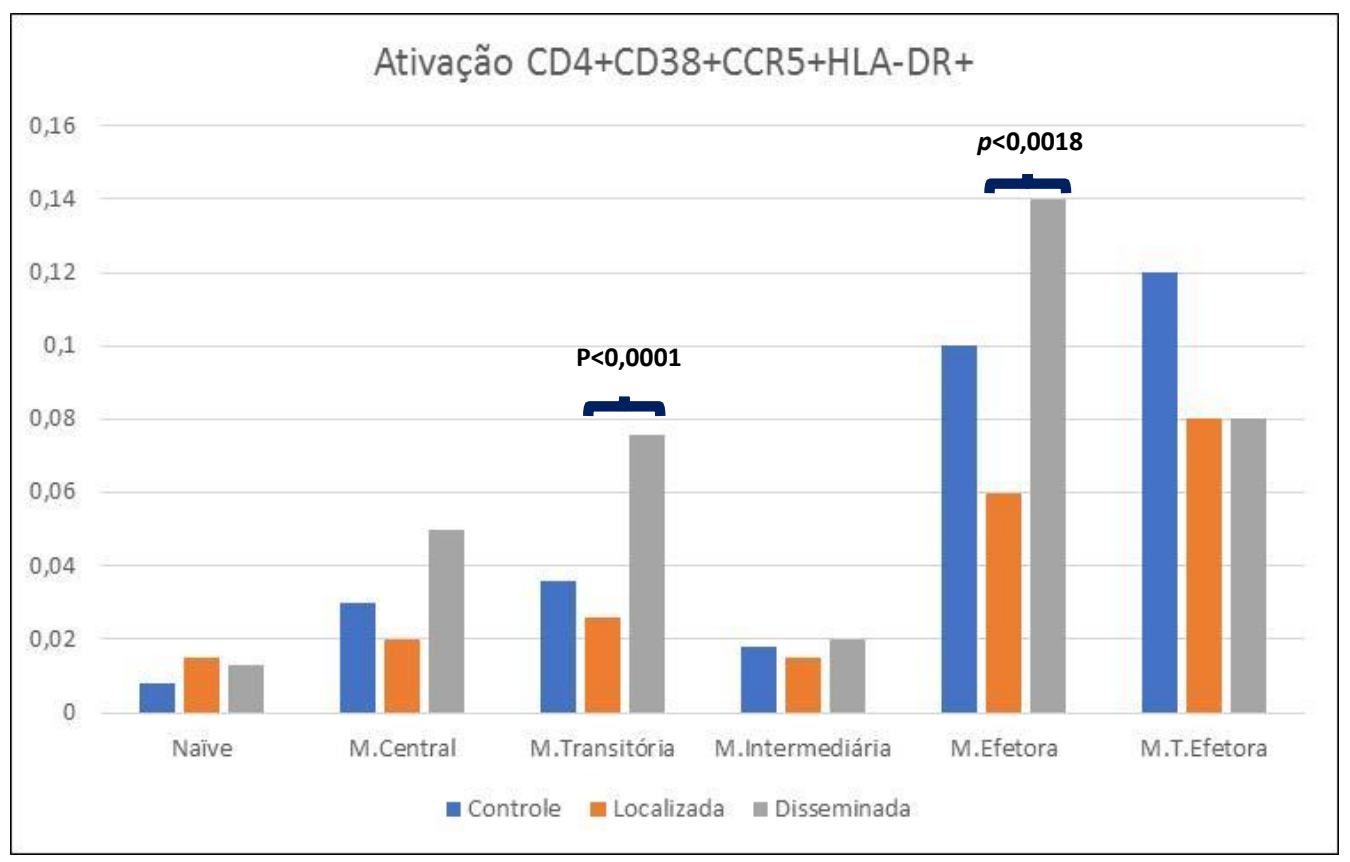

Figura e Tabela: Na análise da co-expressão de CD38+ CCR5+HLA-DR+ vemos aumento da ativação na coorte de doença disseminada em comparação com doença localizada em quase todas as sub-populações, testadas com quase todas apresentando significância estatística pelo teste de Mann-Whitney bicaudal para significância estatística de $p<0,05$.

\begin{tabular}{lcccc}
\hline & Controle & Localizada & Disseminada & $\begin{array}{c}\text { Valor } \boldsymbol{p} \text { entre local. e } \\
\text { disseminada }\end{array}$ \\
\hline Naive & 0,008 & 0,015 & 0,013 & 0,83 \\
M.Central & 0,03 & 0,02 & 0,05 & 0,2 \\
M.Transitória & 0,036 & 0,026 & 0,076 & $<0,0001$ \\
M.Intermed. & 0,018 & 0,015 & 0,02 & 0,06 \\
M.Efetora & 0,1 & 0,06 & 0,14 & 0,0018 \\
M.Term.Efetora & 0,12 & 0,08 & 0,08 & 0,97 \\
\hline
\end{tabular}

Figura e Tabela: Tanto a figura como a tabela mostram a mesma tendência de aumento na ativação, nesta co-expressão de CD38+CCR5+HLA-DR+, também analisados em relação às diferenças de medianas pelo teste U de Mann-Whitney. 
Distribuição da Senescência/Exaustão por co-expressão dos marcadores dentro dos imunofenótipos de linfócito T CD4

\begin{tabular}{lccccccccc}
\hline & $\begin{array}{l}\text { CD28/ } \\
\text { PD1 }\end{array}$ & $\begin{array}{l}\text { CD28/ } \\
\text { CD95 }\end{array}$ & $\begin{array}{l}\text { CD28/ } \\
\text { CD57 }\end{array}$ & $\begin{array}{l}\text { PD1/C } \\
\text { D57 }\end{array}$ & $\begin{array}{l}\text { PD1/C } \\
\text { D95 }\end{array}$ & $\begin{array}{l}\text { CD57/ } \\
\text { CD95 }\end{array}$ & $\begin{array}{l}\text { CD28/ } \\
\text { PD1/ } \\
\text { CD57 }\end{array}$ & $\begin{array}{l}\text { CD28/ } \\
\text { PD1/ } \\
\text { CD95 }\end{array}$ & $\begin{array}{l}\text { PD1/C } \\
\text { D57/ } \\
\text { CD95 }\end{array}$ \\
\hline Controle & 21,15 & 44,95 & 0,66 & 1,83 & 22,25 & 1,8 & 0,49 & 20,35 & 1,23 \\
Localizada & 22,8 & 53,2 & 0,92 & 1,34 & 22,2 & 1,38 & 0,69 & 21,2 & 1,01 \\
Valor $\boldsymbol{p}$ & 0,38 & 0,33 & 0,23 & 0,89 & 0,53 & 0,65 & 0,28 & 0,45 & 0,74 \\
& & & & & & & & & \\
Controle & 21,15 & 44,95 & 0,66 & 1,83 & 22,25 & 1,8 & 0,49 & 20,35 & 1,23 \\
Disseminada & 24,35 & 56,4 & 1,32 & 3,32 & 28,85 & 2,88 & 0,95 & 23 & 2,06 \\
Valor $\boldsymbol{p}$ & 0,32 & 0,26 & 0,038 & 0,02 & 0,09 & 0,008 & 0,09 & 0,27 & 0,01 \\
& & & & & & & & & \\
Localizada & 22,8 & 53,2 & 0,92 & $\mathbf{1 , 3 4}$ & 22,2 & $\mathbf{1 , 3 8}$ & 0,69 & 21,2 & $\mathbf{1 , 0 1}$ \\
Disseminada & 24,35 & 56,4 & 1,32 & $\mathbf{3 , 3 2}$ & 28,85 & $\mathbf{2 , 8 8}$ & 0,95 & 23 & $\mathbf{2 , 0 6}$ \\
Valor $\boldsymbol{p}$ & 0,48 & 0,43 & 0,05 & $\mathbf{0 , 0 0 5 1}$ & 0,07 & $\mathbf{0 , 0 0 3 2}$ & 0,11 & 0,42 & $\mathbf{0 , 0 0 3 2}$ \\
\hline
\end{tabular}


Distribuição do perfil de Senescência e Exaustão por co-expressão de marcadores dentro dos imunofenótipos de Linfócito T CD4

PD1+CD57+

Gráfico

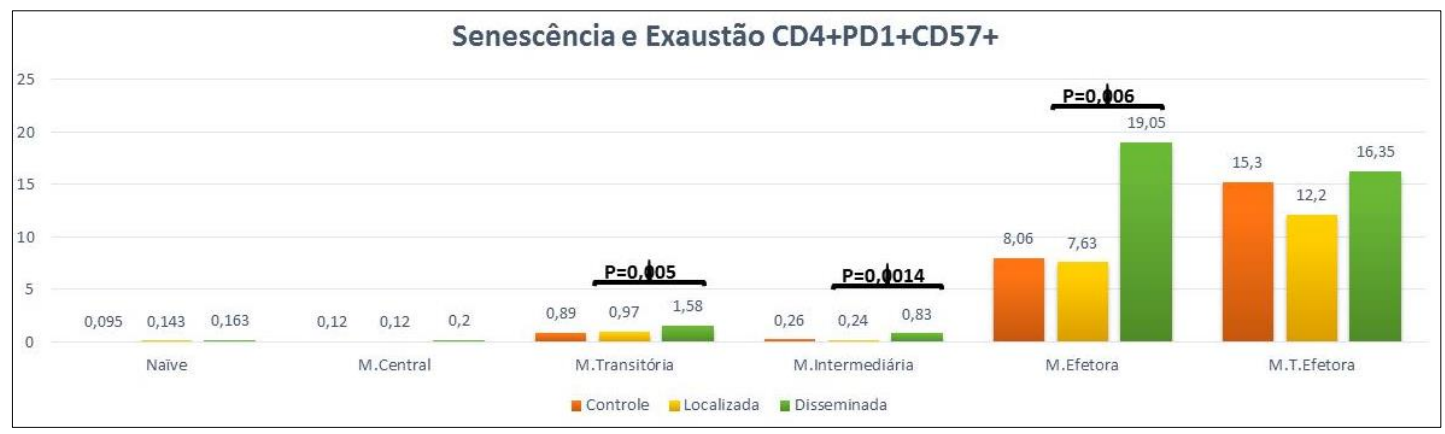

\begin{tabular}{lcccc}
\hline & Controle & Localizada & Disseminada & $\begin{array}{c}\text { Valor } \boldsymbol{p} \text { entre local. } \\
\text { disseminada }\end{array}$ \\
\hline Naive & 0,095 & 0,143 & 0,163 & 0,19 \\
M. Central & 0,12 & 0,12 & 0,2 & 0,059 \\
M. Transitória & $\mathbf{0 , 8 9}$ & $\mathbf{0 , 9 7}$ & $\mathbf{1 , 5 8}$ & $\mathbf{0 , 0 0 5}$ \\
M. Intermed. & $\mathbf{0 , 2 6}$ & $\mathbf{0 , 2 4}$ & $\mathbf{0 , 8 3}$ & $\mathbf{0 , 0 0 1 4}$ \\
M. Efetora & $\mathbf{8 , 0 6}$ & $\mathbf{7 , 6 3}$ & $\mathbf{1 9 , 0 5}$ & $\mathbf{0 , 0 0 6}$ \\
M. Term. Efetora & 15,3 & 12,2 & 16,35 & 0,2 \\
\hline
\end{tabular}

Gráfico e Tabela: Na análise dos resultados na comparação das medianas para esta co-expressão de PD1+CD57, confirma-se a tendência de maior porcentagem na coorte de doença disseminada e neste caso as sub-populações que trazem significância estatística são os fenótipos de Memória Transitória, Memória Efetora e Memória Terminal Efetora. Mann-Whitney U test bi-caudal para significância de $p<0,05$. 
Distribuição do perfil de Senescência e Exaustão por co-expressão de marcadores dentro dos imunofenótipos de Linfócito T CD4

\section{CD95+CD57+}

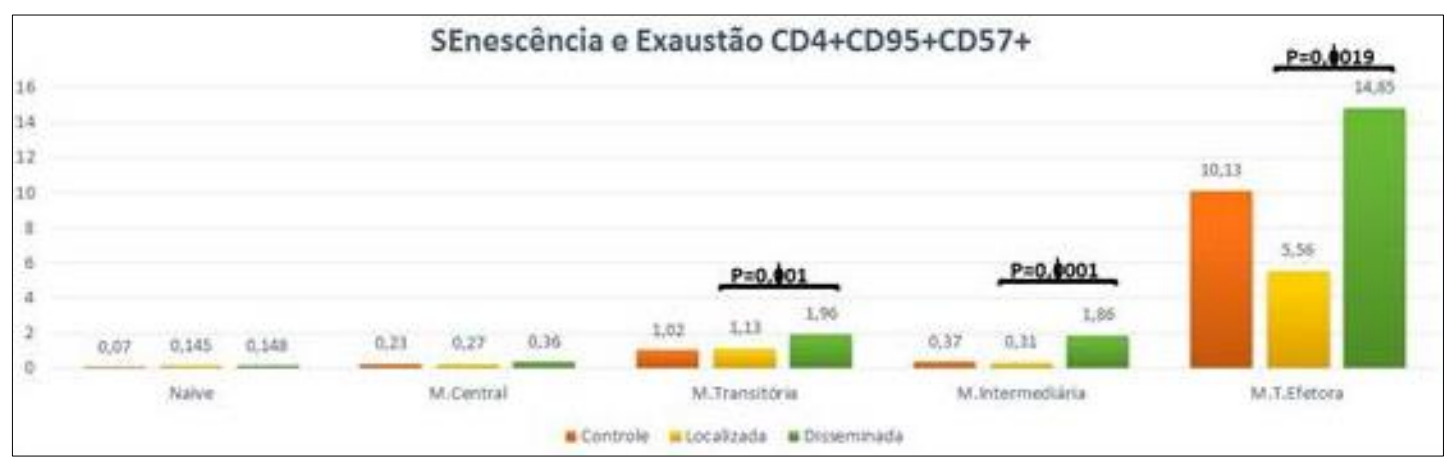

\begin{tabular}{lcccc}
\hline & Controle & Localizada & Disseminada & $\begin{array}{c}\text { Valor } \boldsymbol{p} \text { entre local. e } \\
\text { disseminada }\end{array}$ \\
\hline Naive & 0,07 & 0,145 & 0,148 & 0,28 \\
M.Central & 0,23 & 0,27 & 0,36 & 0,16 \\
M.Transitória & $\mathbf{1 , 0 2}$ & $\mathbf{1 , 1 3}$ & $\mathbf{1 , 9 6}$ & $\mathbf{0 , 0 0 1}$ \\
M.Intermed. & $\mathbf{0 , 3 7}$ & $\mathbf{0 , 3 1}$ & $\mathbf{1 , 8 6}$ & $\mathbf{0 , 0 0 0 1}$ \\
M.Term.Efetora & $\mathbf{1 0 , 1 3}$ & $\mathbf{5 , 5 6}$ & $\mathbf{1 4 , 8 5}$ & $\mathbf{0 , 0 0 1 9}$ \\
\hline
\end{tabular}

Gráfico e Tabela: Na análise dos resultados na comparação das medianas para esta co-expressão de CD95+CD57, confirma-se a tendência de maior porcentagem na coorte de doença disseminada e neste caso as sub-populações que trazem significância estatística são os fenótipos de Memória Transitória, Memória Efetora e Memória Terminal Efetora. Mann-Whitney U test bi-caudal para significância de $p<0,05$. 
Distribuição do perfil de Senescência e Exaustão por co-expressão de marcadores dentro dos imunofenótipos de Linfócito T CD4

\section{PD1+CD57+CD95+}

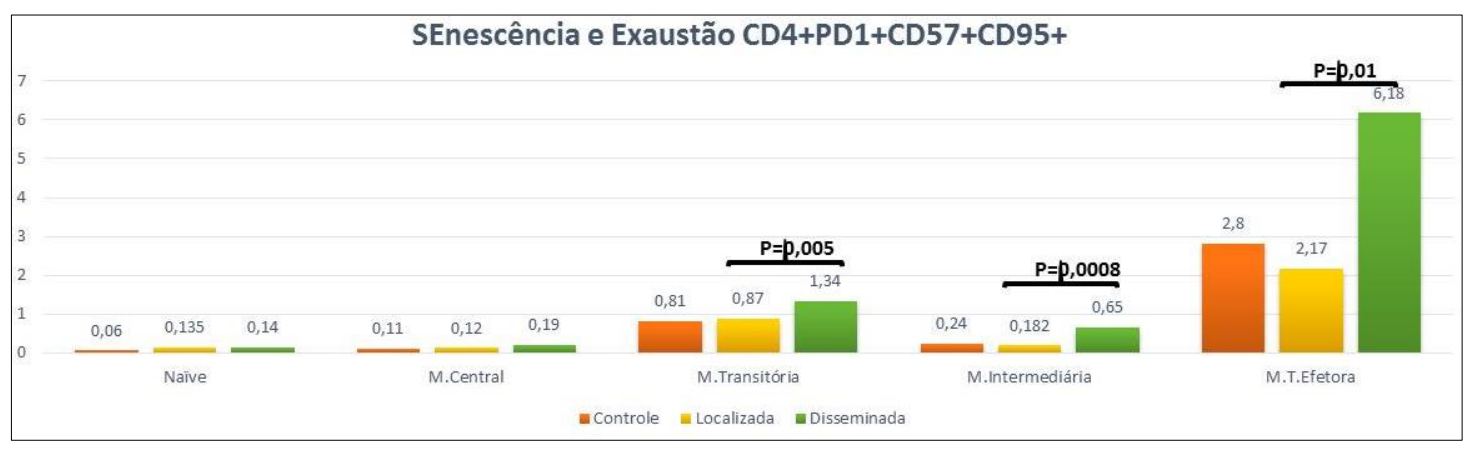

Tabela

\begin{tabular}{lcccc}
\hline & Controle & Localizada & Disseminada & $\begin{array}{c}\text { Valor } \boldsymbol{p} \text { entre local. } \\
\text { disseminada }\end{array}$ \\
\hline Naive & 0,06 & 0,135 & 0,14 & 0,26 \\
M.Central & 0,11 & 0,12 & 0,19 & 0,05 \\
M.Transitória & $\mathbf{0 , 8 1}$ & $\mathbf{0 , 8 7}$ & $\mathbf{1 , 3 4}$ & $\mathbf{0 , 0 0 5}$ \\
M.Intermed. & $\mathbf{0 , 2 4}$ & $\mathbf{0 , 1 8 2}$ & $\mathbf{0 , 6 5}$ & $\mathbf{0 , 0 0 0 8}$ \\
\hline
\end{tabular}

Gráfico e Tabela: Na análise dos resultados na comparação das medianas para esta co-expressão de PD1+CD57+CD95, confirma-se a tendência de maior porcentagem na coorte de doença disseminada e neste caso as sub-populações que trazem significância estatística são os fenótipos de Memória Transitória. Mann-Whitney $\mathrm{U}$ test bi-caudal para significância de $p<0,05$. 


\section{APÊNDICE DE LINFÓCITOS T CD8}

\section{Ativação de CD8 para marcadores individuais}

\section{CCR5+}

Gráfico

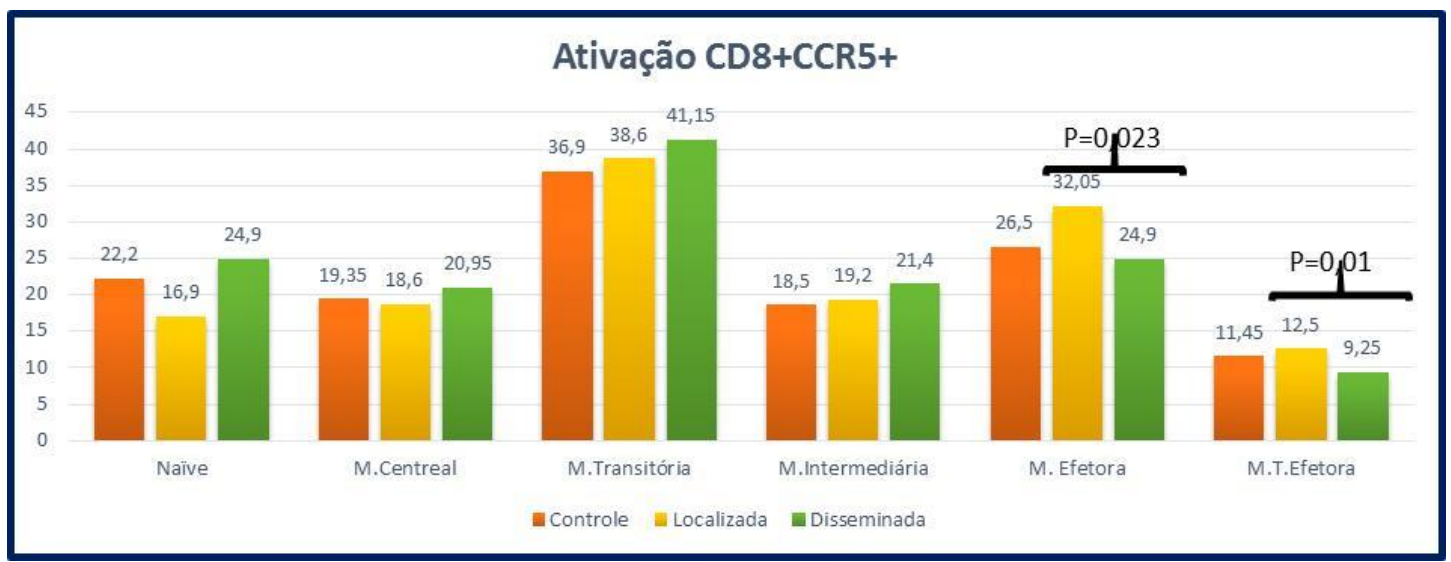

Tabela:

\begin{tabular}{lcccc}
\hline \multicolumn{1}{c}{ CCR5 } & Controle & Localizada & Disseminada & $\begin{array}{c}\text { Valor } \boldsymbol{p} \text { entre local. } \mathbf{e} \\
\text { disseminada }\end{array}$ \\
\hline Naive & 22,2 & 16,9 & 24,9 & 0,06 \\
M. Central & 19,3 & 18,6 & 20,9 & 0,87 \\
M. Transitória & 36,9 & 38,6 & 41,1 & 0,31 \\
M. Intermed. & 18,5 & 19,2 & 21,4 & 0,37 \\
M. Efetora & $\mathbf{2 6 , 5}$ & $\mathbf{3 2 , 0}$ & $\mathbf{2 4 , 9}$ & $\mathbf{0 , 0 2 3}$ \\
M. Term .Efetora & $\mathbf{1 1 , 4}$ & $\mathbf{1 2 , 5}$ & $\mathbf{9 , 2 5}$ & $\mathbf{0 , 0 1}$ \\
\hline
\end{tabular}

Gráfico e Tabela: Mesmo sem atingir significância estatística na seleção isolada de CCR5, existe uma distribuição estatisticamente significativa que no caso mostra maior porcentagem de fenótipo CCR5 isolado na coorte de doença localizada. Mann-Whitney U test bicaudal para $p<0,05$ 


\section{Ativação de CD8 para marcadores individuais}

\section{HLA-DR+}

\section{Gráfico}

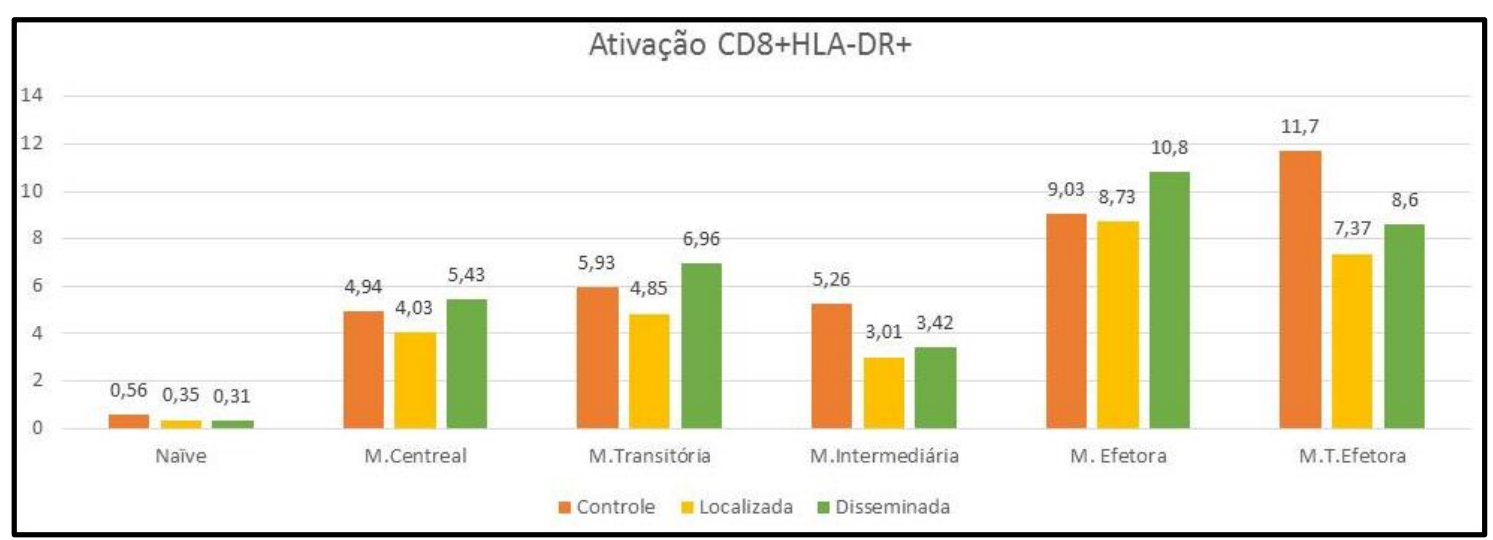

Tabela:

\begin{tabular}{lcccc}
\hline \multicolumn{1}{c}{ HLA-DR } & Controle & Localizada & Disseminada & $\begin{array}{c}\text { Valor } \boldsymbol{p} \text { entre local. e } \\
\text { disseminada }\end{array}$ \\
\hline Naive & 0,5 & 0,35 & 0,3 & 0,74 \\
M. Central & 4,9 & 4,0 & 5,4 & 0,56 \\
M. Transitória & 5,9 & 4,8 & 6,9 & 0,14 \\
M. Intermed. & 5,2 & 3,0 & 3,4 & 0,34 \\
M. Efetora & 9,0 & 8,7 & 10,8 & 0,16 \\
M. Term. Efetora & 11,7 & 7,3 & 8,6 & 0,53 \\
\hline
\end{tabular}

Gráfico e Tabela. Tendência ao aumento da porcentagem de linfócitos T CD8 selecionados para HLA DR, sem significância estatística. Mann-Whitney U test bicaudal para $p<0,05$ 
A ativação linfocitária dos linfócitos T CD8 selecionados para co-expressão dos marcadores de ativação mantém a mesma característica de aumento da ativação na coorte de doença disseminada

\begin{tabular}{lccc}
\hline & CD38+HLA-DR+ & CD38+CCR5+ & $\begin{array}{c}\text { CD38+CCR5+HLA- } \\
\text { DR+ }\end{array}$ \\
\hline Controle & 0,67 & 0,59 & 0,29 \\
Localizada & 0,63 & 0,60 & 0,27 \\
Valor $\boldsymbol{p}$ & 0,44 & 0,92 & 0,87 \\
& & & \\
Controle & $\mathbf{0 , 6 7}$ & $\mathbf{0 , 5 9}$ & $\mathbf{0 , 2 9}$ \\
Disseminada & $\mathbf{1 , 4 5}$ & $\mathbf{1 , 3 5}$ & $\mathbf{0 , 6 1}$ \\
Valor $\boldsymbol{p}$ & $\mathbf{0 , 0 3 5}$ & $\mathbf{0 , 0 0 4 6}$ & $\mathbf{0 , 0 1}$ \\
& & & \\
Localizada & $\mathbf{0 , 6 3}$ & $\mathbf{0 , 6 0}$ & $\mathbf{0 , 2 7}$ \\
Disseminada & $\mathbf{1 , 4 5}$ & $\mathbf{1 , 3 5}$ & $\mathbf{0 , 6 1}$ \\
Valor $\boldsymbol{p}$ & $\mathbf{0 , 0 0 0 3}$ & $\mathbf{0 , 0 0 0 2}$ & $\mathbf{0 , 0 0 1}$ \\
\hline
\end{tabular}

Tabela: Comparação das medianas das porcentagens nas coortes, em relação às diferentes coexpressões dos marcadores. Mann-Whitney U test, bicaudal, para significância de $p<0,05$. 
Distribuição da ativação linfocitária dentro das sub-populações para coexpressão de CD38+HLA DR+ mantém o mesmo padrão de maior ativação na doença disseminada

Gráfico: Comparação de medianas de porcentagem de linfócitos T CD8+ com coexpressão de CD38 e HLA-DR distribuídos nas diferentes sub-populações linfocitárias.

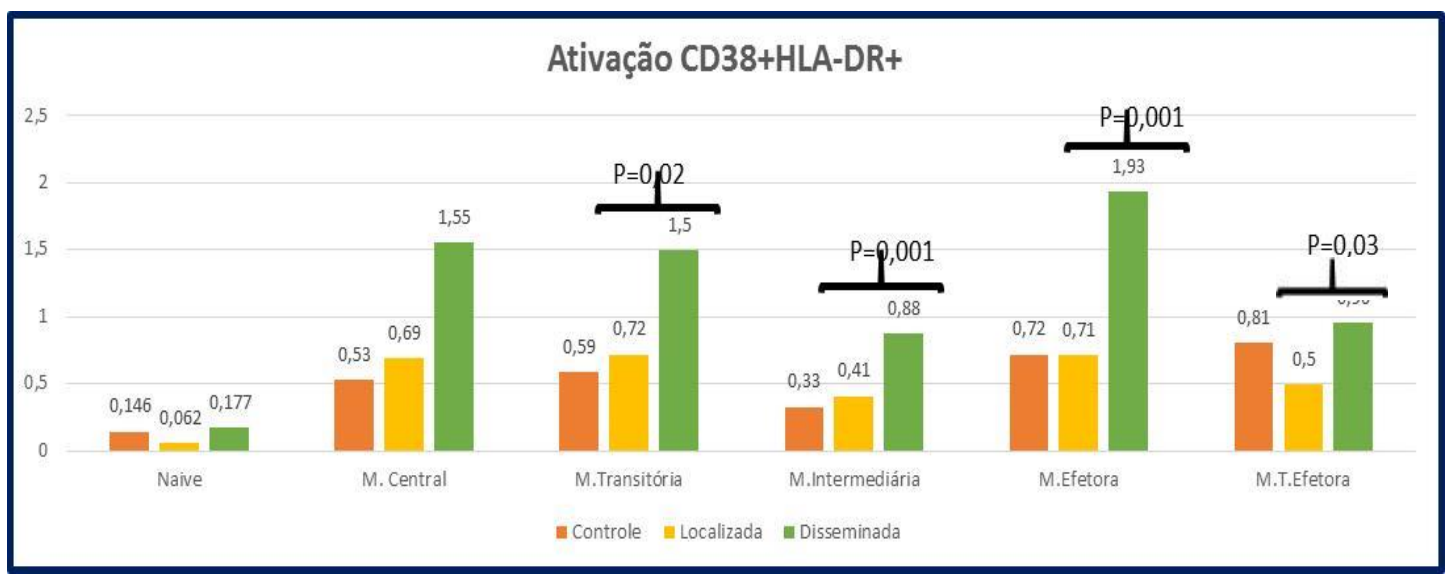

Tabela: Comparação de medianas de porcentagem de linfócitos T CD8+ com coexpressão de CD38 e HLA-DR distribuídos nas diferentes sub-populações linfocitárias.

\begin{tabular}{lcccc}
\hline CD38+HLA-DR+ & Controle & Localizada & Disseminada & $\begin{array}{c}\text { Valor } \boldsymbol{p} \text { entre local. e } \\
\text { disseminada }\end{array}$ \\
\hline Naive & $\mathbf{0 , 1 4}$ & $\mathbf{0 , 0 6 2}$ & $\mathbf{0 , 1 7}$ & $\mathbf{0 , 0 0 6}$ \\
M. Central & 0,53 & 0,69 & 1,55 & 0,10 \\
M. Transitória & $\mathbf{0 , 5 9}$ & $\mathbf{0 , 7 2}$ & $\mathbf{1 , 5}$ & $\mathbf{0 , 0 2}$ \\
M. Intermed. & $\mathbf{0 , 3 3}$ & $\mathbf{0 , 4 1}$ & $\mathbf{0 , 8 8}$ & $\mathbf{0 , 0 1}$ \\
M. Efetora & $\mathbf{0 , 7 2}$ & $\mathbf{0 , 7 1}$ & $\mathbf{1 , 9 3}$ & $\mathbf{0 , 0 0 1}$ \\
M. Term. Efetora & $\mathbf{0 , 8 1}$ & $\mathbf{0 , 5 0}$ & $\mathbf{0 , 9 6}$ & $\mathbf{0 , 0 3}$ \\
\hline
\end{tabular}

Gráfico e Tabela: Comparação das medianas das porcentagens nas coortes, em relação à coexpressão de CD38+HLA DR mostra maior porcentagem na coorte de doença disseminada, ainda que sejam uma proporção relativamente pequenas de células. Mann-Whitney U test, bicaudal, para significância de $p<0,05$. 
Distribuição da ativação linfocitária dentro das sub-populações para coexpressão de CD38+CCR5+ mantém o mesmo padrão de maior ativação na doença disseminada.

Gráfico:

\section{CD38+CCR5+}

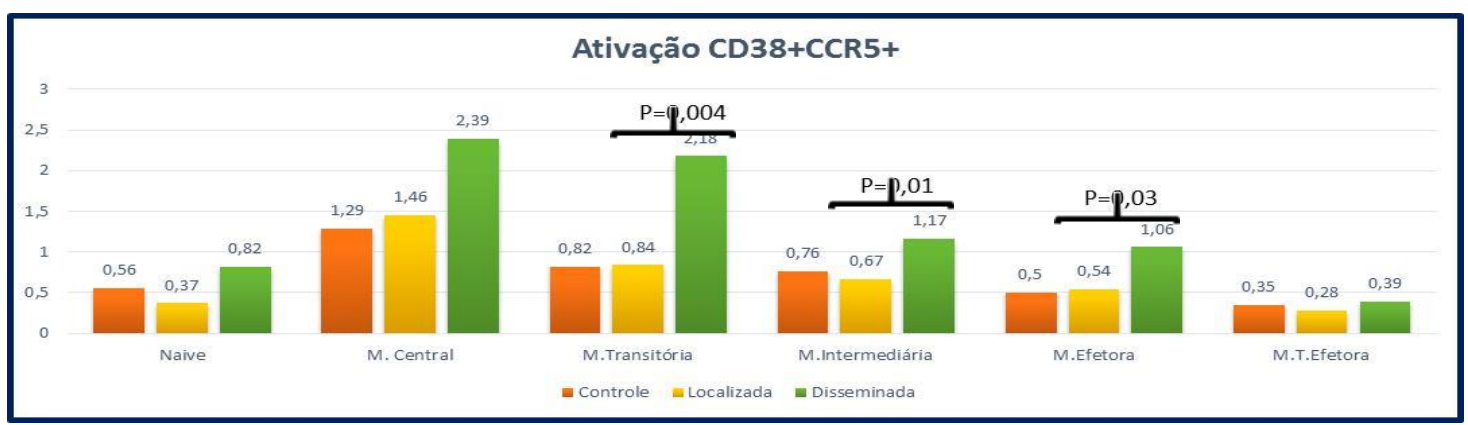

Tabela:

\begin{tabular}{lcccc}
\hline CD38+CCR5+ & Controle & Localizada & Disseminada & $\begin{array}{c}\text { Valor } \boldsymbol{p} \text { entre local. e } \\
\text { disseminada }\end{array}$ \\
\hline Naive & - & - & - & - \\
M. Central & 1,29 & 1,46 & 2,39 & 0,55 \\
M. Transitória & $\mathbf{0 , 8 2}$ & $\mathbf{0 , 8 4}$ & $\mathbf{2 , 1 8}$ & $\mathbf{0 , 0 0 4}$ \\
M. Intermed. & $\mathbf{0 , 7 6}$ & $\mathbf{0 , 6 7}$ & $\mathbf{1 , 1 7}$ & $\mathbf{0 , 0 1}$ \\
M. Efetora & $\mathbf{0 , 5 0}$ & $\mathbf{0 , 5 4}$ & $\mathbf{1 , 0 6}$ & $\mathbf{0 , 0 3}$ \\
M. Term. Efetora & 0,35 & 0,28 & 0,39 & 0,24 \\
\hline
\end{tabular}

Gráfico e Tabela: Comparação das medianas das porcentagens nas coortes, em relação à coexpressão de CD38+CCR5 mostra também maior porcentagem na coorte de doença disseminada, ainda que sejam uma proporção relativamente pequenas de células. Mann-Whitney U test, bicaudal, para significância de $p<0,05$. 
F- Distribuição da ativação linfocitária dentro das sub-populações para coexpressão de CD38+CCR5+HLA DR mantém o mesmo padrão de maior ativação na doença disseminada.

\section{CD38+CCR5+HLD-DR+}

\section{Gráfico:}

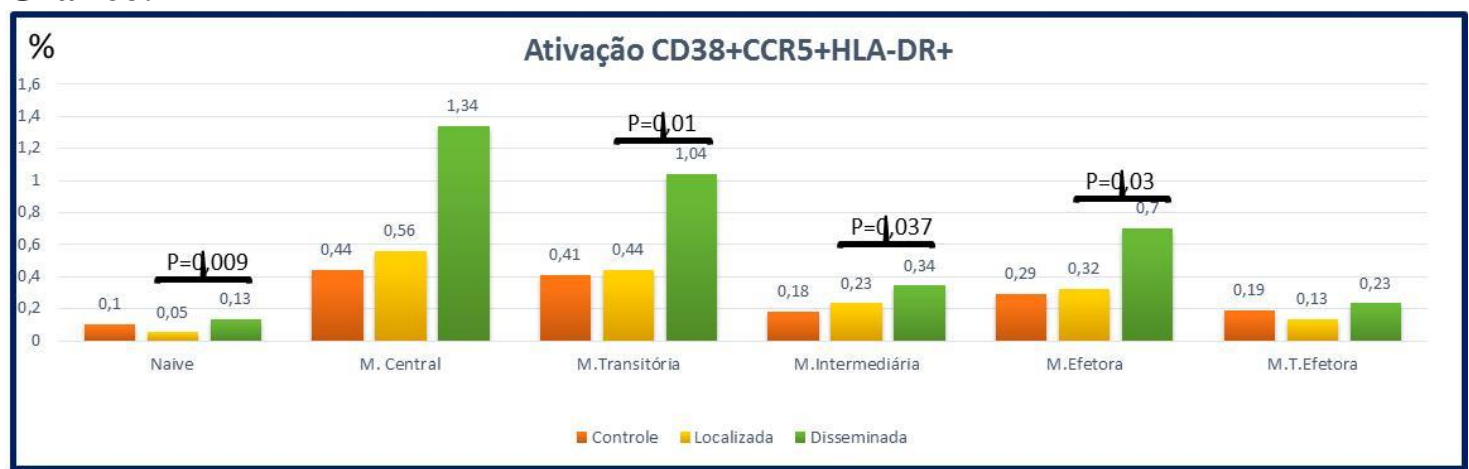

Tabela:

\begin{tabular}{lcccc}
\hline CD38+CCR5+HLA-DR+ & Controle & Localizada & Disseminada & $\begin{array}{c}\text { Valor } \boldsymbol{p} \text { entre local. e } \\
\text { disseminada }\end{array}$ \\
\hline Naive & $\mathbf{0 , 1 0}$ & $\mathbf{0 , 0 5}$ & $\mathbf{0 , 1 3}$ & $\mathbf{0 , 0 0 9}$ \\
M. Central & 0,44 & 0,56 & 1,34 & 0,08 \\
M. Transitória & $\mathbf{0 , 4 1}$ & $\mathbf{0 , 4 4}$ & $\mathbf{1 , 0 4}$ & $\mathbf{0 , 0 1}$ \\
M. Intermed. & $\mathbf{0 , 1 8}$ & $\mathbf{0 , 2 3}$ & $\mathbf{0 , 3 4}$ & $\mathbf{0 , 0 3 7}$ \\
M. Efetora & $\mathbf{0 , 2 9}$ & $\mathbf{0 , 3 2}$ & $\mathbf{0 , 7 0}$ & $\mathbf{0 , 0 3}$ \\
M. Term. Efetora & 0,19 & 0,13 & 0,23 & 0,32 \\
\hline
\end{tabular}

Gráfico e Tabela: Comparação das medianas das porcentagens nas coortes, em relação à coexpressão de CD38+CCR5+HLA-DRmostra também maior porcentagem na coorte de doença disseminada, ainda que sejam uma proporção relativamente pequenas de células. Mann-Whitney U test, bicaudal, para significância de $p<0,05$. 
Distribuição dos marcadores de senescência e exaustão dos linfócitos T CD8+ dentro dos imunofenótipos. Análise por marcador individual.

\section{Gráfico:}

\section{CD28+}

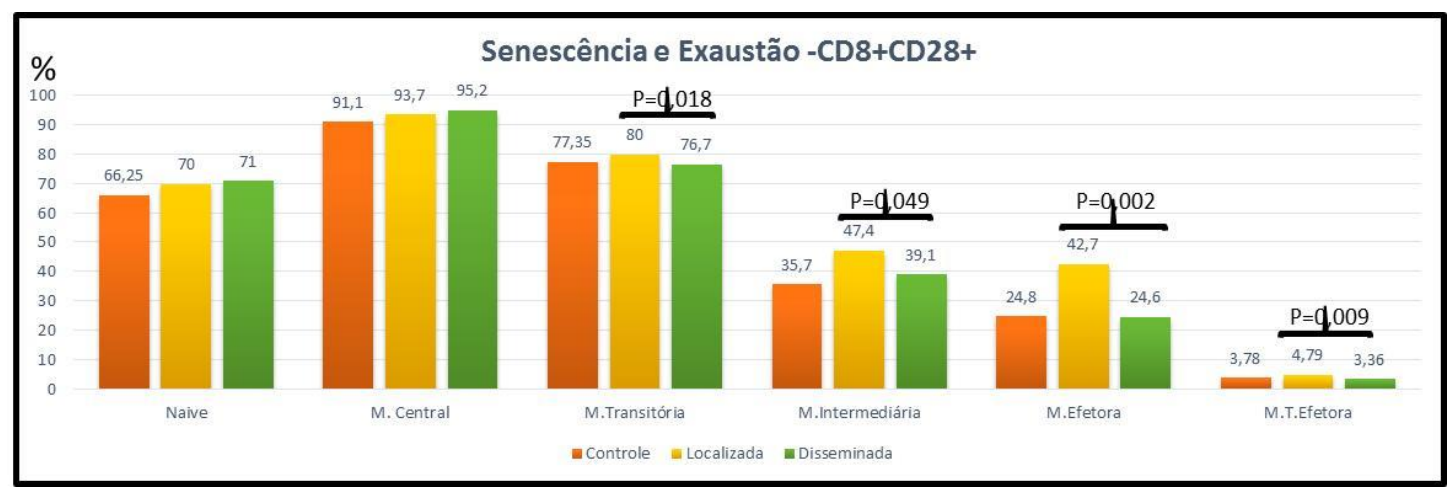

Tabela:

\begin{tabular}{lcccc}
\hline \multicolumn{1}{c}{ CD28+ } & Controle & Localizada & Disseminada & $\begin{array}{c}\text { Valor } \boldsymbol{p} \text { entre local. } \\
\text { disseminada }\end{array}$ \\
\hline Naive & 66,2 & 70,0 & 71 & 0,69 \\
M. Central & 91,1 & 93,7 & 95,2 & 0,35 \\
M. Transitória & $\mathbf{7 7 , 3}$ & $\mathbf{8 0 , 0}$ & $\mathbf{7 6 , 7}$ & $\mathbf{0 , 0 1 8}$ \\
M. Intermed. & $\mathbf{3 5 , 7}$ & $\mathbf{4 7 , 4}$ & $\mathbf{3 9 , 1}$ & $\mathbf{0 , 0 4 9}$ \\
M. Efetora & $\mathbf{2 4 , 8}$ & $\mathbf{4 2 , 7}$ & $\mathbf{2 4 , 6}$ & $\mathbf{0 , 0 0 2}$ \\
M. Term. Efetora & $\mathbf{3 , 7}$ & $\mathbf{4 , 7 9}$ & $\mathbf{3 , 3 6}$ & $\mathbf{0 , 0 0 9}$ \\
\hline
\end{tabular}

Gráfico e Tabela: Os dados mostram que na comparação das medianas há evidência de maiores índices de senescência e exaustão para a coorte de doença localizada quando analisados de acordo com a ontogenia linfocitária. Mann-Whitney U test, com significância parap $<0,05$. 
Distribuição dos marcadores de senescência e exaustão dos linfócitos T CD8+ dentro dos imunofenótipos. Análise por marcador individual.

\section{CD57+}

\section{Gráfico:}

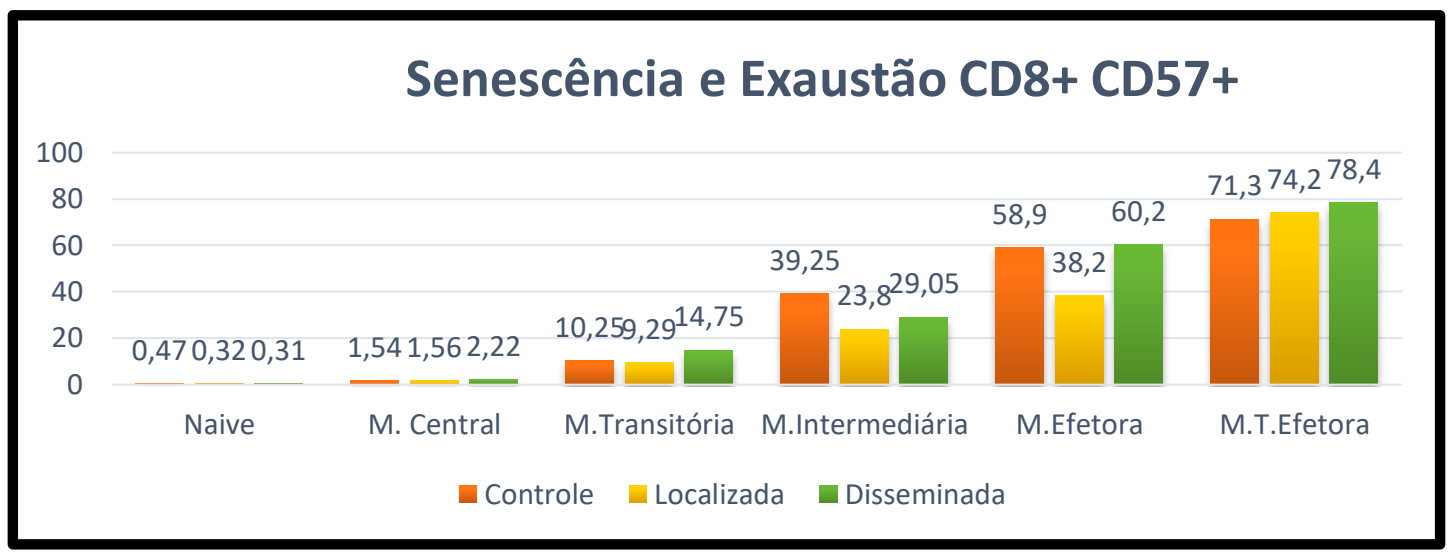

Tabela:

\begin{tabular}{lcccc}
\hline \multicolumn{1}{c}{ CD57+ } & Controle & Localizada & Disseminada & $\begin{array}{c}\text { Valor } \boldsymbol{p} \text { entre local. e } \\
\text { disseminada }\end{array}$ \\
\hline Naive & 0,47 & 0,32 & 0,31 & 0,99 \\
M. Central & 1,54 & 1,56 & 2,22 & 0,31 \\
M. Transitória & $\mathbf{1 0 , 2 5}$ & $\mathbf{9 , 2 9}$ & $\mathbf{1 4 , 7 5}$ & $\mathbf{0 , 0 0 9}$ \\
M. Intermed. & 39,25 & 23,8 & 29,05 & 0,20 \\
M. Efetora & $\mathbf{5 8 , 9 0}$ & $\mathbf{3 8 , 2}$ & $\mathbf{6 0 , 2 0}$ & $\mathbf{0 , 0 2}$ \\
M. Term. Efetora & 71,30 & 74,2 & 78,40 & 0,13 \\
\hline
\end{tabular}

Gráfico e Tabela: Os dados mostram que na comparação das medianas há evidência de maiores índices de senescência e exaustão para a coorte de doença disseminada quando analisados de acordo com a ontogenia linfocitária, privilegiando as células e Memória Transitória e de memória Efetora . Mann-Whitney U test, com significância para $p<0,05$. 
Distribuição dos marcadores de senescência e exaustão dos linfócitos T CD8+ dentro dos imunofenótipos. Análise por marcador individual.

\section{PD1}

\section{Gráfico:}

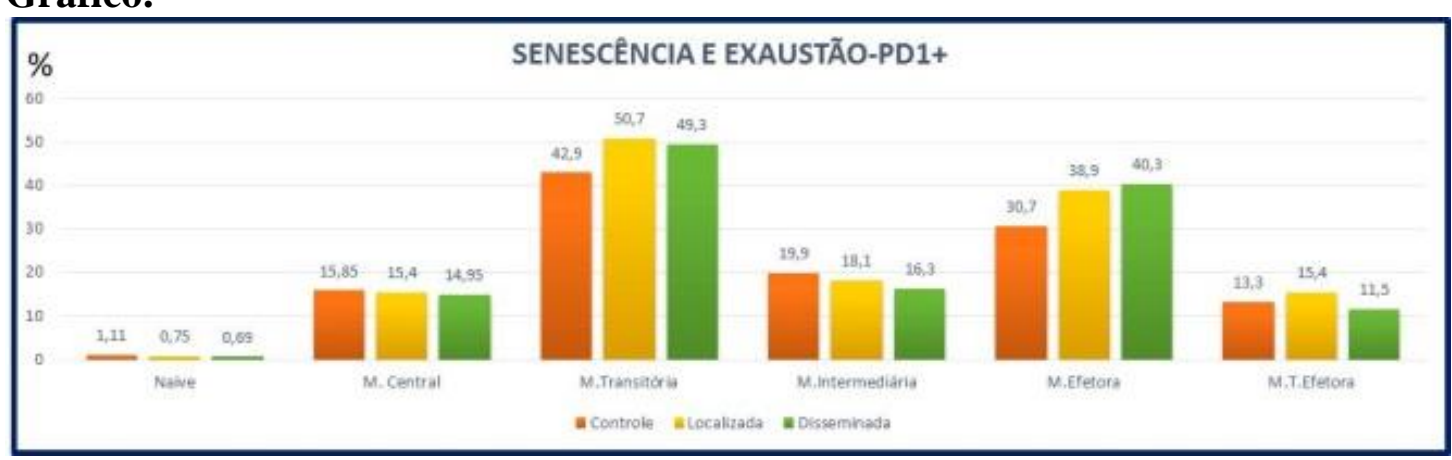

Tabela:

\begin{tabular}{lcccc}
\hline \multicolumn{1}{c}{ PD1+ } & Controle & Localizada & Disseminada & $\begin{array}{c}\text { Valor } \boldsymbol{p} \text { entre local. } \mathbf{c} \\
\text { disseminada }\end{array}$ \\
\hline Naive & 1,11 & 0,75 & 0,69 & 0,72 \\
M.Central & 15,85 & 15,40 & 14,95 & 0,92 \\
M.Transitória & 42,90 & 50,70 & 49,30 & 0,98 \\
M.Intermed. & 19,90 & 18,10 & 16,30 & 0,59 \\
M.Efetora & 30,70 & 38,90 & 40,30 & 0,56 \\
M.Term.Efetora & 13,30 & 15,40 & 11,50 & 0,58 \\
\hline
\end{tabular}

Gráfico e Tabela: Os dados mostram que na comparação das medianas não há evidência de diferenças de senescência e exaustão em nenhuma das sub-populações linfocitárias. Mann-Whitney U test, com significância para $p<0,05$. 
Distribuição da Senescência/Exaustão por co-expressão de marcadores na população total de CD8

\section{CD28+CD95}

\section{Gráfico:}

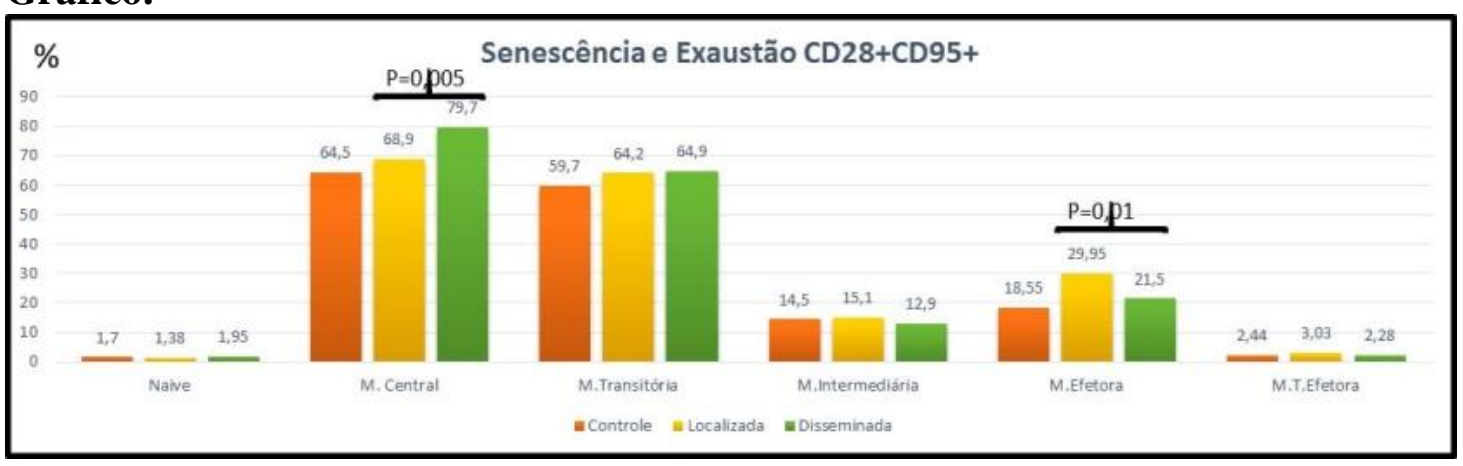

Tabela:

\begin{tabular}{lcccc}
\hline CD28+CD95+ & Controle & Localizada & Disseminada & $\begin{array}{c}\text { Valor } \boldsymbol{p} \text { entre local. e } \\
\text { disseminada }\end{array}$ \\
\hline Naive & 1,7 & 2,38 & 1,95 & 0,05 \\
M.Central & $\mathbf{6 4 , 5 0}$ & $\mathbf{6 8 , 9 0}$ & $\mathbf{7 9 , 7 0}$ & $\mathbf{0 , 0 0 5}$ \\
M.Transitória & 59,70 & 64,20 & 64,90 & 0,42 \\
M.Intermed. & 14,50 & 15,10 & 12,90 & 0,86 \\
M.Efetora & $\mathbf{1 8 , 5 5}$ & $\mathbf{2 9 , 9 5}$ & $\mathbf{2 1 , 5 0}$ & $\mathbf{0 , 0 1}$ \\
M.Term.Efetora & 2,44 & 3,03 & 2,28 & 0,15 \\
\hline
\end{tabular}

Gráfico e Tabela: Os dados mostram que na comparação das medianas há evidência de maiores índices de senescência e exaustão para a coorte de doença localizada na maioria das sub-populações linfocitárias, embora na sub-população de células e memória central há maior porcentagem deste imunofenótipo na coorte de Doença Disseminada. Mann-Whitney U test, com significância para $p<$ 0,05 . 
Distribuição da Senescência/Exaustão por co-expressão de marcadores na população total de CD8

\section{CD28+ PD1+.}

Gráfico:

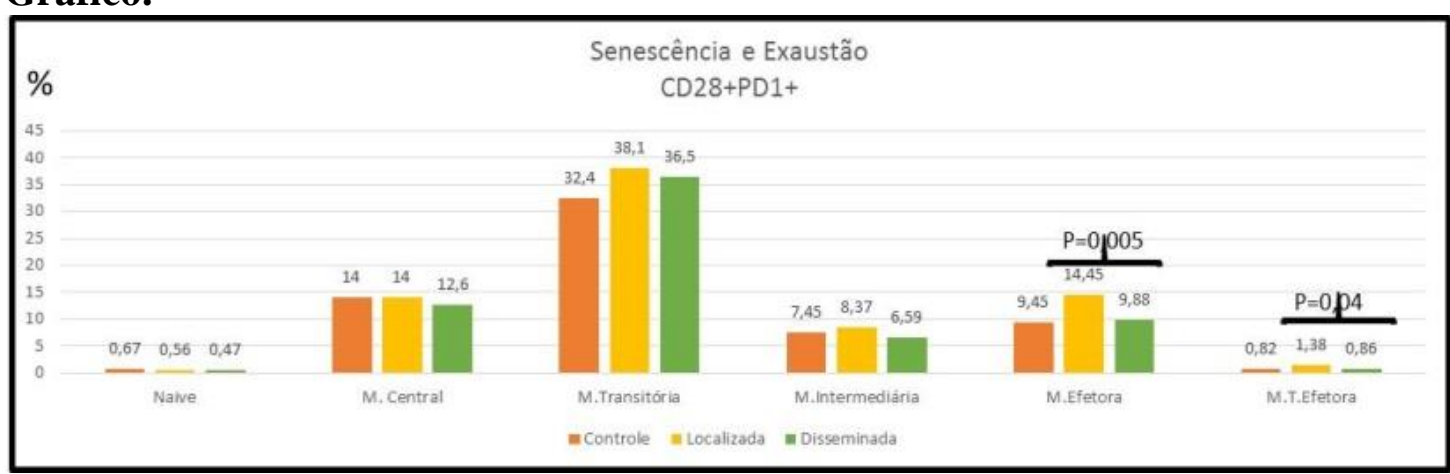

Tabela:

\begin{tabular}{lcccc}
\hline CD28+PD1+ & Controle & Localizada & Disseminada & $\begin{array}{c}\text { Valor } \boldsymbol{p} \text { entre local. e } \\
\text { disseminada }\end{array}$ \\
\hline Naive & 0,67 & 0,56 & 0,47 & 0,52 \\
M. Central & 14 & 14 & 12,6 & 0,78 \\
M. Transitória & 32,40 & 38,10 & 36,50 & 0,17 \\
M. Intermed. & 7,45 & 8,37 & 6,59 & 0,26 \\
M. Efetora & $\mathbf{9 , 4 5}$ & $\mathbf{1 4 , 4 5}$ & $\mathbf{9 , 8 8}$ & $\mathbf{0 , 0 0 5}$ \\
M. Term. Efetora & 0,82 & 1,38 & 0,86 & 0,04 \\
\hline
\end{tabular}

Gráfico e Tabela: Os dados mostram que na comparação das medianas há evidência de maiores índices de senescência e exaustão para a coorte de doença localizada na maioria das sub-populações linfocitárias, com significância estatística apenas na sub-população de Memória Efetora. MannWhitney U test, com significância para $p<0,05$. 
Distribuição da Senescência/Exaustão por co-expressão de marcadores na população total de CD8

\section{CD28+ CD57.}

\section{Gráfico:}

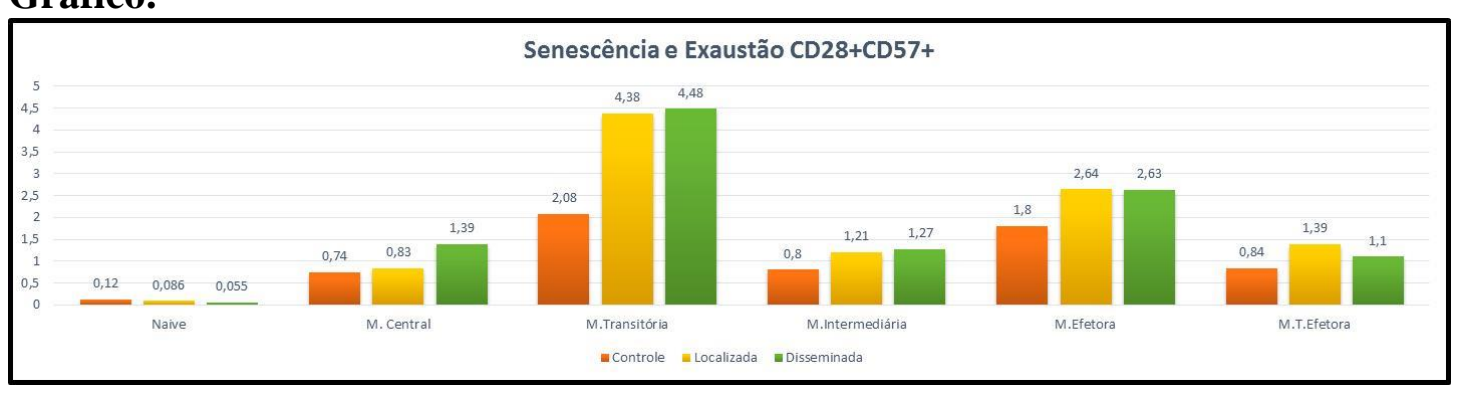

Tabela:

\begin{tabular}{lcccc}
\hline CD28+CD57+ & Controle & Localizada & Disseminada & $\begin{array}{c}\text { Valor } \boldsymbol{p} \text { entre local. e } \\
\text { disseminada }\end{array}$ \\
\hline Naive & 0,12 & 0,08 & 0,05 & 0,14 \\
M. Central & 0,74 & 0,83 & 1,39 & 0,32 \\
M. Transitória & 2,08 & 4,38 & 4,48 & 0,73 \\
M. Intermed. & 0,80 & 1,21 & 1,27 & 0,86 \\
M. Efetora & 1,80 & 2,64 & 2,63 & 0,23 \\
M. Term. Efetora & 0,84 & 1,39 & 1,10 & 0,09 \\
\hline
\end{tabular}

Gráfico e Tabela: Os dados mostram que na comparação das medianas não há evidência de nenhuma diferença nas sub-populações ontogenéticas. Mann-Whitney U test, com significância para $p<0,05$. 
Distribuição da Senescência/Exaustão por co-expressão de marcadores na população total de CD8

\section{PD1+ CD57.}

\section{Gráfico:}

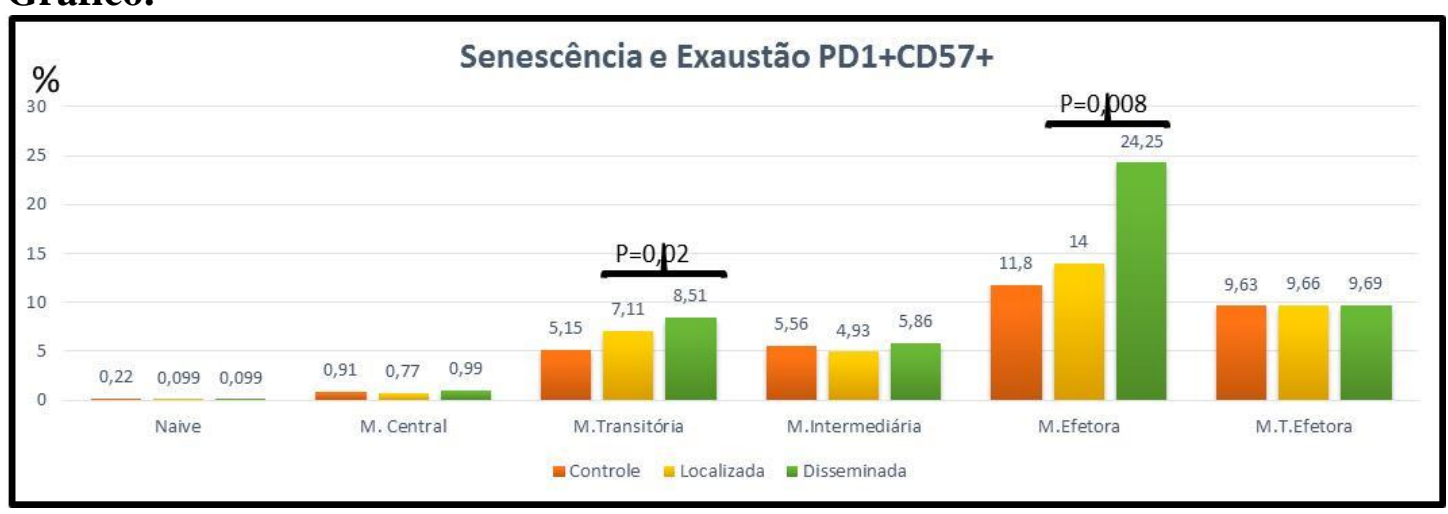

Tabela: Dados da comparação entre a mediana das porcentagens dos linfócitos $\mathrm{T}$ CD8, selecionados para co-expressão de PD1+CD57+

\begin{tabular}{lcccc}
\hline \multicolumn{1}{c}{ PD1+CD57+ } & Controle & Localizada & Disseminada & $\begin{array}{c}\text { Valor } \boldsymbol{p} \text { entre local. e } \\
\text { disseminada }\end{array}$ \\
\hline Naive & 0,22 & 0,09 & 0,09 & 0,62 \\
M. Central & 0,91 & 0,77 & 0,99 & 0,50 \\
M. Transitória & $\mathbf{5 , 1 5}$ & $\mathbf{7 , 1 1}$ & $\mathbf{8 , 5 1}$ & $\mathbf{0 , 0 2}$ \\
M. Intermed. & 5,56 & 4,93 & 5,86 & 0,41 \\
M. Efetora & $\mathbf{1 1 , 8}$ & $\mathbf{1 4}$ & $\mathbf{2 4 , 2 5}$ & $\mathbf{0 , 0 0 8}$ \\
M. Term. Efetora & 9,63 & 9,66 & 9,69 & 0,87 \\
\hline
\end{tabular}

Gráfico e Tabela: Os dados mostram que na comparação das medianas há evidências de maior senescência nesta co-expressão entre PD1+CD57 na coorte de doença disseminada. Mann-Whitney U test, com significância para $p<0,05$. 
Distribuição da Senescência/Exaustão por co-expressão de marcadores na população total de CD8

\section{PD1+ CD95.}

\section{Gráfico:}

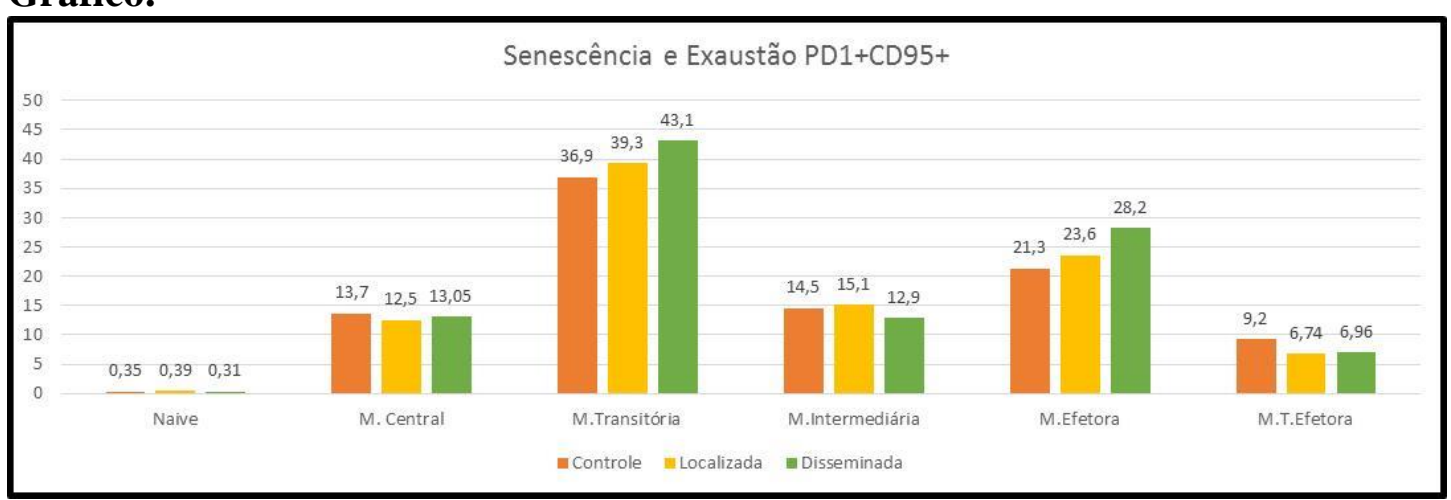

Tabela:

\begin{tabular}{lcccc}
\hline \multicolumn{1}{c}{ PD1+CD95+ } & Controle & Localizada & Disseminada & $\begin{array}{c}\text { Valor } \boldsymbol{p} \text { entre local. e } \\
\text { disseminada }\end{array}$ \\
\hline Naive & 0,35 & 0,39 & 0,31 & 0,89 \\
M. Central & 13,7 & 12,5 & 13,05 & 0,64 \\
M. Transitória & 36,9 & 39,3 & 43,1 & 0,30 \\
M. Intermed. & 14,5 & 15,1 & 12,9 & 0,86 \\
M. Efetora & 21,3 & 23,6 & 28,2 & 0,14 \\
M. Term. Efetora & 9,20 & 6,74 & 6,96 & 0,54 \\
\hline
\end{tabular}

Gráfico e Tabela: Os dados mostram que na comparação das medianas há evidências de maior senescência nesta co-expressão entre PD1+CD95 na coorte de doença disseminada. Mann-Whitney U test, com significância para $p<0,05$. 
Distribuição da Senescência/Exaustão por co-expressão de marcadores na população total de CD8

\section{CD57+CD95+.}

\section{Gráfico:}

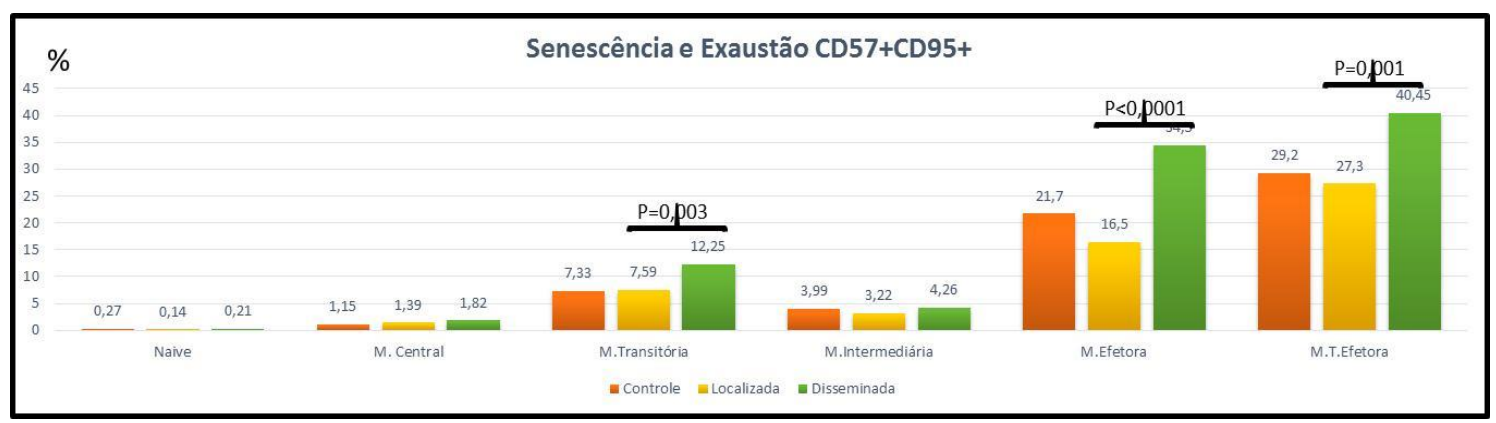

Tabela:

\begin{tabular}{lcccc}
\hline \multicolumn{1}{c}{ CD57+CD95+ } & Controle & Localizada & Disseminada & $\begin{array}{c}\text { Valor } \boldsymbol{p} \text { entre local. } \\
\text { disseminada }\end{array}$ \\
\hline Naive & 0,27 & 0,14 & 0,21 & 0,76 \\
M. Central & 1,15 & 1,39 & 1,82 & 0,37 \\
M. Transitória & $\mathbf{7 , 3 3}$ & $\mathbf{7 , 5 9}$ & $\mathbf{1 2 , 2 5}$ & $\mathbf{0 , 0 0 3}$ \\
M. Intermed. & 3,99 & 3,22 & 4,26 & 0,17 \\
M. Efetora & $\mathbf{2 1 , 7}$ & $\mathbf{1 6 , 5}$ & $\mathbf{3 4 , 5}$ & $<\mathbf{0 , 0 0 0 1}$ \\
M. Term. Efetora & $\mathbf{2 9 , 2}$ & $\mathbf{2 7 , 3}$ & $\mathbf{4 0 , 4 5}$ & $\mathbf{0 , 0 0 1}$ \\
\hline
\end{tabular}

Gráfico e Tabela: Os dados mostram que na comparação das medianas há evidências de maior senescência nesta co-expressão entre CD57+CD95 na coorte de doença disseminada. Mann-Whitney U test, com significância para $p<0,05$. 
Distribuição da Senescência/Exaustão por co-expressão de marcadores na população total de CD8

\section{CD28+PD1+ CD57.}

\section{Gráfico:}

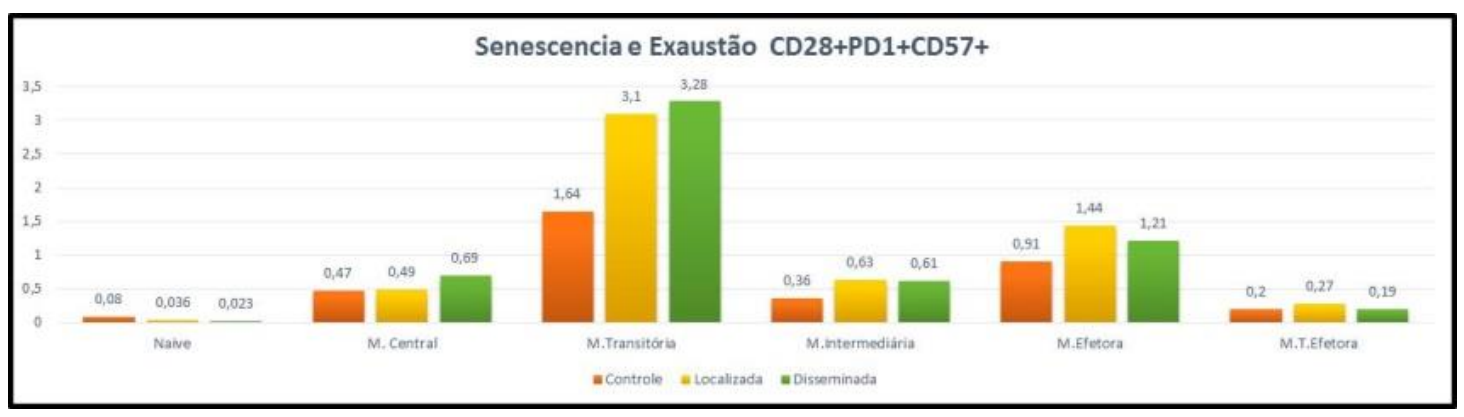

Tabela:

\begin{tabular}{lcccc}
\hline CD28+PD1+CD57+ & Controle & Localizada & Disseminada & $\begin{array}{c}\text { Valor } \boldsymbol{p} \text { entre local. e } \\
\text { disseminada }\end{array}$ \\
\hline Naive & 0,08 & 0,036 & 0,023 & 0,73 \\
M. Central & 0,47 & 0,49 & 0,69 & 0,43 \\
M. Transitória & 1,64 & 3,10 & 3,28 & 0,97 \\
M. Intermed. & 0,36 & 0,63 & 0,61 & 0,33 \\
M. Efetora & 0,91 & 1,44 & 1,21 & 0,36 \\
M. Term. Efetora & 0,20 & 0,27 & 0,19 & 0,15 \\
\hline
\end{tabular}

Gráfico e Tabela: Os dados mostram que na comparação das medianas não há evidências de maior senescência nesta co-expressão entre CD28+PD1+ CD57 na coorte de doença disseminada. MannWhitney $\mathrm{U}$ test, com significância para $p<0,05$. 
Distribuição da Senescência/Exaustão por co-expressão de marcadores na população total de CD8

\section{CD28+PD1+CD95+.}

\section{Gráfico:}

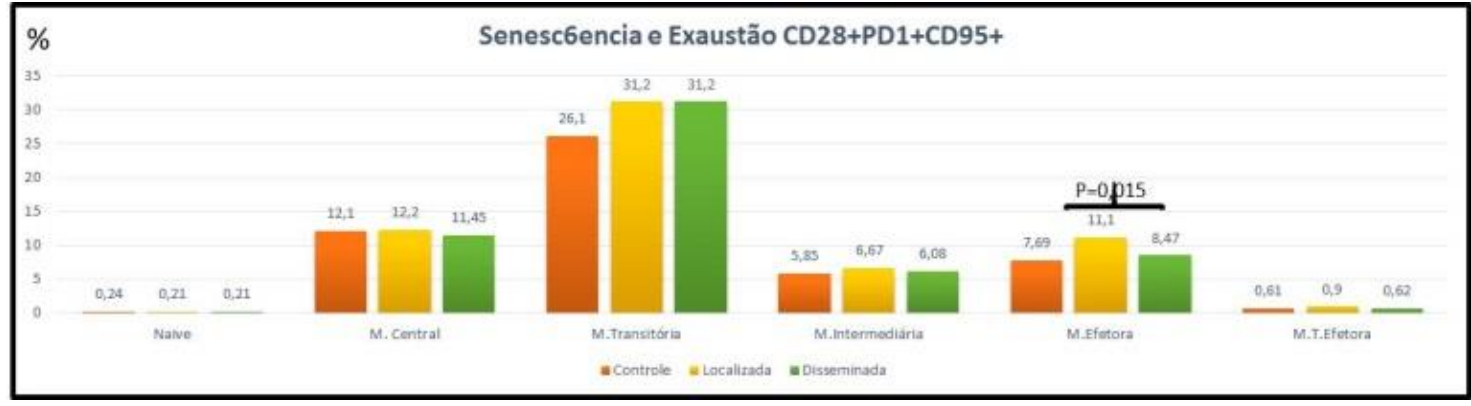

Tabela:

\begin{tabular}{lcccc}
\hline CD28+PD1+CD95+ & Controle & Localizada & Disseminada & $\begin{array}{c}\text { Valor } \boldsymbol{p} \text { entre local. e } \\
\text { disseminada }\end{array}$ \\
\hline Naive & 0,24 & 0,21 & 0,21 & 0,96 \\
M. Central & 12,1 & 12,2 & 11,45 & 0,74 \\
M. Transitória & 26,1 & 31,2 & 31,2 & 0,66 \\
M. Intermed. & 5,85 & 6,67 & 6,08 & 0,60 \\
M. Efetora & $\mathbf{7 , 6 9}$ & $\mathbf{1 1 , 1}$ & $\mathbf{8 , 4 7}$ & $\mathbf{0 , 0 1 5}$ \\
M. Term. Efetora & 0,61 & 0,90 & 0,62 & 0,30 \\
\hline
\end{tabular}

Gráfico e Tabela: Os dados mostram que na comparação das medianas há evidências apenas de maior senescência nesta co-expressão entre CD28+PD1+ CD95+ na coorte de doença localizada. Mann-Whitney U test, com significância para $p<0,05$. 
Distribuição da Senescência/Exaustão por co-expressão de marcadores na população total de CD8

$$
\text { PD1+ CD57+CD95+. }
$$

\section{Gráfico:}

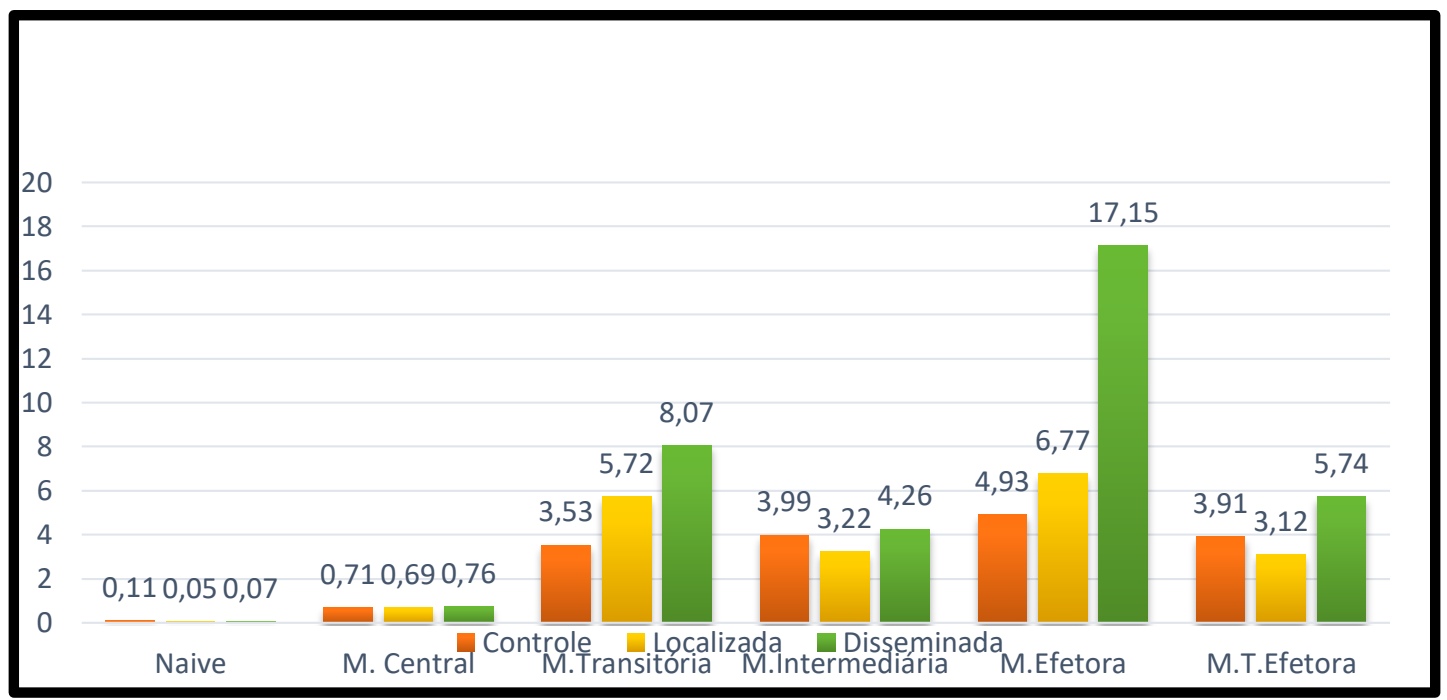

Tabela:

\begin{tabular}{lcccc}
\hline PD1+CD57+CD95+ & Controle & Localizada & Disseminada & $\begin{array}{c}\text { Valor } \boldsymbol{p} \text { entre local. } \\
\text { disseminada }\end{array}$ \\
\hline Naive & 0,11 & 0,05 & 0,07 & 0,74 \\
M.Central & 0,71 & 0,69 & 0,76 & 0,52 \\
M. Transitória & $\mathbf{3 , 5 3}$ & $\mathbf{5 , 7 2}$ & $\mathbf{8 , 0 7}$ & $\mathbf{0 , 0 0 8}$ \\
M. Intermed. & 3,99 & 3,22 & 4,26 & 0,17 \\
M. Efetora & $\mathbf{4 , 9 3}$ & $\mathbf{6 , 7 7}$ & $\mathbf{1 7 , 1 5}$ & $\mathbf{0 , 0 0 0 6}$ \\
M. Term. Efetora & 3,91 & 3,12 & 5,74 & 0,11 \\
\hline
\end{tabular}

Gráfico e Tabela: Os dados mostram que na comparação das medianas há evidências apenas de maior senescência nesta co-expressão entre PD1+CD57+ CD95+ na coorte de doença disseminada. Mann-Whitney U test, com significância para $p<0,05$. 